\title{
DAMAGE AND REPAIR IN EXPERIMENTAL CORTICAL DEMYELINATION
}

\author{
Dissertation \\ for the award of the degree \\ "Doctor of Philosophy" (Ph.D.) \\ Division of Mathematics and Natural Sciences \\ of the Georg-August-Universität Göttingen \\ submitted by
}

Enrique Garea Rodríguez

from Minden, Germany

Göttingen 2009 
Thesis Committee:

Prof. Christine Stadelmann-Nessler (Reviewer)

Department of Neuropathology, University Medical Center Göttingen

Prof. Eberhard Fuchs (Reviewer)

Clinical Neurobiology Laboratory, German Primate Center

Prof. Mikael Simons

Membrane Biology, Max-Planck-Institute for Experimental Medicine

Date of oral examination: 


\section{DEDICADO A MIS PADRES}




\section{Declaration}

I hereby declare that I wrote this thesis independently and with no other sources and aids than quoted. This thesis has not been submitted elsewhere for any academic degree.

Enrique Garea Rodriguez

Date: 29.10 .2009 


\section{CONTENTS}

FIGURES _ _ VII

TABLES _ VII

ABBREVIATIONS __ VIII

SUMMARY_ 1

1. INTRODUCTION _ 3

1.1 Multiple Sclerosis___ 3

1.1.1 Etiology of MS 3

1.1.2 Clinical presentation _ 4

1.1.3 Immunology __ 5

1.1.4 Histopathology__ 6

1.1.5 Cortical lesions 6

1.1.6 Remyelination 8

1.1.7 Mechanisms of remyelination ___ 8

1.2 Myelin__ 9

1.2.1 Structure and function of myelin _ 9

1.2.2 Myelin proteins _ 10

1.3 Oligodendrogenesis _ 11

1.3.1 Developmental oligodendrogenesis___ 11

1.3.2 Proliferation and differentiation promoting factors__ 13

1.3.3 Adult oligodendrogenesis _ 13

1.4 Animal models of MS

1.4.1 Toxin-induced demyelination models _ 14

$1.4 .2 \mathrm{EAE} 16$

1.4.3 Targeted cortical EAE model____ 17

1.5 Aim 18

2. MATERIALS AND METHODS _ 19

2.1 Study design _ 19

2.2 Animals and groups __ 22

2.3 Solutions and reagents___ 23

2.4 Operations and procedures __ 27

2.4.1 Immunogen 27

2.4.2 Sensitization procedure 27

2.4.3 Intracerebral stereotactic injection__ 27

2.4.4 5-bromo-2-deoxyuridine (BrdU) injection __ 28

2.4.5 Blood sampling and serum preparation___ 29

2.5 Enzyme-linked immunosorbent assay (ELISA) for detection of anti-MOG autoantibodies 229

2.6 Histology__ 30 
2.6.1 Tissue processing

2.6.1.1 Perfusion and sectioning 30

2.6.1.2 Deparaffination and dehydration of histological sections __ 30

2.6.2 Histochemical stainings ___ 31

2.6.2.1 Hematoxylin and eosin (HE) staining___ 31

2.6.2.2 Bielschowsky silver staining (modified) __ 31

2.6.3 Immunohistochemistry _ـ 32

2.6.3.1 Antigen retrieval 32

2.6.3.2 GFAP immunohistochemistry __ 32

2.6.3.3 MBP immunohistochemistry 33

2.6.3.4 ED1 immunohistochemistry 33

2.6.3.5 MBP/NogoA double immunohistochemistry ___ 34

2.6.3.6 Olig2/PLP double immunofluorescence___ 34

2.6.3.7 NogoA/BrdU double immunohistochemistry ___ 35

2.6.3.8 Olig2/BrdU double immunohistochemistry ___ 36

2.7 Photoimaging and morphometric analysis___ 36

2.8 Statistics _ 39

3. RESULTS

3.1 Detection of anti-MOG autoantibody titres _ 40

3.2 Gliosis _ 40

3.3 Topology of de- and remyelination in the focal cortical EAE model___ 42

3.3.1 Extent of demyelinated area___ 45

3.3.2 Length of subpial lesions _ 47

3.3.3 Fraction of myelinated axons 47

3.4 Evaluation of activated macrophages/microglia___ 48

3.4.1 Density of activated macrophages within center of lesion 51

3.4.2 Density of activated macrophages/microglia throughout all cortical layers _ 52

3.5 Axonal integrity 54

3.6 Oligodendrocyte loss and recovery___ 55

3.6.1 Oligodendrocyte density _ـ 56

3.6.2 Proliferation of NogoA-positive oligodendrocytes __ 58

3.7 Oligodendroglial progenitors _ـ 61

3.7.1 Proliferation of oligodendroglial progenitors _ 64

4 DISCUSSION _ 69

4.1 Targeted cortical demyelination shares similarities with cortical MS lesions _ 69

4.2 Effect of repeated demyelinating lesions on remyelination 71

4.3 Inflammation in repeated targeted cortical EAE lesions _ 72

4.4 Preserved axonal intregrity after repetitive demyelination__ 73

4.5 Oligodendrocyte recruitment in the targeted cortical EAE model __ 74

4.6 The origin of proliferated OPCs _ 76

4.7 Indications of overstrained remyelination capacity _ 77

4.8 Role of reactive astrocytes on remyelination

4.9 Hormonal effects on targeted cortical EAE 78

4.10 Conclusions__ 79 
6.1 Effect of targeted cortical EAE lesion on estrous cycle

100

6.2 Acknowledgements 101

6.3 Curriculum Vitae 102 


\section{FIGURES}

Figure 1: Proliferation and differentiation of oligodendrocytes during development $\_12$

Figure 2: Experimental design __ 21

Figure 3: Regions of interest used for histological evaluation ___ 38

Figure 4: Anti-MOG autoantibody titres

Figure 5: HE-staining of local gliosis

Figure 6: GFAP immunohistochemistry of local gliosis $\quad 42$

Figure 7: Focal cortical EAE lesion

Figure 8: Cortical demyelination and remyelination after repetitive lesion induction _ 45

Figure 9: Extent of demyelination -46

Figure 10: Fraction of myelinated axons 48

Figure 11: Inflammatory demyelination in the focal cortical EAE model

Figure 12: Transient activation of macrophages/microglia _ 51

Figure 13: Density of activated macrophages/microglia __ 53

Figure 14: Axonal integrity__ 54

Figure 15: Axonal density _ 55

Figure 16: Loss of oligodendrocytes during focal cortical inflammatory demyelination 56

Figure 17: Spontaneous recovery of oligodendrocytes in subpial lesions

Figure 18: Density of oligodendrocytes

Figure 19: Oligodendrocyte proliferation during remyelination $\quad 59$

Figure 20: Proliferation of NogoA-positive cells after repeated demyelinating events 60

Figure 21: Early effects of lesion induction on proliferation of NogoA-positive cells _ 60

Figure 22: Effect of lesion induction on proliferation of mature oligodendrocytes after

remyelination

Figure 23: Unaltered oligodendroglial progenitor population $\_64$

Figure 24: Density of oligodendroglial progenitors 64

Figure 25: Proliferation of olig2-positive OPCs within subpial lesions ___ 66

Figure 26: OPC proliferation after repeated demyelinating events __ 67

Figure 27: Early effects of lesion induction on OPC proliferation __ 67

Figure 28: Effects of lesion induction on OPC proliferation after remyelination __ 68

\section{TABLES}

Table 1: Numbers of animals, groups and time points of the repetitive lesioning approach

Table 2: Numbers of animals, groups and time points of the single lesioning approach 


\section{ABBREVIATIONS}

ABH Biozzi mice

antibody high Biozzi mice

ADEM

acute disseminated encephalomyelitis

ANOVA

analysis of variance

AP

alkaline phosphatase

APAAP

alkaline phosphatase anti-alkaline phosphatase

APC

antigen presenting cell

APP

amyloid precursor protein

BBB

blood brain barrier

BCIP

5-bromo-4-chloro-3-indolyl phosphate

bFGF

basic fibroblast growth factor

BrdU

5-bromo-2-deoxyuridine

BSA

bovine serum albumin

CCR5

chemokine (C-C motif) receptor 5

CNP1

2',3'-cyclic nucleotide 3'-phosphodiesterase 1

CNS

central nervous system

CXCL1

chemokine (C-X-C motif) ligand 1

CXCR3

chemokine (C-X-C motif) receptor 3

Cy3

indocarbocyanine 3

DAB

3,3'-diaminobenzidine tetrachloride

DNA

deoxyriribonucleic acid

EAE

experimental autoimmune encephalomyelitis

EDSS

expanded disability status scale

ELISA

enzyme-linked immunosorbent assay

Erb2

eukaryotic ribosome biogenesis protein 2

FCS

fetal calf serum

FGF

fibroblast growth factor

FGF-2

fibroblast growth factor-2

GABA

gamma-aminobutyric acid

GC

galactocerebroside (also known as GalC)

GFAP

glial fibrillary acidic protein 


\begin{tabular}{|c|c|}
\hline HE staining & hematoxylin and eosin staining \\
\hline ICAM-I & intercellular adhesion molecule-I \\
\hline IFA & incomplete Freund's adjuvant \\
\hline IFN- $\gamma$ & interferon- $\gamma$ \\
\hline IGF-1 & insulin-like growth factor-1 \\
\hline $\operatorname{IgG}$ & immunoglobulin $\mathrm{G}$ \\
\hline IL-1 $\beta$ & interleukin-1 $\beta$ \\
\hline IL-2 & interleukin-2 \\
\hline IP-10 & interferon-inducible protein- 10 \\
\hline LFA-1 & leukocyte function-associated antigen-1 \\
\hline LIF & leukemia inhibitory factor \\
\hline LSD-test & least significance difference test \\
\hline M1 & primary motor cortex \\
\hline MAG & myelin-associated glycoprotein \\
\hline MBP & myelin basic protein \\
\hline MHC & major histocompatibility complex \\
\hline MMP & matrix metalloprotease \\
\hline MOG & myelin oligodendrocyte glycoprotein \\
\hline MS & multiple sclerosis \\
\hline Myt1 & myelin transcription factor 1 \\
\hline NBT & 4-nitro blue tetrazolium chloride \\
\hline NG2 & neuronal/glial 2 (proteoglycan) \\
\hline Nkx2.2 & Nk2 transcription factor related, locus 2 \\
\hline NMDA & N-methyl D-aspartate \\
\hline NRG1 & Neuregulin 1 \\
\hline NT3 & neurotrophin 3 \\
\hline $\mathrm{O} 4$ & anti-oligodendrocyte marker $\mathrm{O} 4$ \\
\hline Olig1 & oligodendrocyte transcription factor 1 \\
\hline OPC & oligodendrocyte precursor cell \\
\hline PBS & phosphate buffered saline \\
\hline PDGF- $\alpha \mathrm{R}$ & platelet-derived growth factor- $\alpha$ receptor \\
\hline
\end{tabular}




$\begin{array}{ll}\text { PDGF } & \text { platelet-derived growth factor } \\ \text { PFA } & \text { paraformaldehyde } \\ \text { PLP } & \text { proteolipid protein } \\ \text { PPMS } & \text { primary progressive MS } \\ \text { rMOG } & \text { recombinant myelin oligodendrocyte glycoprotein } \\ \text { RMS } & \text { rostral migratory pathway } \\ \text { RRMS } & \text { relapsing-remitting MS } \\ \text { S1 } & \text { primary somatosensory cortex } \\ \text { Sox2 } & \text { Sry-related HMG box } \\ \text { SPMS } & \text { secondary progressive MS } \\ \text { SVZ } & \text { subventricular zone } \\ \text { TBS } & \text { Tris buffered saline } \\ \text { TGF- } \beta & \text { transforming growth factor- } \beta \\ \text { Th1 cells } & \text { T helper cells } \\ \text { TNF- } \alpha & \text { tumor necrosis factor- } \alpha \\ \text { Tris } & \text { tris(hydroxymethyl)aminomethane } \\ \text { Tris-EDTA } & \text { tris-ethylenediaminetetraacetic acid } \\ \text { VCAM-I } & \text { vascular cell adhesion molecule-I } \\ \text { VLA-4 } & \text { very late antigen-4 (integrin alpha4beta1) } \\ \text { ZTE } & \text { Zentrale Tierexperimentelle Einrichtung } \\ & \end{array}$




\section{SUMMARY}

Remyelination represents an important self repair mechanism in demyelinating diseases such as multiple sclerosis (MS). The intrinsic regenerative potential of the cerebral cortex is considerable, however cortical MS lesions frequently fail to remyelinate, especially at later stages of the disease. Repeated demyelinating events are one assumed cause of remyelination failure and the subject of this work.

The aim of the study was to determine whether repetitive demyelinating episodes may exhaust the intrinsic cortical remyelinating capacity. Therefore, MS-like lesions were induced in the rat targeted cortical experimental autoimmune encephalomyelitis (EAE) model in a repeated manner. After subcutaneous immunization with recombinant rat myelin oligodendrocyte glycoprotein (rMOG), a cytokine cocktail composed of the proinflammatory cytokines tumor necrosis factor- $\alpha$ (TNF- $\alpha$ ) and interferon- $\gamma$ (IFN- $\gamma$ ) was stereotactically injected in the rat cerebral cortex thereby leading to focal inflammatory demyelinating lesions. Lesions were repetitively induced at intervals of three weeks, simulating the repetitive events in relapsing-remitting MS.

Histological analysis revealed widespread subpial and intracortical demyelinated lesions within the injected cortical hemisphere 3 days after lesion induction. Demyelination was accompanied by loss of mature oligodendrocytes and activation/recruitment of macrophages/microglia at this time point. However, three weeks after lesion induction extensive remyelination, restoration of oligodendrocyte population and resolution of inflammation was observed. This picture of de- and remyelination was consistently observed even after four cycles of demyelination at the same anatomical area. Although the fraction of myelinated axons was extensively restored after repetitive lesioning it did not fully recover. The initial inflammatory response measured by the density of activated macrophages/microglia was markedly stronger compared to the subsequent episodes. In contrast to NogoA-positive cells, oligodendrocyte transcription factor 2 (olig2)-positive oligodendrocyte precursor cell (OPC) density was stable and even increased at particular time points. Proliferation of olig2 and NogoA-positive cell populations was observed during demyelination. However, only few proliferated NogoA-positive cells were 
identified within remyelinated lesions, in contrast to substantial proliferation of olig2positive OPCs.

This work demonstrates the extensive intrinsic regenerative capacity of the rat cerebral cortex after repeated demyelinating insults. Four cycles of cortical demyelinating episodes did not lead to reduction of the cortical remyelinating capacity in our experimental setting. Our results suggest furthermore that oligodendroglial recruitment occurs by differentiation of existing rather than newly generated OPCs within the cerebral cortex. Findings from these studies will contribute to understanding the underlying processes of remyelination with implications for MS. 


\section{INTRODUCTION}

MS also known as encephalomyelitis disseminata, is one of the most common neurological diseases in young adults. MS was first described by Jean Martin Charcot in 1868 and is currently believed to be an autoimmune disorder causing inflammatory demyelination in the central nervous system (CNS). In northern Europe the general population prevalence of MS varies in average between 20-60/100000, being more common in females (Sospedra and Martin, 2005).

As MS is a complex and heterogeneous disorder, many questions remain open despite intensive research. The main focus of this study addresses cortical pathology of MS which extent has been underestimated for a long time by the scientific community. This chapter provides an introduction to clinical and pathological features of multiple sclerosis, especially focussing on cortical grey matter pathology. In addition, remyelination, oligodendroglial recruitment and genesis will be addressed. Finally, the targeted cortical EAE model which is used for studying repetitive inflammatory demyelination will be introduced.

\subsection{Multiple Sclerosis}

\subsubsection{Etiology of MS}

Despite extensive efforts the etiology of MS remains enigmatic. MS is considered to be autoimmune in nature, but its exact cause remains still unknown. However, it occurs to be a result of genetic and environmental factors (Sospedra and Martin, 2005; Gold et al., 2006).

Genetic predisposition seems to play a role since first-degree relatives and monozygotic twins of affected individuals show a higher risk to develop MS (Sospedra and Martin, 2005). Furthermore, susceptible genes on chromosome 6p21 in the area of the major histocompatibility complex (MHC) seem to account for $10-60 \%$ of genetic risk in MS (Hillert and Olerup, 1993; Haines et al., 1998; Oksenberg et al., 2008). 
In addition to genetic factors, epidemidological studies strongly suggest that environmental factors are involved in disease predisposition. To these factors belong e.g. sunlight exposure and ultraviolet radiation, hormonal and hygienic status, as well as the consequences of socioeconomic and industrial development (Sospedra and Martin, 2005).

Infectious agents have been furthermore postulated to cause MS. This is supported by studies showing a possible association between viral infections and exacerbations of MS symptoms (Bebbe et al., 1967; Sibley et al., 1985). Especially, the Epstein-Barr virus (EBV) has been related to MS but its direct implication in the disease remains unproven (Johnson, 1994; Bagert, 2009).

\subsubsection{Clinical presentation}

MS patients suffer from a variety of neurological symptoms, such as optic neuritis, sensory disturbances, weakness, diplodia, diminished dexterity, ataxia, fatigue and bladder dysfunction. Symptoms occur in either discrete attacks (relapsing forms) or slowly accumulating over time (progressive forms). The initial symptoms are often transient and mild, but worsen often with time ending with permanent disability. With regard to its clinical course, three main subtypes have been described (Lublin et al., 1996):

\section{Relapsing-remitting MS (RRMS):}

The relapsing remitting subtype is the most frequent (85-90\%) subtype of MS. It is characterized by relapses followed by remissions without any disease activity in between. Despite remission, disability may accumulate after each relapse.

Primary progressive MS (PPMS):

This subtype is characterized by progressive disability from onset of the disease, with no or occasional relapses and remissions. Approximately 10 to $15 \%$ percent of all MS patients show a primary progressive course.

Secondary progressive MS (SPMS): 
The secondary progressive subtype describes patients with initial relapsing-remitting MS, who then experience progressive disability with no definite remission. The conversion from the relapsing-remitting to the secondary progressive phase on average takes place between 15 and 20 years after disease onset.

\subsubsection{Immunology}

MS is considered to be caused by an autoimmune response against unknown antigens of the myelin sheaths. According to this concept, myelin antigens are recognized by professional antigen presenting cells (APCs) and presented in the periphery via MHC class II molecules to T helper 1 (Th1) cells. Following activation, priming and clonal expansion, CD4-positive cells infiltrate the CNS where they re-encounter their antigen. Upon restimulation by microglia, CD4-positive cells initiate effector functions such as the secretion of the pro-inflammatory cytokines TNF- $\alpha$, IFN- $\gamma$ and interleukin 2 (IL-2) (Merril, 1992). Thereby, attracted macrophages and resident microglia become activated, which in turn contribute to the inflammatory milieu by the release of matrix metalloproteinases (MMPs), oxyradicals and TNF- $\alpha$. In addition, the secretion of the chemoattractants interferon-inducible protein-10 (IP-10) and Rantes and the activation of their respective receptors chemokine (C-X-C motif) receptor 3 (CXCR3) and chemokine (C-C motif) receptor 5 (CCR5), promote the recruitment of leukocytes into the sites of inflammation (Simpson et al., 1998; Martínez-Cáceres et al., 2002). CNS migration through the blood brain barrier (BBB) is enabled by the upregulation of the intercellular adhesion molecule-I (ICAM-I) and the vascular cell adhesion molecule-I (VCAM-I) on endothelial cells and their ligands leukocyte function-associated antigen-1 (LFA-1) and very late antigen-4 (VLA-4), the last ones being expressed on the surface of activated effector cells (Yusuf-Makagiansar et al., 2002).

Class I MHC-restricted CD8-positive cells are supposed to play an important role in MS. They are considered to directly target oligodendrocytes and axons, indicated by secretion of cytotoxic granules and upregulation of cytotoxic T-cell markers such as Fas, Fasligand and granzyme B (Lazzarini, 2004). B- and plasma-cells located in the meninges and perivascular space is suggested to contribute to the pathogenesis by mediating 
myelin-specific antibody responses in a subset of MS patients (Lucchinetti et al., 2000; Serafini et al., 2004). Antibodies may bind to membrane bound antigens enabling Fcreceptor-mediated cytotoxicity and phagocytosis by activated macrophages. Furthermore, the complement cascade is initiated (Lazzarini, 2004).

Inflammation usually resolves after each relapse and is promoted by a transition of CD4positive Th1 to Th2 cells. These lymphocytes secrete anti-inflammatory cytokines such as IL-4, IL5, IL-10, IL-13 and transforming growth factor- $\beta$ (TGF- $\beta$ ), silencing the inflammatory reaction (Issazadeh et al., 1995).

\subsubsection{Histopathology}

MS is characterized by multifocal, demyelinated plaques with glial scar formation. T-cell infiltration occurs in all active MS lesions. However, histopathological heterogeneity was observed in MS lesions. Accordingly, four histopathological patterns were proposed (Lucchinetti et al., 2000). Pattern I describes a macrophage-associated demyelination promoted by toxic products such as TNF- $\alpha$ or reactive oxygen species (Probert et al., 2000; Griot et al., 1990). In addition to macrophage activation, antibody and complement-mediated demyelination takes place in pattern II. Distal oligodendrogliopathy (pattern III) and primary oligodendrocyte degeneration (Pattern IV) was observed in a subgroup of patients (Lucchinetti et al., 2000).

Importantly, these patterns describe the acute phase of disease in which inflammation and demyelination is still ongoing, and therefore termed "active" lesions. In contrast, chronic or inactive lesions, lacking signs of active demyelination, are characterized by demyelination, astrogliosis, axonal damage, and loss and can not be arranged to one of the four aforementioned patterns (Lazzarini, 2004).

\subsubsection{Cortical lesions}

Grey matter involvement in MS has already been observed in early disease history (Taylor, 1892; Sander, 1898; Brownel and Hughes, 1962). Later however, cortical lesions have been overseen for decades. Due to significant improvement in staining techniques, 
they were finally rediscovered by the end of the century (Kidd et al., 1999; Peterson et al., 2001; Bo et al., 2003). Since the use of sensitive in vivo imaging techniques, the importance of cortical involvement becomes more apparent (Filippi et al., 1996; Geurts et al., 2005; Kangarlu et al., 2007).

Cortical demyelination is a frequent phenomenon occurring in $90 \%$ of MS patients with long disease duration (Albert et al., 2007). On average, between 10-25\% of cortical grey matter is demyelinated (Albert et al., 2007; Bo et al., 2003; Kutzelnigg et al., 2005; Gilmore et al., 2009). In the progressive stage of the disease CNS grey matter is even more affected compared to white matter (Gilmore et al., 2009). Three main types of cortical lesions have been described, namely leukocortical lesions, which extend through white and grey matter, pure intracortical lesions and subpial lesions. Last mentioned lesion type is the most frequent and extensive one (Peterson et al., 2001; Bo et al., 2003).

Compared to white matter lesions, cortical demyelination is less inflammatory, presenting with reduced lymphocyte infiltration and reduced microglia activation (Peterson et al., 2001; Bo et al., 2003). Furthermore, complement deposition, limited astrogliosis and relative axonal preservation was reported (Schwab and McGeer, 2002; Peterson et al., 2001; Wegner et al., 2006; Vercellino et al., 2005). Despite weak lymphocyte-mediated inflammation, follicle-like structures harbouring B-cells were observed in the sulcal meninges of SPMS patients. These structures are associated with enhanced axonal damage and disability (Serafini et al., 2004; Magliozzi et al., 2007). In addition to moderate axonal damage, neuronal loss and cortical atrophy was reported (Wegner et al., 2006). On the contrary, reduction of synaptic densities does not necessarily occur (Vercelino et al., 2005; Kutzelnigg et al., 2007). However, reduced expression of amino acid transporters and gamma-aminobutyric acid (GABA) related transcripts, and enhanced excitotoxicity underline the functional consequences of cortical MS lesions (Vercellino et al., 2007; Dutta et al., 2006).

Classically, MS patients present with sensory and motor symptoms. In case of cortical involvement patients may additionally suffer from cognitive and neuropsychiatric symptoms, thus contributing to disease severity already in early stages of the disease (Skegg et al., 1993; Haase et al., 2003; Zarei et al., 2006). 


\subsubsection{Remyelination}

Remyelination is an important repair mechanism and is accompanied by functional recovery such as the reestablishment of salutatory conduction and the resolution of clinical symptoms (Smith et al., 1979; Jeffery et al., 1997; Merkler and Liebetanz, 2006). Remyelinated axons have thinner and shorter internodes and usually do not attain original dimensions (Blakemore, 1974; Ludwin and Maitland, 1984). In histological sections of MS patients, remyelinated areas are characterized by pale and less dense myelin, so called "shadow plaques" (Itoyama et al., 1980). Furthermore, remyelinated lesions can be detected by magnetic resonance imaging (Barkhof et al., 2003; Merkler et al., 2005).

Remyelination is a frequent phenomenon, occurring in more than $50 \%$ of MS plaques (Lucchinetti et al., 1999; Patrikios et al., 2006, Patani et al., 2007). However, the grade of remyelination depends on anatomical location and disease stage (Stadelmann and Brück, 2008; Goldschmidt et al., 2009). As an example, regions close to the ventrikel walls remyelinate less, opposed to those in the deep white matter (Patrikios et al., 2006). In turn, cortical grey matter remyelination is more frequent and extensive compared to white matter lesions (Albert et al., 2007). Despite long disease duration extensive remyelination can occur, but fails in the majority of cases at later stages of the disease (Patani et al., 2007; Goldschmidt et al., 2009).

Remyelination is neuroprotective, preventing secondary axonal damage (Kornek et al., 2000; Irvine and Blakemore, 2008; Trapp and Nave, 2008). Furthermore, the presence of myelin proteins such as proteolipid protein (PLP) and 2',3'-cyclic nucleotide 3'phosphodiesterase 1 (CNP1), plays an important role in axon stability (Lappe-Siefke et al., 2003; Griffiths et al., 1998; Edgar and Garbern, 2004).

\subsubsection{Mechanisms of remyelination}

Loss of remyelination capacity is considered to play an important role in MS pathology, however, the mechanisms causing impaired remyelination are not fully understood. To date there are three main hypotheses which describe the different possible causes of remyelination failure (Franklin and ffrench-Constant 2008). The first is known as the 
failure of recruitment hypothesis, in which inadequate provision of OPCs might be the cause of incomplete or total lack of myelin restoration. The second hypothesis describes how OPCs, after being recruited into the sites of demyelination fail to differentiate to remyelinating oligodendrocytes. Lastly, the dysregulation hypothesis suggests that remyelination might fail due to disturbances of the precise coordination of regenerative cellular events (Franklin and Kotter, 2008). Furthermore, disturbed axon-glia interactions may hinder remyelination (Franklin, 2002). Age is an aggravating factor for the efficacy of endogenous remyelination as shown in animal studies (Sim et al., 2002; Shen et al., 2008).

Treatments improving remyelination are not available yet. However, basic research in animal models proposes new approaches for future remyelination strategies. These include the enhancement of endogenous repair mechanisms such as the proliferation and differentiation of endogenous OPCs (Franklin and Kotter, 2008). Furthermore, successful transplantation of myelinating cells has been proven in several animal studies, but its therapeutic potential in humans remains open (Stangel und Trebst, 2006). The current standard therapy for MS consists of treatment with immunomodulatory drugs. These therapeutic approaches may indirectly influence remyelination by preventing further myelin damage (Lazzarini, 2004).

\subsection{Myelin}

\subsubsection{Structure and function of myelin}

Neurons communicate by depolarizing the electrical potentials of their membranes, a process called action potential. This occurs by exchange of sodium and potassium along closely distributed channels on the axon. The majority of axons are wrapped by lipid-rich, lamellar structures named myelin sheaths. Due to the myelin-sheaths insulating properties, action potentials jump between myelin free spaces, a process called salutatory conduction. This provides fast and energy-efficient signaling over longer distances, allowing cross linking of remote brain areas. In the CNS myelin sheaths are built by specialized cells called oligodendrocytes. The complex radial geometry allows these cells 
to build multiple internodes on axons within their reaching area. Axons are accompanied by many oligodendrocytes, each of one myelinating a particular segment along the axonal route. In contrary, dendrites are never myelinated. Myelin sheaths are compact spiraled cellular processes that contain two plasma membranes and no cytoplasm. Opposed to other cell membranes, myelin is composed of up to $75 \%$ of lipids. Furthermore, a variety of membrane proteins and cytoskeletal components are involved in formation and maintenance of this complex cell organelle. Briefly, the most abundant ones are PLP, the myelin basic protein (MBP), and the myelin associated glycoprotein (MAG).

\subsubsection{Myelin proteins}

PLP is the major integral membrane protein of myelin consisting of four transmembrane domains. It is distributed in compact myelin, and is important for structural stability of myelin, keeping normal spacing between single sheaths. Lack of PLP and its splice variant DM20 does not impair myelination but leads to structural disturbances followed by axonal damage in adulthood (Trapp and Nave, 2008).

MBP is an extrinsic membrane protein located in the cytoplasmic leaflets of compact myelin. The MBP deficient shiverer mouse shows hypo- and dysmyelination, indicating an important role of this protein in myelin formation and preservation (Lazzarini, 2004).

MAG is located in the periaxosomal and mesoaxonal membranes of compact myelin. This protein has been shown to participate in the control of compact myelin distribution and is essential for myelination and axonal integrity (Quarles, 2007).

Myelin oligodendrocyte glycoprotein (MOG) is an integral membrane protein consisting of an immunoglobulin $\mathrm{G}(\mathrm{IgG})$-like extracellular domain, a transmembrane domain, a membrane associated domain and two cytoplasmic domains. Quantitatively, it comprises of $0.05-0.1 \%$ of total myelin protein. However, it is of high immunological importance since it is an autoantigen frequently used to induce EAE. MOG is suggested to be a cellular adhesive molecule, regulating oligodendrocyte microtubule stability. Further, MOG might mediate interactions between myelin and the immune system, in particular the complement cascade (Lazzarini, 2004). 


\subsection{Oligodendrogenesis}

\subsubsection{Developmental oligodendrogenesis}

Neurons, astrocytes and oligodendrocytes are the most common cell types in the vertebrate CNS. Oligodendrocytes arise from the neuroepithelial cells of discrete neural tube regions (Ono et al., 1995). They first appear as so called oligodendrocyte precursor cells (OPCs) along the rostro-caudal extent at the ventral part of the spinal cord. In more rostral parts of the CNS the earliest oligodendroglial precursors are located in the ventricular and subventricular zone (Ono et al., 1997). Later, new sources of proliferation are available, such as the medial and lateral ganglionic eminence, from where new OPCs migrate into the developing cerebral cortex (reviewed in Miller, 2002).

Proliferation, migration and maturation of oligodendrocytes are orchestrated by a variety of signaling molecules, but also by gene and protein expression. At the beginning both neuronal and oligodendroglial lineages respond to the signaling molecule sonic hedgehog and express the transcription factor Olig2 (Zhou et al, 2001). Later, combinatory expression of olig1, olig2 and $\mathrm{Nk} 2$ transcription factor related locus 2 (Nkx2.2) provides the generation of OPCs. At this stage OPCs can be detected with the monoclonal antibody A2B5, which is directed against a specific ganglioside epitope (Zhou et al., 2001). Further, migrating early progenitors express the sulfated proteoglycan neuronal/glial 2 (NG2) and the platelet derived growth factor receptor $\alpha$ (PDGF- $\alpha \mathrm{R})$, by which they can be distinguished from neuronal precursors. Motoneurons also express Olig2, but they follow the neuronal lineage by additional expression of Ngn1 and Ngn2 (Lu et al., 2002). Once departed from the neuronal lineage, precursors differentiate to astrocytes and oligodendrocytes and are therefore termed oligodendrocyte-type-2 astrocyte (O-2A) progenitor cells (Raff et al., 1984). OPCs continue their maturation and express galactosulfatide, which is detectable using the monoclonal anti-oligodendrocyte marker O4 (Warrington and Pfeiffer, 1992). O4-positive OPCs, also termed late OPCs are postmigratory but still proliferative (Pfeiffer et al., 1993).

After migration from the germinal zones, OPCs evenly distribute in gray and white matter followed by a wave of differentiation spreading from the corpus callosum towards the pial surface (Nishiyama et al., 1996; Pringle et al., 1992; Reynolds and Hardy, 1997). 
Differentiation is mediated by down regulation of NG2 and PDGF- $\alpha$ R. In addition, myelin proteins are expressed such as MAG, CNP, MBP but not PLP and MOG. Finally, myelinating oligodendrocytes express PLP and MOG. Premyelinating oligodendrocytes which do not differentiate to myelinating oligodendrocytes undergo apoptosis, occurring in approximately $50 \%$ of these cells. However, a small population of proliferative late OPCs remains in the adult CNS after development.

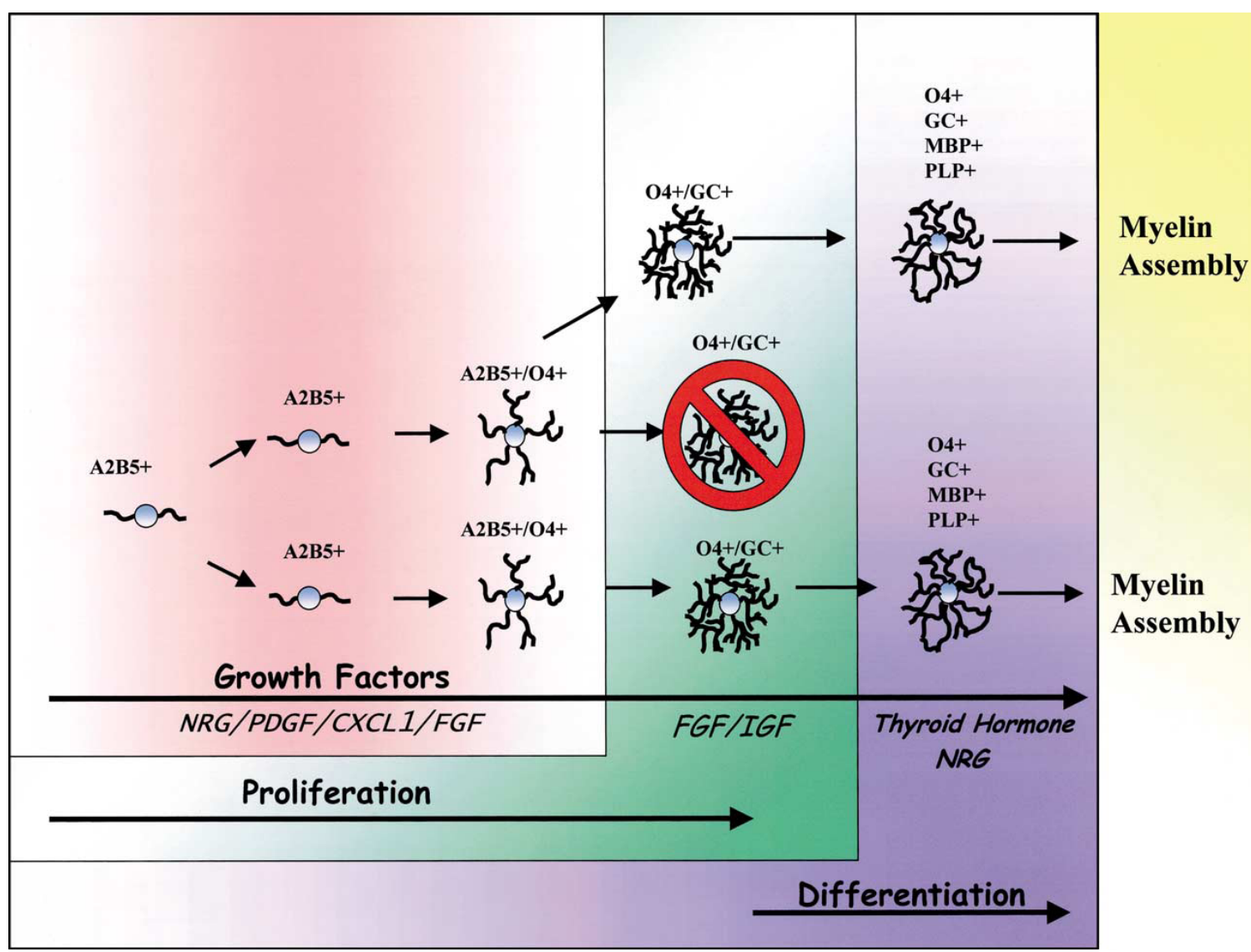

(Figure obtained from Miller, 2002)

\section{Figure 1: Proliferation and differentiation of oligodendrocytes during development}

Developmental oligodendroglial precursor cells (OPCs) derive from the subventricular zone (SVZ) of the neural tube. Upon the proliferative and migratory effects of hormonal factors such as platelet-derived growth factor (PDGF) and fibroblast growth factor (FGF), early OPCs can be detected using the monoclonal antibody A2B5. During the transition from proliferation to differentiation of oligodendroglial cells, the expression of surface antigens such as galactocebroside (GC) and galactosulfatide (which can be recognized by the monoclonal antibody O4) increases. Myelin proteins such as myelin basic protein (MBP) and proteolipid protein (PLP) are expressed at late stages of differentiation and are required for myelin assembly. OPCs which do not complete the maturation process undergo apoptosis. 


\subsubsection{Proliferation and differentiation promoting factors}

A variety of trophic factors promote proliferation. As an example, plateled derived growth factor (PDGF) which is released by astrocytes and neurons, increases proliferation of OPCs by acting on its receptor PDGF $\alpha \mathrm{R}$ (Noble et al., 1988; Pringle et al., 1992; Yeh et al., 1991). PDGF is not only a potential mitogen, it is also required for oligodendroglial survival (Fruttiger et al., 1999). The beneficial effects of PDGF are enhanced by the presence of the chemokine (C-X-C motif) ligand 1 (CXCL1) (Robinson et al., 1998). Moreover, CXCL1 regulates the migration of immature progenitors (Tsai et al., 2002). The basic fibroblast growth factor (FGFb) also supports proliferation by enhancing the expression of PDGF- $\alpha \mathrm{R}$ on OPCs (McKinnon et al., 1991). Further promoters of proliferation are neurotrophin-3 (NT3), fibroblast growth factor 2 (FGF2), neuregulin-1 (NRG1) and its receptor eukaryotic ribosome biogenesis protein 2 (Erb2) (Barres et al., 1994, Qian et al., 1997; Vartanian et al., 1999; Park et al., 2001).

Differentiation is accompanied by upregulation of TGF- $\beta$. Additionally, the numbers of precursors can be controlled by altering the availability of survival factors such as PDGF. Proliferation and differentiation mechanisms mesh, as factors which promote differentiation on the one hand, in turn inhibit proliferation (Lazzarini, 2004).

\subsubsection{Adult oligodendrogenesis}

After development, a quiescent population of $\mathrm{NG} 2$ and PDGF $\alpha$ R expressing OPCs remains in the adult CNS. In contrast to developmental OPCs, adult OPCs show a more mature phenotype as they also express O4 (Dawson et al., 2000). Adult OPCs derive from developmental ones or from type B cells of the subventricular zone (Wren et al., 1992; Lazzarini, 2004). Adult OPCs are abundant in the CNS and account for between 3 to $9 \%$ of all cells. Further, spinal cord OPC:oligodendrocyte ratio is $1: 4$, whereas $1: 1$ ratio was found in gray matter (Dawson et al., 2003). The reason why adult OPCs do not differentiate to oligodendrocytes and why they remain as a quiescent abundant population is still unknown. Likely, gray matter environment arrests oligodendrocyte differentiation in an immature state, by the relative down regulation of humoral factors to a subthreshold level during adulthood (Dawson et al., 2000; Levine et al., 2001; Lazzarini, 
2004). However, adult OPCs are considered to differentiate to myelinating oligodendrocytes and replace lost ones, providing a potential source of remyelination in the diseased CNS, as occurring in MS and experimental demyelination. The higher ratio of OPC:oligodendrocyte in cerebral cortex compared to spinal cord provides a potent source of remyelinating cells that could explain the relatively effective cortical remyelination in MS patients (Lazzarini, 2004). Other studies indicate that OPCs may be involved in synaptic function (Bergles et al., 2000; Jabs et al., 2005; Karadottir et al., 2008).

As in developmental myelination, remyelination is associated with the upregulation of the transcription factors Olig2, Nkx2.2, myelin transcription factor 1 (Myt1) and Sry-related HMG box (Sox2) (Fancy et al., 2004; Watanabe et al., 2004; Talbott et al., 2005; Vana et al., 2007). Furthermore, adult OPC proliferation and differentiation is promoted by humoral factors. The most potent mitogen is PDGF acting via its receptor PDGFaR, which is uniquely expressed on OPCs (Noble et al., 1988; Wolswijk et al., 1991). FGF stimulates proliferation, partly by enhancing PDGF $\alpha \mathrm{R}$ expression, and inhibits differentiation on the other hand (Besnard et al., 1989; Bansal and Pfeifer et al., 1994; McKinnon et al., 1990). The role of NT3 in adult oligodendrogenesis is not clear so far. However, studies indicate both, proliferative and differentiative effects of NT3, acting in combination with PDGF and basic fibroblast growth factor (bFGF) (Ibarrola et al., 1996; McTigue et al., 1998). Insulin-like growth factor-1 (IGF-1) increases proliferation and survival, enhances differentiation, and modulates expression of MBP in both OPCs and oligodendrocytes (Barres et al., 1992; McMorris and Dubois-Dalcq, 1988; Saneto et al., 1988).

\subsection{Animal models of MS}

\subsubsection{Toxin-induced demyelination models}

A number of animal models are available to study MS pathology and demyelination. One of the most used approaches is the injection of gliotoxic agents into locations of the CNS, producing focal demyelinating lesions. Due to the fact that spontaneous remyelination 
takes place in almost all of these lesions, toxin induced demyelination provides a potent tool to study endogenous remyelination and oligodendrocyte recruitment, but also the engraftment of transplanted cells.

Lysolecithin (lysophosphatidyl choline) is a membrane solubilizing agent and was first used in experimental demyelinaton by Hall (Hall, 1972). Injection into the rat dorsal funiculus produces ellipsoid shaped demyelination which extends longitudinally over 3 to $8 \mathrm{~mm}$. Lysolecithin has a particular toxicity for myelin and oligodendrocytes. However, marginal loss of axons and astrocytes occurs in the point of injection. Following demyelination, oligodendrocyte and Schwann cell remyelination takes place.

Injection of ethidium bromide into the rat spinal cord results in much larger areas of demyelination than in the lysolecithin model (Yajima and Suzuki, 1979; Blakemore et al., 1982). This deoxyriribonucleic acid (DNA) intercalating agent kills oligodendrocytes, oligondendrocyte precursors and astrocytes. Both oligodendrocyte and Schwann cell remyelination takes place, depending on location and species (Woodruff and Franklin, 1999; Jeffery and Blakemore, 1997). As mentioned above, spontaneous remyelination occurs in all toxin-induced demyelination models. Therefore, the contribution of engrafted cells is difficult to evaluate. For this reason, X-radiation prior to gliotoxin injection is used to deplete the local OPC population and inhibit endogenous remyelination (Hinks et al., 2001). Exogenous remyelination via cell transplantation can then be investigated in this model.

The cuprizone mouse model is a widely used non-invasive model to investigate effects directly related to demyelination and remyelination within the CNS (Blakemore, 1973; Matsushima and Morell, 2001). Feeding young adult mice with the cuprizone (biscyclohexanone-oxalhidrazone) for 5 weeks results in synchronous and consistent demyelination of the corpus callosum. Furthermore, strong spontaneous remyelination occurs rapidly after cuprizone removal from the diet.

In addition to aforementioned models demyelination can be induced by the injection of anti-galactocerebroside antibodies and complement (Keirstead and Blakemore, 1997). Compared to gliotoxins, lesions involve a greater area of the dorsal funiculus, but in turn are shorter in length. Furthermore, less axonal loss takes place. 


\subsubsection{EAE}

Experimental autoimmune encephalomyelitis (EAE) is an inflammatory demyelinating disease of the CNS. EAE was first described by Rivers and colleagues in 1933 who observed that vaccination with rabbit CNS homogenate resulted in brain inflammation in rhesus monkeys (Rivers et al., 1933). Today EAE is the most used animal model of MS and acute disseminated encephalomyelitis (ADEM). EAE is nowadays induced by active immunization with a single injection of defined myelin peptides/proteins such as MBP, PLP and MOG (Kabat et al., 1951; Gold et al., 2006). The disease can be reliably induced in many different species, such as in the marmorset monkey, guinea pig, mouse and rat. Depending on the genetic background of the species or strain and the antigen used for vaccination, EAE reproduces many clinical and immunopathological aspects of MS (Hohlfeld and Wekerle, 2001; Gold et al., 2006).

The autoimmune response against myelin sheath components is driven by encephalitogenic CD4-positive T cells (Ben-Nun et al., 1981). This is enabled by professional APCs which present antigen to fully reactive $\mathrm{T}$ cells (Dustin and Cooper, 2000). In addition, B cell derived autoantibodies play an important role in rat and marmorset leading to extensive demyelination, but not in mice (Schluesener et al., 1987; Linington et al., 1988; Genain et al., 1995; von Budingen et al., 2004). Furthermore, components of the innate immune system like macrophages and Toll-like receptors are involved in disease pathogenesis (Takeda et al., 2003; Munz et al., 2005).

Clinically, EAE disease is evaluated by a standardized EAE clinical score, the equivalent to the expanded disability status scale (EDSS) used in humans (Kurtzke, 1983). The clinical course of EAE can be either monophasic as in rats immunized with MBP, relapsing-remitting like in PLP/MOG peptide-immunized SJL mice, or secondary progressive such as observed in antibody high (ABH) Biozzi mice (Pender, 1987; Fritz et al., 1983; McRae et al., 1992; Hampton et al., 2008, Gold et al., 2006).

To date, MOG is the only antigen that induces a significant demyelinating antibodymediated immune response. 


\subsubsection{Targeted cortical EAE model}

Studying cortical MS pathology is hampered by the lack of adequate animal models, as conventional EAE predominantly affects the spinal cord, but rarely the brain. Indeed, toxin-induced demyelination approaches are available, however, they do not reflect the autoimmune nature of MS. To overcome this limitation the targeted cortical EAE model was established by Merkler and colleagues (Merkler et al., 2006). Lewis rats are subcutaneously immunized with a subthreshold dose of MOG which leads to production of anti-MOG autoantibodies, but not to overt neurological symptoms. Following peripheral immune priming, lesions are induced by injection of pro-inflammatory cytokines into the cerebral cortex.

The underlying concept of this model is that application of TNF- $\alpha / \mathrm{IFN}-\gamma$ locally attracts blood born monocytes and lymphocytes into the target area, going inline with transient BBB leakage. This allows vaccination derived anti-MOG autoantibodies to penetrate into the CNS paremchyma and to bind to their epitopes on the myelin surface. Finally, demyelination is mediated by a combination of complement and antibody-dependent cellular cytotoxicity mechanisms (Linington et al., 1988; Gold et al., 2006).

Histopathologically, the targeted cortical EAE model is characterized by extensive subpial and intracortical demyelination and oligodendroglial loss. The subpial lesions are reminiscent to cortical type III lesions observed in MS patients (Merkler et al., 2006; Peterson et al., 2001). In addition, demyelination is accompanied by microglia/macrophage activation, CD4- and CD8-positive $\mathrm{T}$ cell infiltration, and complement deposition. Furthermore, an acute axonal damage but no substantial neuronal loss was observed. In contrast to targeted white matter lesions, extensive cortical remyelination takes place and inflammation resolves within two weeks post lesion induction (Kerschensteiner et al., 2004; Merkler et al., 2006). For mentioned reasons, focal cortical EAE model is very suitable for demyelination and remyelination studies. 


\subsection{Aim}

The failure to achieve remyelination is considered to play an important role in $\mathrm{MS}$, however the mechanisms causing this failure are not fully understood. Inadequate provision of OPCs is a proposed cause of impaired or total lack of myelin restoration. A further hypothesis describes how OPCs, after being recruited into the sites of demyelination fail to differentiate to remyelinating oligodendrocytes. Irrespective of the aforementioned theories and age-dependent effects, frequency of demyelinating events may also play a role in MS. The reason for focussing on the cerebral cortex is based upon its ability to remyelinate during early stages of the disease, even after indications of repetitive demyelinating events. However, limited or impaired myelin restoration in patients with long disease duration indicates an exhaustion of the remyelination capacity.

My thesis addressed whether chronic demyelinated lesions within the cerebral cortex in MS patients are the result of repetitive demyelinating episodes.

The aims were:

1. to induce repetitive inflammatory demyelinated lesions within the same cortical area in the targeted cortical rat EAE model of MS

2. to characterize de- and re-myelination after repeated lesion inductions

3. to characterize oligodendroglial recruitment in targeted cortical EAE lesions

4. to investigate the effects of repeated targeted cortical EAE lesions on inflammation and axonal density 


\section{MATERIALS AND METHODS}

The study was carried out at the laboratories of the Department of Neuropathology and the animal house (Zentrale Tierexperimentelle Einrichtung, ZTE) of the University Medical Center, Göttingen, according to the approval of the Bezirksregierung Braunschweig.

\subsection{Study design}

Our objective in the present study was to determine whether repetitive demyelinating cortical episodes may exhaust the intrinsic cortical remyelinating capacity. For this purpose, we induced repeated lesions (each of which simulates a "demyelinating episode") at fixed intervals and a defined location in the rat cortex followed by histological assessment at different time points.

In the classical rodent EAE model, lesions are mostly confined to the spinal cord but only rarely affected the cerebral cortex. Therefore, a new model of MS was established that allows for EAE lesions to be targeted in the cerebral cortex with high accuracy in terms of the time point and location of lesion evolvement as well as lesion recovery (Merkler et al., 2006). In this animal model, rats are immunized with a subclinical dose of recombinant myelin oligodendrocyte glycoprotein (rMOG). Subclinical MOG immunization induces anti-MOG antibodies without overt clinical symptoms per se. In a second step, pro-inflammatory mediators are stereotactically injected into the rat cerebral cortex $1 \mathrm{~mm}$ caudal to bregma and $2 \mathrm{~mm}$ lateral to the sagittal suture, which finally induce focal extensive subpial and intracortical lesions (Figure 2). According to Paxinos stereotactic brain atlas, the affected area includes the motor (M1) and sensory cortex (S1) and allows for future behavioural analysis with regard to putative motor and sensory implications (Paxinos, 1998). The time points chosen for histological evaluation include the maximum extent of demyelination, which occurs at day 3 post lesion induction and remyelination at day 21. Lesioning was then repeated at the same particular area a total of four times at 21-day intervals, thus providing the necessary time for recovery between each demyelinating event. Animals were sacrificed at previously mentioned time points 
after the first, second and fourth lesioning episodes. Histological analysis was performed with respect to demyelination, remyelination, recruitment of oligodendrocytes, inflammatory infiltrates and axonal integrity. By computer-aided and manual analysis, the following parameters were analyzed and quantified: demyelinated area, fraction of myelinated fibres and cell densities.

In order to investigate oligodendrocyte recruitment in more detail, the proliferative kinetics of oligodendroglial populations in response to demyelination was analysed. Therefore, animals were labelled with the proliferation marker 5-bromo-2-deoxyuridine (BrdU), which is incorporated in dividing cells.

High and stable serum levels of anti-MOG autoantibodies are an important prerequisite for induction of demyelinating episodes. Therefore, serum levels of MOG autoantibodies were monitored by ELISA beginning from the initial lesion (day 18 post immunization) until the last lesion induction (day 82 post immunization). 


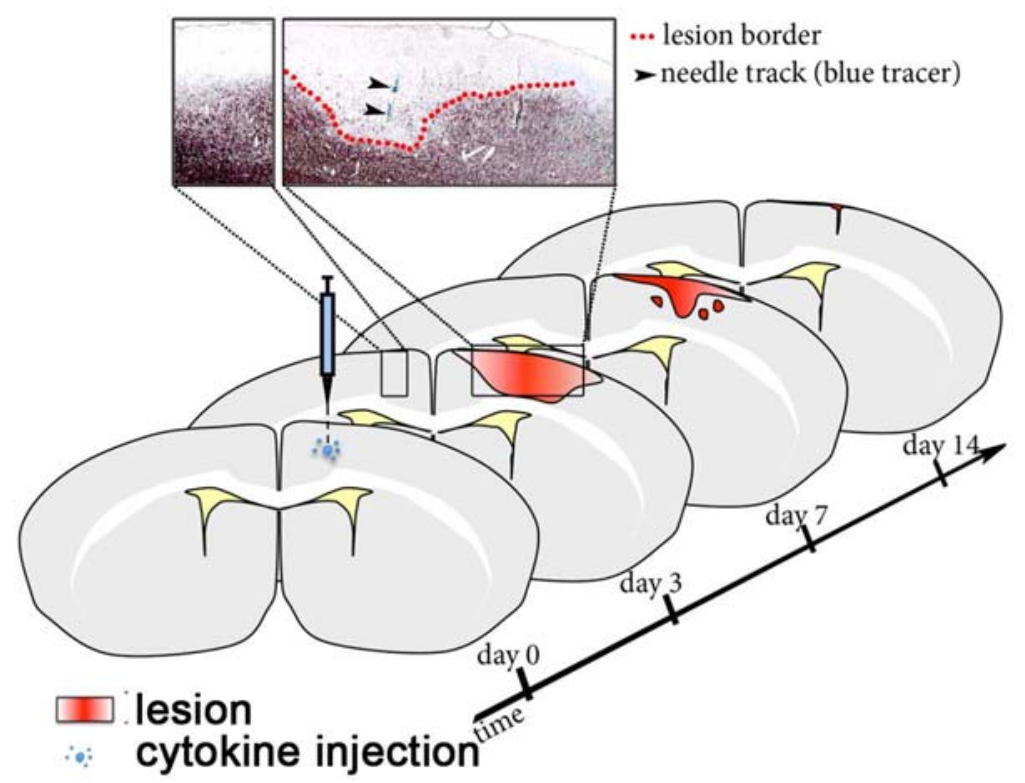

s.c.

MOG injection

Repeated induction of cortical demyelination
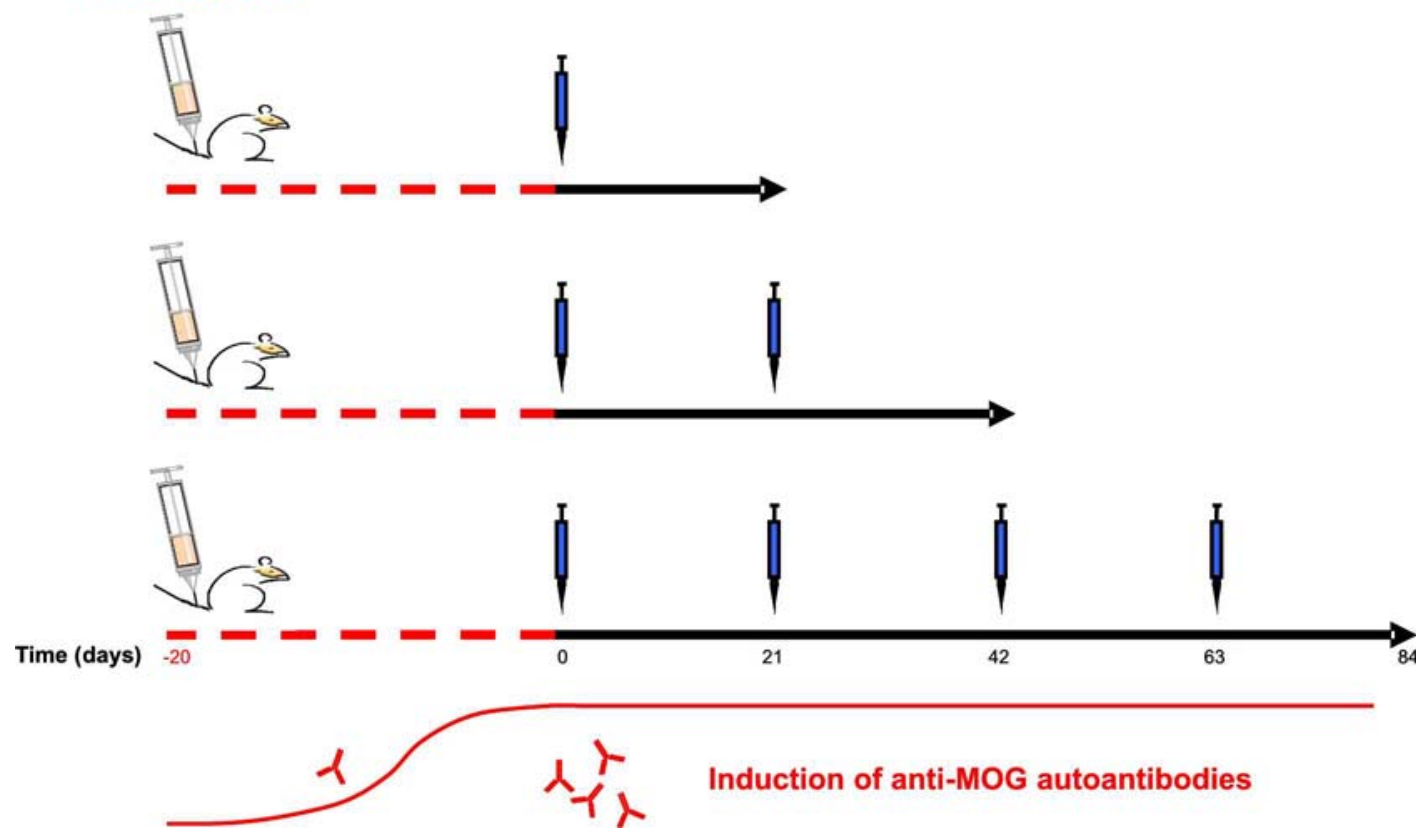

Figure 2: Experimental design 


\subsection{Animals and groups}

A total number of $\mathrm{n}=101$ adult female Lewis rats $(195 \mathrm{~g} \pm 15$, Harlan, Horst, Netherlands) were included in this study. The animals were kept in groups (max. 8 animals per cage) on a 12:12 h light/dark cycle with food and water provided ad libitum. All experiments were approved by the Bezirksregierung Braunschweig, Germany.

This study consisted of 5 independent experiments from which 4 were pooled for the repetitive lesioning approach (Table 1), as interexperimental variations were negligible. In an additional experiment, proliferation of oligodendroglial cells were analysed in more detail (Table 2). The following tables show the total numbers of animals used:

\begin{tabular}{|c|c|c|c|c|c|c|}
\hline \multirow{2}{*}{ immunization } & \multicolumn{2}{|c|}{$\begin{array}{c}1^{\text {st }} \text { injection } \\
\text { days post injection* }\end{array}$} & \multicolumn{2}{c|}{$\begin{array}{c}2^{\text {nd }} \text { injection } \\
\text { days post injection* }\end{array}$} & \multicolumn{2}{|c|}{$\begin{array}{c}4^{\text {th }} \text { injection } \\
\text { days post injection* }\end{array}$} \\
\cline { 2 - 7 } & $\mathbf{3}$ & $\mathbf{2 1}$ & $\mathbf{3}$ & $\mathbf{2 1}$ & $\mathbf{3}$ & $\mathbf{2 1}$ \\
\hline \hline s.c. MOG & 9 & 11 & 7 & 5 & 8 & 18 \\
\hline s.c. IFA & 6 & - & - & - & 4 & - \\
\hline no & $6^{\dagger}$ & - & - & - & - & - \\
\hline
\end{tabular}

${ }^{*}$ sacrifice of animals; ${ }^{\dagger} 3$ of 6 animals were killed immediately after injection

Table 1: Numbers of animals, groups and time points of the repetitive lesioning approach

\begin{tabular}{|c|c|c|c|}
\hline \multirow[t]{2}{*}{ immunization } & \multicolumn{3}{|c|}{$\begin{array}{c}\mathbf{1}^{\text {st }} \text { injection } \\
\text { days post injection* }\end{array}$} \\
\hline & 3 & 21 & $21 \ddagger$ \\
\hline s.c. MOG & 4 & 6 & - \\
\hline s.c. IFA & 5 & 6 & $6^{+}$ \\
\hline
\end{tabular}

Table 2: Numbers of animals, groups and time points of the single lesioning approach 


\subsection{Solutions and reagents}

Phosphate buffered saline (PBS):

PBS (Dulbecco, Biochrom AG) $\quad 9.55 \mathrm{~g}$

distilled water

$1000 \mathrm{ml}$

1M sulfuric acid:

$\begin{array}{ll}96 \% \text { sulfuric acid (Merck) } & 51.1 \mathrm{ml} \\ \text { distilled water } & 448.9 \mathrm{ml}\end{array}$

4\% paraformaldehyde (PFA):

$\begin{array}{ll}\text { PFA (Merck, Germany) } & 40 \mathrm{~g} \\ \text { 1.0 M sodium hydroxide } & 1 \mathrm{drop} \\ 10 \text {-fold PBS } & 100 \mathrm{ml} \\ \text { distilled water } & 9000 \mathrm{ml} \\ \text { adjust to pH } 7.3 & \end{array}$

$0.05 \%$ Triton containing phosphate buffered saline (PBST):

$\begin{array}{ll}\text { PBS } & 1000 \mathrm{ml} \\ \text { Triton X-100 (MP Biomedicals) } & 500 \mu 1\end{array}$

Bielschowsky silver staining:

$20 \%$ silver nitrate solution:

$\begin{array}{ll}\text { silver nitrate (Roth) } & 10 \mathrm{~g} \\ \text { distilled water } & 50 \mathrm{ml}\end{array}$

Developer stock solution:

37\% formalin (Merck) 20ml 


$\begin{array}{ll}\text { citric acid (Merck) } & 0.5 \mathrm{~g} \\ 65 \% \text { nitric acid (Merck) } & 2 \text { drops } \\ \text { distilled water } & 100 \mathrm{ml}\end{array}$

$2 \%$ sodium thiosulfate solution:

sodium thiosulfate pentahydrate $\quad 10 \mathrm{~g}$

(Merck)

distilled water

$500 \mathrm{ml}$

H \& E staining:

$1 \%$ acid rinse:

$30 \%$ hydrochloric acid $2 \mathrm{ml}$

100\% Isopropyl alcohol (Merck) 198ml

$1 \%$ eosin solution:

Eosin-G Certistain@ (Merck) 2ml

$70 \%$ isopropyl alcohol 198ml

(filter before use)

Immunohistochemistry:

$10 \mathrm{mM}$ citric acid buffer:

$\begin{array}{ll}\text { citric acid (Merck)) } & 2.1 \mathrm{~g} \\ \text { distilled water } & 1000 \mathrm{ml} \\ \text { adjust to pH } 6 & \end{array}$

Tris-ethylenediaminetetraacetic acid (Tris-EDTA) buffered saline:

Trizma base (Sigma) $\quad 1.21 \mathrm{~g}$ 
1.0M EDTA $\quad 1 \mathrm{ml}$

distilled water $\quad 1000 \mathrm{ml}$

adjust to $\mathrm{pH} 9$

$0.2 \%$ casein block:

Tropix (Applied Biosystems) $\quad 2 \mathrm{~g}$

PBS $1000 \mathrm{ml}$

Tween 20 (Merck) $\quad 1 \mathrm{ml}$

heat Tropix/PBS to $50^{\circ} \mathrm{C}$ until it dissolves

1.0M Tris/HCl stock solution:

trizma base (Sigma) $\quad 121 \mathrm{~g}$

$30 \%$ hydrochloric acid $\quad 400 \mathrm{ml}$

sodium chloride (Merck) $\quad 170 \mathrm{~g}$

distilled water fill up to $1000 \mathrm{ml}$

adjust to $\mathrm{pH} 7.5$

TBS working solution (washing buffer for immunohistochemistry):

sodium chloride (Merck) $\quad 9 \mathrm{~g}$

$1.0 \mathrm{M}$ Tris/ $\mathrm{HCl} \quad 50 \mathrm{ml}$

adjust to $\mathrm{pH} 7.5$

Fast Red working solution:

0.1M TBS (pH 8.2) 49ml

naphtol-ASMX-phosphate (Sigma) 10mg

dimethylformamide (Sigma) $\quad 1 \mathrm{ml}$

1.0M levimasole (Sigma) $\quad 50 \mu \mathrm{l}$

Fast Red TR salt (Sigma) $\quad 0.05 \mathrm{~g}$

filter before use 
3,3'-diaminobenzidine tetrachloride (DAB) working solution:

$\begin{array}{ll}\text { DAB (Sigma) } & 25 \mathrm{mg} \\ \text { PBS } & 50 \mathrm{ml} \\ 30 \% \text { hydrogen peroxidase (Merck) } & 30 \mu \mathrm{l}\end{array}$

$1 \%$ nickel ammonium sulfate solution:

$$
\begin{array}{ll}
\text { nickel ammonium sulfate (Merck) } & 0.1 \mathrm{~g} \\
\text { distilled water } & 10 \mathrm{ml}
\end{array}
$$

4-nitro blue tetrazolium chloride (NBT) stock solution:

$70 \%$ N,N-dimethylformamide $\quad 1 \mathrm{ml}$

(Sigma)

NBT (Roche)

$100 \mathrm{mg}$

5-bromo-4-chloro-3-indolyl phosphate (BCIP) stock solution:

$70 \% \mathrm{~N}, \mathrm{~N}$-dimethylformamide $\quad 1 \mathrm{ml}$

(Sigma)

BCIP (Roche)

$50 \mathrm{mg}$

NBT/BCIP buffer:

1.0M Tris (Sigma-Aldrich) $\quad 100 \mathrm{ml}$

$5.0 \mathrm{M} \mathrm{NaCl}$ (Merck) 20ml

1.0M MgCl (Merck) 50ml

distilled water $\quad 100 \mathrm{ml}$

NBT/BCIP working solution:

NBT stock solution $\quad 225 \mu 1$ 
BCIP stock solution

NBT/BCIP buffer
$175 \mu 1$

$50 \mathrm{ml}$

\subsection{Operations and procedures}

\subsubsection{Immunogen}

Recombinant MOG (rMOG) was produced as described by Adelmann and colleagues (Adelmann et al., 1995). Briefly, rMOG corresponding to the N-terminal sequence of rat MOG (amino acids 1-125) was expressed in Escherichia coli and purified to homogeneity. The purified protein was dissolved in $6 \mathrm{~mol} / \mathrm{l}$ of urea and dialysed against $20 \mathrm{mmol} / \mathrm{l}$ of sodium acetate buffer ( $\mathrm{pH} 3.0$ ). Finally, the sample was stored at $-70^{\circ} \mathrm{C}$.

\subsubsection{Sensitization procedure}

Rats $(\mathrm{n}=68)$ were anaesthetized by inhalation anaesthesia with isoflurane (Abbot, Germany) and injected subcutaneously at the base of tail with a total volume of $100 \mu 1$ of rMOG $(50 \mu \mathrm{g}$ MOG diluted in saline) emulsified in incomplete Freund's adjuvant (IFA; Sigma-Aldrich Chemie GmbH, Steinheim, Germany). For control experiments, rats ( $\mathrm{n}=$ 27) were injected subcutaneously at the base of the tail with a total volume of $100 \mu 1$ of saline emulsified in IFA. A subset of animals $(n=6)$ received no s.c. injection (native controls). For induction of a targeted EAE lesion, MOG-sensitized rats were kept for 1921 days and then given a stereotactic injection of cytokines into a predetermined location of the cerebral cortex.

\subsubsection{Intracerebral stereotactic injection}

Animals were anaesthesized by intraperitoneal (i.p.) injection of ketamine $60 \mathrm{mg} / \mathrm{kg}$ bodyweight (Inresa, Freiburg, Germany) and xylazine $8 \mathrm{mg} / \mathrm{kg}$ bodyweight (Riemser, Greifswald, Germany). One $\mathrm{ml}$ of warmed sterile saline was administered subcutaneously to maintain normal hydration during the surgical procedure and recovery. Following loss 
of consciousness, the rats were mounted on a stereotactic device (Stoelting Co, IL, USA). A fine hole was then drilled through the scull $1 \mathrm{~mm}$ caudal to bregma and $2 \mathrm{~mm}$ lateral to the sagittal suture. To minimize the risk of brain damage, the drilling head was removed before penetrating the scull. The remaining thin scull was then opened by a fine scalpel, giving access to the surface of the brain. A finely calibrated glass capillary (Braun, Germany) was then stereotactically inserted, targeting the cortex at approximately 1.7 $\mathrm{mm}$ depth. The rats were then injected with $1 \mu \mathrm{l}$ of a cytokine mixture composed of 250 ng of recombinant rat tumour necrosis factor- $\alpha$ (TNF- $\alpha$; R\&D Systems, Abingdon, UK) and $150 \mathrm{U}$ of recombinant rat interferon- $\gamma$ (IFN- $\gamma$; PeproTech, London, UK) dissolved in phosphate-buffered saline (PBS, Dulbecco instamed, Biochrom AG, Germany) over a 3min period. A trace of monastral blue (Fluka, Germany) was added as a marker dye for better visibility. Unsensitized (native) control animals (Table 1) and a subgroup of s.c. MOG immunized animals (Table 2) received PBS and monastral blue alone. After injection, the capillary was carefully withdrawn and the operation site was sealed by suture. To provide analgesia, Temgesic C) (Essex Pharma GnbH, Germany) was administered at $0.03 \mathrm{mg} / \mathrm{kg}$ during surgery and 6 hours later. Stereotactic cytokine injection was performed up to four times at intervals of 21 days, always targeting the same area (Tables 1 and 2).

\subsubsection{5-bromo-2-deoxyuridine (BrdU) injection}

To determine proliferation of oligodendroglial cells after lesion induction, BrdU labelling was performed. A subset of s.c. MOG $(n=44)$ and s.c. IFA $(n=17)$ immunized animals were injected intraperitonealy twice daily with $1.5 \mathrm{ml} 0.9 \% \mathrm{NaCl}$ solution (Braun, Germany) containing 100mg/kg (animal weight) 5-bromo-2-deoxyuridine (BrdU, Sigma). In a subgroup of animals, BrdU administration was started immediately after a single lesion induction and continued until the animals were sacrificed at day three post lesion induction. In animals which were kept for 21 days after lesion induction, BrdU was administered for 5 days starting at day 2 after each final intracerebral cytokine/PBS injection. 


\subsubsection{Blood sampling and serum preparation}

In a randomly selected group of animals, blood samples were taken 1-3 days before and 18-21 days after each intracerebral cytokine injection. Therefore, the rats were shortly anaesthetized by gas inhalation with isoflurane (Abbot, Germany). Following loss of consciousness, a blood sample (approx. $1 \mathrm{ml}$ ) was immediately taken from the sublingual vein. Bleeding was then stopped by pressing a piece of cotton soaked in iron (III) chloride on the tongue. Collected blood samples were centrifuged (Centrifuge 5415 R, Eppendorf, Germany) at 13000rpm for $10 \mathrm{~min}$. The supernatant was then taken off and stored at $-20^{\circ} \mathrm{C}$ for further measurements.

\subsection{Enzyme-linked immunosorbent assay (ELISA) for detection of anti-MOG autoantibodies}

To monitor the immune response, anti-MOG autoantibody serum levels were determined by ELISA. As a first step, 96-well maxisorp microtiter plates (Nunc, Langenselbold, Germany) were coated with rMOG at $0.4 \mu \mathrm{g} / 50 \mu \mathrm{l} /$ well dissolved in PBST (phosphate buffered saline $+0.05 \%$ Triton). The plates were then wrapped in damp towels and stored at room temperature for 4 hours. Afterwards, the content was discarded by inverting the plates and tapping the bottom on paper towels. Plates were then blocked with $5 \%$ bovine serum albumin (BSA, Serva) dissolved in PBS $(200 \mu 1 /$ well) for $1 \mathrm{~h}$ at room temperature and washed subsequently 5 times with water. As a last step, wells were filled with $200 \mu 1$ each and incubated for $15 \mathrm{~min}$ at room temperature. Before storing at $-20^{\circ} \mathrm{C}$ the plates were tapped on paper towels as described earlier.

Rat sera were prepared by diluting 1:100 in PBST. In addition, 1:3 serial dilutions of each sample were added on a MOG coated plate starting with the upper row. The plates were then kept humid for $2 \mathrm{~h}$ at room temperature. To remove unbound antibodies, plates were washed 6 times with PBST. Afterwards, 50 $\mu 1$ of IgG-specific horseradish peroxidiseconjugated goat anti-rat antibody (1:10000 in PBST; Pierce, Rockford, IL, USA) was added to each well and kept humid for 2 hours at room temperature. Following proper

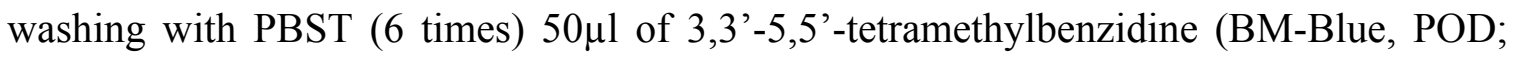
Roche, Basel, Switzerland) was added as a substrate. After the first row of wells 
developed a blue colour, reaction was stopped immediately by adding $50 \mu 1$ of $1 \mathrm{M} \mathrm{H}_{2} \mathrm{SO}_{4}$ (Merck) to all wells. Finally, optical density (OD) was measured at 450nm (Model 680, Bio-Rad, Hercules, CA, USA). Antibody titres were defined as the serum dilutions at half maximum OD.

\subsection{Histology}

\subsubsection{Tissue processing}

\subsubsection{Perfusion and sectioning}

Animals were anaesthetized by injecting a lethal dose of $14 \%$ chloral hydrate (Merck). After loss of consciousness, transcardial perfusion was performed through the left cardial ventricle with PBS followed by 4\% paraformaldehyde. Brains were then dissected and stored for $24 \mathrm{~h}$ in $4 \%$ paraformaldehyde at $4^{\circ} \mathrm{C}$. After fixation, the brain was cut in $4 \mathrm{~mm}$ thick slices and washed in water. In addition, slices were gradually dehydrated by performing alcohol/xylol/paraffin series overnight using an automated tissue processor (Thermo Scientific, Germany). The next day, slices were embedded in paraffin. Tissue blocks were then cut in $1-2 \mu \mathrm{m}$ thin coronal sections. Serial sections adjacent to the injection site were used for further histology (injection site was recognized/identified by traces of monastral blue).

\subsubsection{Deparaffination and dehydration of histological sections}

Prior to histological stainings, sections were deparaffinized by performing graded xylol (Merck) and isopropyl alcohol (Merck) series as follows: 4 x 100\% xylol (8min), 1 x xylol/alcohol (1:1, 1min), 2 x 100\% alcohol (4min), 1 x 90\% alcohol (4min), 1x 70\% alcohol (4min), 1x 50\% alcohol (4min), 1x distilled water.

Dehydration was achieved by performing the above described series in reversed order. 


\subsubsection{Histochemical stainings}

\subsubsection{Hematoxylin and eosin (HE) staining}

HE staining was performed to obtain a general overview with regard to inflammation and astrocytosis. Sections were deparaffinized as described above, washed 3 times with distilled water and placed into Mayers Hämalaun (Merck, Germany) for 5 min. Afterwards, sections were washed with distilled water and differentiated by dipping slides once into $1 \%$ acid rinse. Subsequently, bluing was performed by bathing slides in flowing tap water for $10 \mathrm{~min}$. Slides were then washed in distilled water and placed into eosin solution for $5 \mathrm{~min}$. In addition, slides were washed (once again) in distilled water and dehydrated as described earlier. Alcohol series were performed quickly to avoid excessive elution of eosin. Finally, slides were mounted using DePex mounting medium (VWR International, Germany) and coverslipped.

\subsubsection{Bielschowsky silver staining (modified)}

To assess axonal integrity Bielschowsky silver staining was performed. Sections were deparaffinized as described earlier and washed 3 times with distilled water. Afterwards, sections were placed in $10 \%$ silver nitrate solution for $20 \mathrm{~min}$. Concentrated $(32 \%)$ ammonium hydroxide (Merck, Germany) was added drop by drop to the nitrate solution until the formed precipitate cleared. Following washing in distilled water, the slides were placed into the silver nitrate/ammonium hydroxide solution for $15 \mathrm{~min}$ and kept dark. While washing the slides in distilled water (containing few drops of ammonium hydroxide), 10 drops of developer stock solution was added to silver nitrate/ammonium hydroxide solution using a stirrer. Subsequently, the slides were placed into this solution for about 1 minute until color of the tissue turned to ochery. In addition, excessive silver nitrate was washed out using $2 \%$ sodium thiosulfate solution. After a final wash with distilled water, slides were dehydrated as described earlier and mounted using DePex mounting medium (VWR International, Germany) and coverslipped. 


\subsubsection{Immunohistochemistry}

\subsubsection{Antigen retrieval}

Loss of immunoreactivity caused by paraformaldehyde fixation can be reversed if tissue is exposed to heat and acid:

Hydrated and washed slides were placed in closed polystyrene cuvettes filled to the top with $10 \mathrm{mM}$ citric acid $(\mathrm{pH}=6)$ or $1 \mathrm{mM}$ Tris-EDTA $(\mathrm{pH}=9)$ buffered saline. Slides were heated 5 times for 3 min using a microwave oven (800watt, Bosch). Between each incubation cycle (step), cuvettes were filled up alternately with buffer and distilled water. Before continuing further staining procedure, slides were left to cool down for $30 \mathrm{~min}$ and then washed with distilled water.

\subsubsection{GFAP immunohistochemistry}

Reactive astrogliosis was assessed by immunohistochemistry using glial fibrillary acidic protein (GFAP) as a marker for astrocytes. Slides were washed 5 times in PBS between each step. Following deparaffination, endogenous peroxidases were blocked by placing slides in $3 \%$ hydrogen peroxide (dissolved in PBS) for $20 \mathrm{~min}$ at $4{ }^{\circ} \mathrm{C}$. Unspecific antibody binding was performed by applying $100 \mu 1$ 10\% fetal calf serum (FCS, Biochrom) for 30 min. Afterwards, excessive FCS was removed with a cleaning wipe without washing with PBS. The primary antibody mouse anti-human GFAP (1:50, clone 6F2, Dako) was added overnight at $4^{\circ} \mathrm{C}$. Biotinylated sheep anti-mouse (1:200, Amersham) and ExtrAvidin (1:1000, Sigma) were applied consecutively for $1 \mathrm{~h}$ at room temperature. Color development with DAB was performed for approximately $5 \mathrm{~min}$ followed by counterstaining with Mayers Hämalaun (Merck, Germany). Finally, slides were dehydrated and mounted using DePex mounting medium (VWR International, Germany) and coverslipped. 


\subsubsection{MBP immunohistochemistry}

Demyelination and remyelination was assessed by immunohistochemistry using MBP as a marker for myelin sheaths. Slides were washed 5 times in PBS between each step, blocking of unspecific antibody binding being an exception. Following deparaffination, endogenous peroxidases were blocked by placing slides in 3\% hydrogen peroxide (dissolved in PBS) for $20 \mathrm{~min}$ at $4^{\circ} \mathrm{C}$. Unspecific antibody binding was performed by incubation with $100 \mu 110 \%$ fetal calf serum (FCS, Biochrom) for $30 \mathrm{~min}$. The primary antibody, rabbit anti-human MBP (1:1500, A0623, Dako), was added overnight at $4^{\circ} \mathrm{C}$. Biotinylated donkey anti-Rabbit (1:200, Amersham) and ExtrAvidin (1:1000, Sigma) were applied consecutively for $1 \mathrm{~h}$ at room temperature. Color development with DAB was performed for approximately $5 \mathrm{~min}$ followed by counterstaining with Mayers Hämalaun (Merck, Germany). In a subset of animals, color reaction was enhanced by adding $2.5 \mathrm{ml}$ of $1 \%$ nickel ammonium sulfate to the substrate solution (adjusted to $\mathrm{pH}$ 7.2). Finally, slides were dehydrated and mounted using DePex mounting medium (VWR International, Germany) and coverslipped.

\subsubsection{ED1 immunohistochemistry}

Inflammation was assessed by immunohistochemistry using ED1 as a marker for macrophages and activated microglia, respectively. Slides were washed 5 times in PBS between each step. Following deparaffination, antigen retrieval $(10 \mathrm{mM}$ citric acid and microwave irradiation) was performed as described above. Afterwards, endogenous peroxidases were blocked by placing slides in 3\% hydrogen peroxide (dissolved in PBS) for $20 \mathrm{~min}$ at $4^{\circ} \mathrm{C}$. Blocking of unspecific antibody binding was achieved by incubation with $100 \mu 110 \%$ FCS for 30min. Afterwards, excessive FCS was removed with a cleaning wipe without washing with PBS. The primary antibody, rabbit anti-human ED1 (clone ED1; Serotec, Oxford, UK), was applied overnight at $4{ }^{\circ} \mathrm{C}$. Biotinylated donkey antirabbit (1:200, Amersham) and ExtrAvidin (1:1000, Sigma) were added consecutively for $1 \mathrm{~h}$ at room temperature. Color development with DAB was performed for approximately 5min followed by counterstaining with Mayers Hämalaun (Merck). Finally, slides were 
dehydrated and mounted using DePex mounting medium (VWR International, Germany) and coverslipped.

\subsubsection{MBP/NogoA double immunohistochemistry}

To determine the oligodendrocyte density within the lesion, double immunohistochemistry was performed using MBP as a marker for myelin sheaths and NogoA (clone 11C7) as a marker for mature oligodendrocytes. Antigen retrieval $(10 \mathrm{mM}$ citric acid and microwave irradiation) was performed followed by blocking of endogenous peroxidases and unspecific antibody binding as described above (see 2.5.3.4). The primary antibody, mouse anti-mAb11C7 (1:20000, kindly provided by M. E. Schwab, ETH Zurich), was added overnight at $4^{\circ} \mathrm{C}$. Biotinylated sheep anti-mouse (1:200, Amersham) and ExtrAvidin (1:1000, Sigma) were applied consecutively for $1 \mathrm{~h}$ at room temperature. Color development with DAB was performed for approximately $5 \mathrm{~min}$. To saturate open binding sites on the first primary antibody, $100 \mu 1$ of Fab antibody (mouse, Dako) was added followed by blocking of unspecific antibody binding sites using $100 \mu 1$ 10\%FCS (containing 0.05\% Triton-X-100, MP Biomedicals). The second primary antibody, rabbit anti-human MBP (1:1500, A0623, Dako), was applied for 2h at room temperature. Henceforth, 0.5M Tris buffered saline (TBS) was used for washing and incubation steps. Mouse anti-rabbit antibody bridge (1:50, Dako), goat anti-mousealkaline phosphatase (AP) (1:50, Dako) and alkaline phosphatase anti-alkaline phosphatase (APAAP) mouse (1:50, Dako) were added consecutively for 1 hour at room temperature. Color reaction was performed using NBT/BCIP (Roche) as substrate. For representative photographs, some sections were stained using Fast Red as a substrate. Finally, slides were mounted with Immu-Mount (ThermoScientific) and coverslipped.

\subsubsection{Olig2/PLP double immunofluorescence}

To determine the oligodendroglial precursor density within the lesion, double immunofluorescence staining was performed using PLP as marker for myelin sheaths and olig2 as a marker for oligodendroglial precursors/early oligodendrocytes. Antigen 
retrieval (1mM Tris-EDTA, pH=9, microwave heating) was followed by blocking with $0.2 \%$ casein (Tropix, I-Block, Applied Biosystems) in PBS for 30min. The first primary antibody, rabbit anti-human olig2 (1:300 in 0.2\% casein, IBL, Germany), was added overnight at $4^{\circ} \mathrm{C}$. The indocarbocyanine 3 (Cy3) conjugated donkey anti-rabbit $\operatorname{IgG}$ $(\mathrm{H}+\mathrm{L})$ secondary antibody (1:300 in $0.2 \%$ casein, Dianova GmbH, Hamburg, Germany) was applied for $1 \mathrm{~h}$ at room temperature. The second primary antibody, mouse anti-PLP (1:2500 in 10\% FCS, clone Plpc1, Biozol), was added overnight at $4^{\circ} \mathrm{C}$ followed by indocarbocyanine $2(\mathrm{Cy} 2)$ conjugated donkey anti-mouse $\operatorname{IgG}(\mathrm{H}+\mathrm{L})$ secondary antibody (1:200 in 10\% FCS, Dianova GmbH, Hamburg, Germany) for 1h at room temperature. Cell nuclei were stained with DAPI (1:10000 in 10\%FCS, Molecular Probes) for 10min at room temperature. Finally, slides were mounted using Fluoromount (Dako) and coverslipped.

\subsubsection{NogoA/BrdU double immunohistochemistry}

To determine the mature oligodendrocyte population derived by cell division after lesion induction, double immunohistochemistry was performed. NogoA was used as a marker for mature oligodendrocytes. BrdU was used as a marker for previous cell division. Antigen retrieval (10mM citric acid and microwave irradiation) was performed followed by blocking of endogenous peroxidases and unspecific antibody binding as described above (2.5.3.4). The primary antibody, rabbit anti-NogoA (1:100 in 10\% FCS, clone $\mathrm{H} 300$, Santa Cruz), was added overnight at $4^{\circ} \mathrm{C}$. Henceforth, $0.5 \mathrm{M}$ Tris buffered saline (TBS) was used for washing and incubation steps till finishing the first staining. Goat anti-rabbit alkaline peroxidase (AP) conjugated antibody (1:50, D0487, Dako) was added for $45 \mathrm{~min}$ at room temperature. Color reaction was performed using Fast Red (Sigma) as a substrate. The second primary antibody, mouse anti-BrdU $(1: 400$ in $10 \%$ FCS, Chemicon), was applied overnight at $4^{\circ} \mathrm{C}$. Biotinylated sheep anti-mouse (1:200 in 10\% FCS, GE Healthcare) and ExtrAvidin (1:1000, Sigma) were added consecutively for $1 \mathrm{~h}$ at room temperature. Color development with DAB was performed for approximately $5 \mathrm{~min}$ followed by counterstaining with Mayers Hämalaun (Merck). Finally, slides were mounted using Immu-Mount (ThermoScientific) and coverslipped. 


\subsubsection{Olig2/BrdU double immunohistochemistry}

To determine the oligodendroglial precursor density derived by cell division after lesion induction, double immunofluorescence staining was performed using olig2 as a marker for oligodendroglial precursors/early oligodendrocytes and $\operatorname{BrdU}$ as a marker for proliferation. Antigen retrieval (Tris-EDTA and microwave heating) was performed followed by blocking with $0.2 \%$ casein in PBS for $30 \mathrm{~min}$. The first primary antibody, rabbit anti-human olig2 (1:300 in $0.2 \%$ casein, IBL, Germany), was added overnight at $4^{\circ} \mathrm{C}$. The Cy3-conjugated donkey anti-rabbit $\operatorname{IgG}(\mathrm{H}+\mathrm{L})$ secondary antibody $(1: 300$ in $0.2 \%$ casein, Dianova GmbH, Hamburg, Germany) was applied for $1 \mathrm{~h}$ at room temperature. As a second primary antibody, mouse anti-BrdU (1:400 in 10\% FCS, Chemicon) was added overnight at $4{ }^{\circ} \mathrm{C}$ followed by $\mathrm{Cy} 2$-conjugated donkey anti-mouse IgG $(\mathrm{H}+\mathrm{L})$ secondary antibody $(1: 200$ in 10\% FCS, Dianova $\mathrm{GmbH}$, Hamburg, Germany) for $1 \mathrm{~h}$ at room temperature. Cell nuclei were stained with DAPI (1:10000 in 10\%FCS, Molecular Probes) for 10min at room temperature. Finally, slides were mounted using Fluoromount (Dako) and coverslipped.

\subsection{Photoimaging and morphometric analysis}

Histological photographs were captured through light and fluorescent microscopes (BX 40 and BX 50, Olympus, Germany) at 20-, 40-, 200-, 400- and 1000-fold magnification, respectively. Images for computer-aided analysis were recorded with digital cameras mounted on mentioned microscopes (Color View II and DP71, Olympus, Germany).

Histological stainings were analysed as followed:

Digital images of MBP-stained sections were recorded through a light microscope (BX 40, Olympus, Germany) with a CCD camera (Color View II, Olympus, Germany) at 200fold magnification. The size of demyelinated lesion was measured using Analysis software (Analysis, Soft Imaging System, Germany). The extent of demyelination was defined as the MBP-negative area $\left(\mathrm{mm}^{2}\right)$. The length of subpial lesion was given in $\mu \mathrm{m}$.

The fraction of myelinated axons was determined in cortical layer III within 4 fields of sight using a counting grid (10x10 squares) at 1000-fold magnification (see Figure 3, A). 
The numbers of MBP-positive myelin sheaths which overlapped the crosses of the counting grid were determined on MBP-stained sections. In addition, the numbers of axons were analysed in the same way on adjacent Bielschowsky-stained sections. Afterwards, MBP-positive fibre counts were normalized to axon counts, second been set to $100 \%$ as a reference.

The macrophage/microglia reaction was determined on ED1-stained sections within two defined cortical areas. First, ED1-positive cells were counted in cortical layer III within the center of lesion within four fields of sight at 1000-fold magnification (Figure 3, A). To capture a broad area of inflammation, a further region of interest (ROI) was chosen. This ROI was defined as the cortical area lying within the upper quadrant of a standardized fictive rectangular cross, which was placed in the middle of the analyzed section orientated in the medial-lateral and dorsal-ventral direction, respectively (Figure 3, C). For both ROIs, the mean number of ED1-positive cells per square millimetre was given.

Axonal integrity was assessed on Bielschowsky silver-stained sections at 1000-fold magnification. Axons were determined in the center of lesion of cortical layer III within 4 fields of sight using a 10x10 counting grid (Figure 3, A). Axonal density was given in percent using untreated control animals as a reference (set to $100 \%$ ).

NogoA-positive cell population was determined on NogoA/MBP double positive-stained sections at 400x-fold magnification. Proliferated NogoA-positive cells were determined on NogoA/BrdU double stained sections. The density of both cell populations were assessed in cortical layers I and II within 11 fields of sight of a 10x10 counting grid, covering the typically affected areas of subpial demyeliantion (Figure 3, B). Cell density was given as cells per square millimetre.

Olig2-positive and olig2/BrdU-double positive cell populations were determined on olig2/BrdU double fluorescent stained sections using a light/fluorescent microscope (BX 51, Olympus, Germany) at 200-fold magnification. Cells were counted in cortical layers I and II within three fields, which is similar to ROI used for evaluation of above mentioned NogoA-positive cell populations (Figure 3, B). Cell densities were given as cells per square millimetre. 
A cell was considered "positive" or "double-positive" when the following two conditions were met:

First, the specific signal must overlap with the cell soma (NogoA, olig2, BrdU, ED1) or its dendritic processes (ED1). Second, a cell must contain a nucleus.

A

cortical layer III

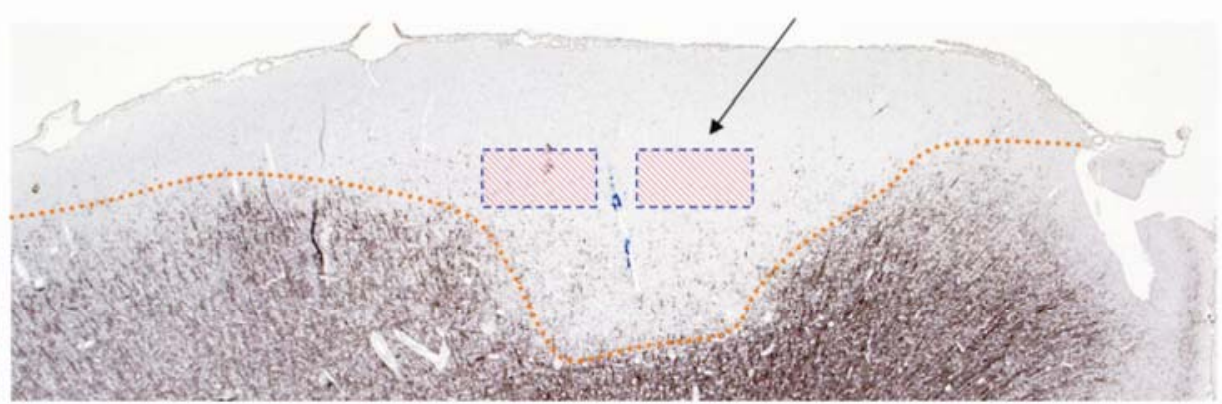

B

cortical layers I-II

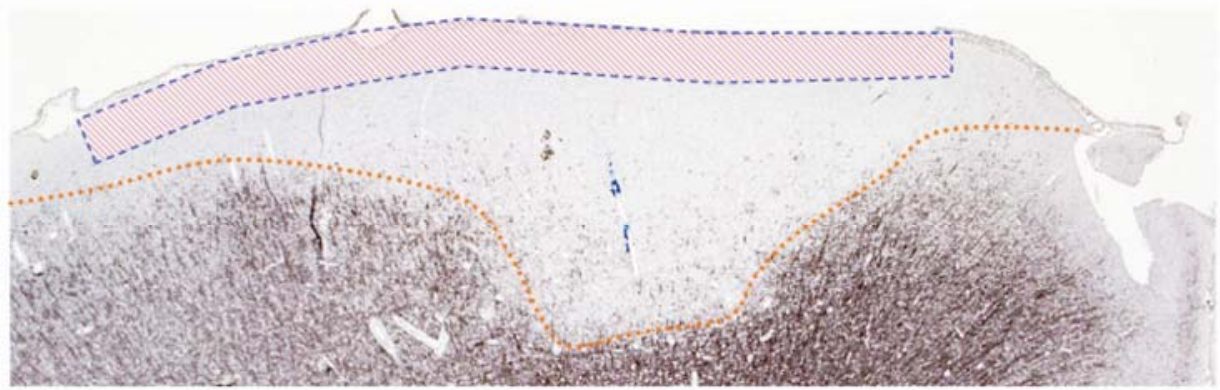

C

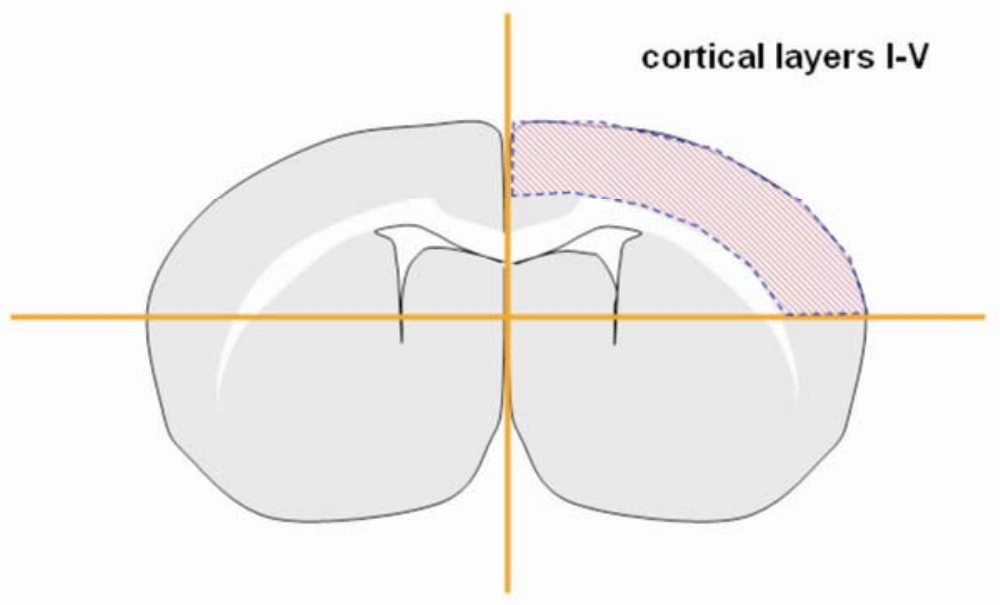

Figure 3: Regions of interest used for histological evaluation 


\subsection{Statistics}

Statistical analysis was performed using a statistical software package (SPSS Version 12 for Windows, SPSS Inc., Chicago, IL, USA). Graphs were visualized with GraphPad version 5 for windows (GraphPad Software, San Diego, CA, USA). Normality of distribution was verified by Kolmogorow-Smirnov-test. Statistical calculations included one-way analysis of variance (ANOVA) if three or more groups were compared, followed by post-hoc least significance difference (LSD)-test. For comparisons between two groups, unpaired t-tests were performed. A probability value of less then 0.05 was considered significant. All data are given as mean + SEM. 


\section{RESULTS}

\subsection{Detection of anti-MOG autoantibody titres}

High and stable serum levels of anti-MOG autoantibodies are an important prerequisite for induction of targeted EAE lesions. Therefore, serum levels of MOG autoantibodies were monitored by ELISA at regular intervals. High and consistent anti-MOG autoantibody titres were detected in s.c. MOG immunized animals at all time points analysed (Figure 4). As expected, s.c. IFA immunized control animals did not reveal a significant antibody response against MOG.

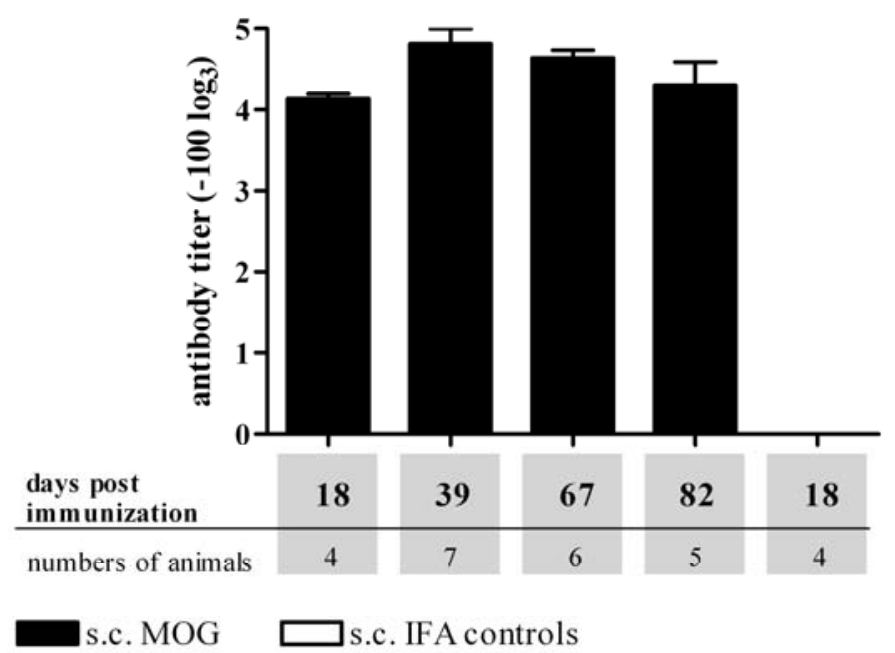

Figure 4: Anti-MOG autoantibody titres

Titres of anti-MOG autoantibodies. Time-course analysis revealed high and consistent anti-MOG antibody titres in s.c. MOG immunized animals. S.c. IFA control animals did not reveal a detectable antibody response against MOG. Data are expressed as mean + SEM. For statistical evaluation, one-way ANOVA was peformed.

* antibody titres refer to the serum dilution needed to achieve half maximum OD

\subsection{Gliosis}

To analyse possible traumatic effects caused by surgical intervention, HE-staining and GFAP immunohistochemistry were performed. HE-staining revealed moderate gliosis and edema restricted to the close proximity of the injection site (Figure 5, A, D and E). This observation was supported by GFAP-staining showing intense GFAP- 
immunoreactivity at similar areas to the HE-staining (Figure 6, A, C, F). In addition, 21 days post lesion induction, a few s.c. MOG immunized animals presented with increased subpial GFAP-immunoreactivity in remyelinated cortical areas. Aside from these aforementioned cases, adjacent areas showed no pathological abnormalities (Figure 5, B and $\mathrm{C}$; Figure 6, B/D/E).

\section{HE- staining}

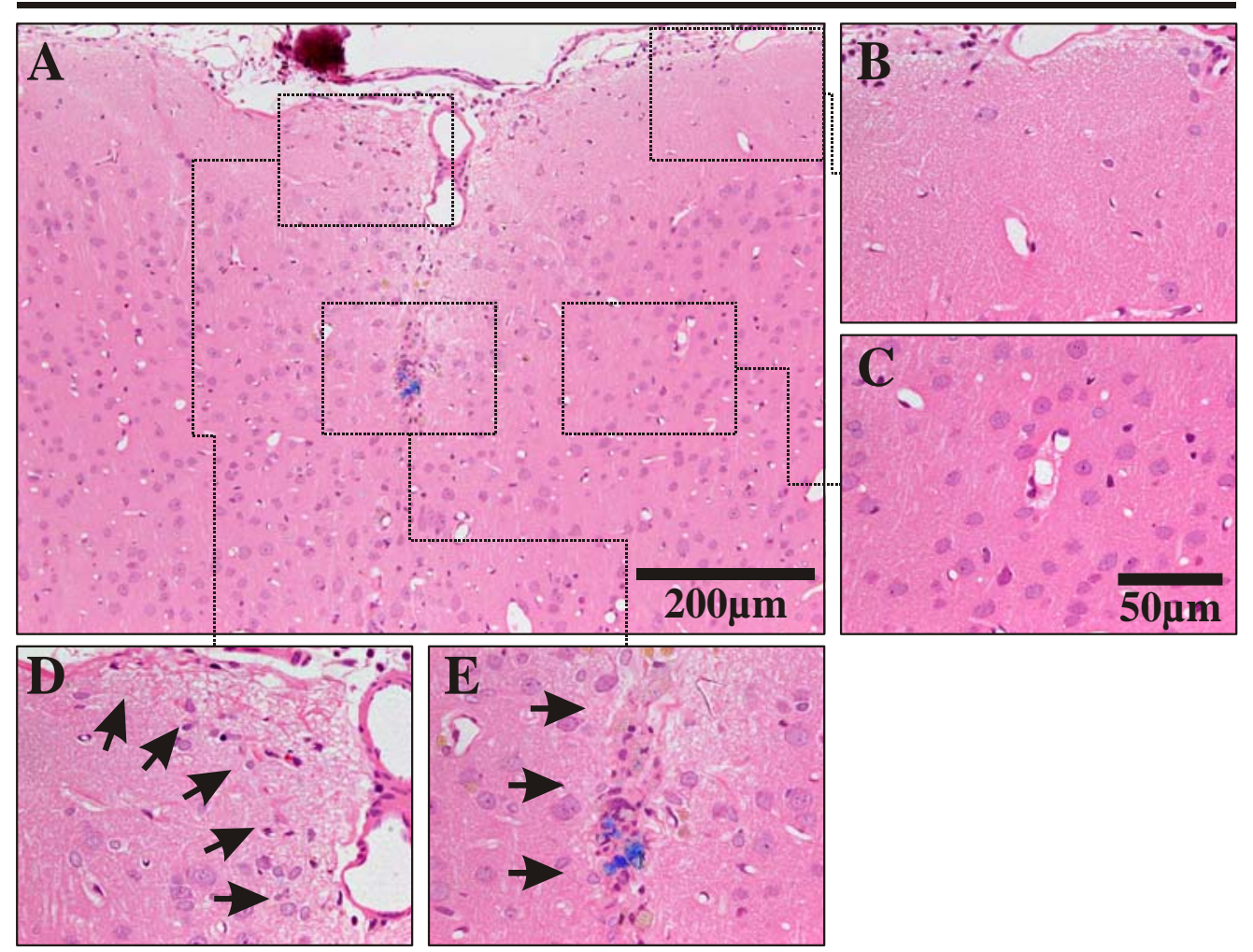

Figure 5: HE-staining of local gliosis

Representative photographs of HE-stained section of a cortical lesion (A-E). Moderate gliosis was observed at close proximity of the needle track (A/D/E). Edema and glial scar formation ( $\mathrm{D}$ and $\mathrm{E}$, indicated by arrows) were restricted to the immediate vicinity of the injection. No pathological abnormalities were observed in adjacent areas within cortical lesion (B/C).

Scale bars: $A=200 \mu \mathrm{m}, \mathrm{B}-\mathrm{E}=50 \mu \mathrm{m}$ 


\section{GFAP- immunohistochemistry}

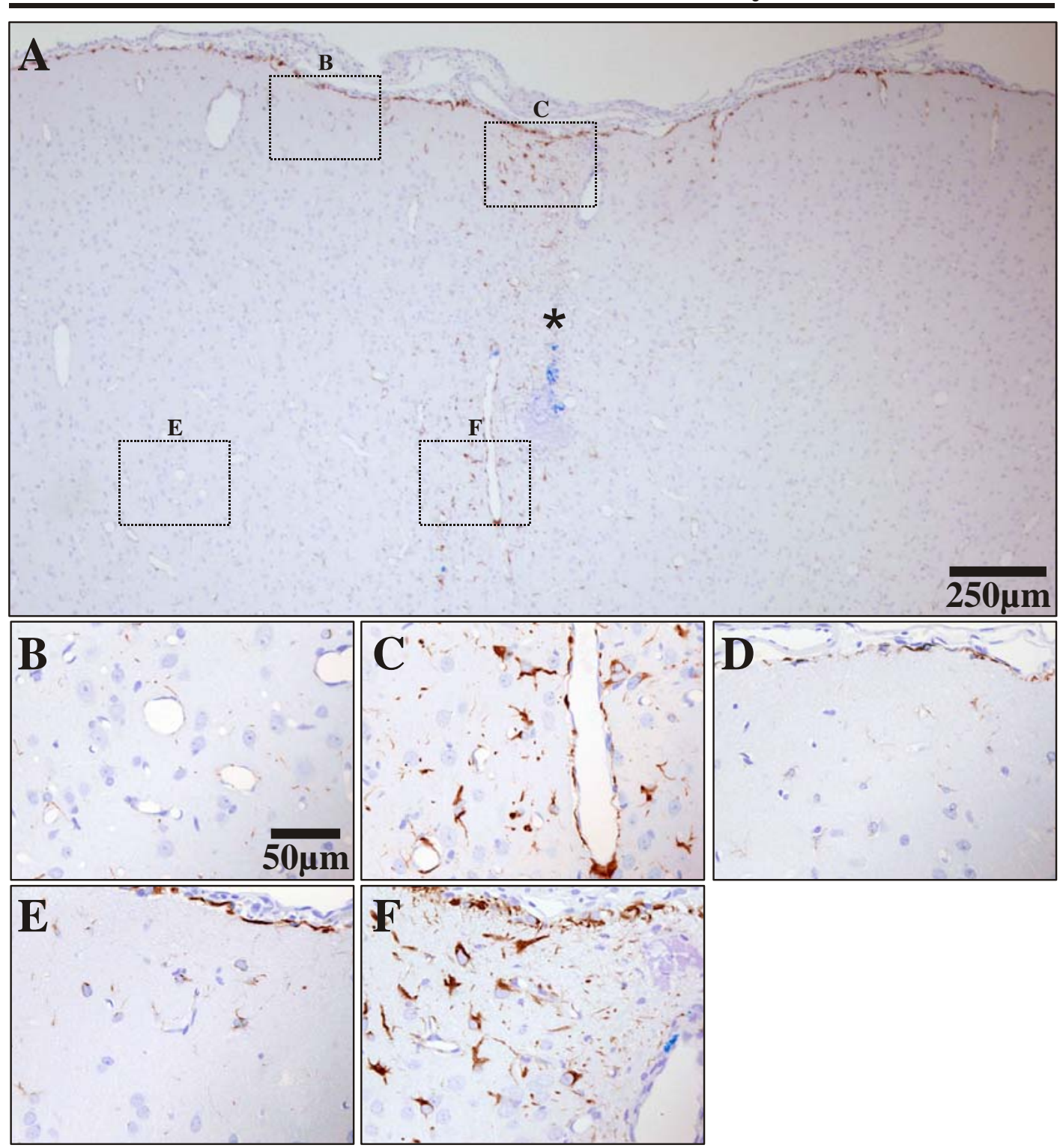

Figure 6: GFAP immunohistochemistry of local gliosis

Representative photographs of GFAP-immunostained section of a cortical lesion (A-F). GFAP immunoreactivity was observed in close proximity to the injection site $(\mathrm{A} / \mathrm{C} / \mathrm{F})$. No pathological abnormalities were observed in adjacent areas within the cortical lesion $(\mathrm{B} / / \mathrm{D} / \mathrm{E})$.

Scale bars: $\mathrm{A}=250 \mu \mathrm{m}, \mathrm{B}-\mathrm{F}=50 \mu \mathrm{m}$

\subsection{Topology of de- and remyelination in the focal cortical EAE model}

MBP immunohistochemistry was performed to assess demyelination and remyelination, respectively. At day three post intracerebral cytokine injection, extensive cortical 
demyelination was observed in MOG primed animals (Figure 7, A-C). With regard to topology, a pronounced widespread subpial lesions was located at the site of injection (Figure 7, A-C), which often extended into deep cortical layers (layers 4-6). In the medial-lateral direction, demyelination extended more superficially (layers 1-3). The topography of these lesions was highly reminiscent of cortical type III lesions found in multiple sclerosis (Peterson et al., 2001). In addition, spots of perivascular lesions were distributed along the ipsilateral cerebral cortex (Figure 7, A and B). Similar lesion pattern and similar extent of demyelination was observed in animals which received two or four intracerebral cytokine injections (Figure 8). The contralateral non-injected hemisphere showed no signs of demyelination (Figure 7, D, E and F). Cytokine injection did not show substantial tissue damage in s.c. IFA immunized control animals, even after repetitive injections (Figure 8). Cortical demyelination is a transient phenomenon; 21 days after lesion induction, extensive remyelination took place (Figure 8) and only few and small areas within the center of the lesion remained demyelinated. Even animals suffering from 2 or 4 demyelinating events showed extensive remyelination and did not differ morphologically from singly induced ones. 

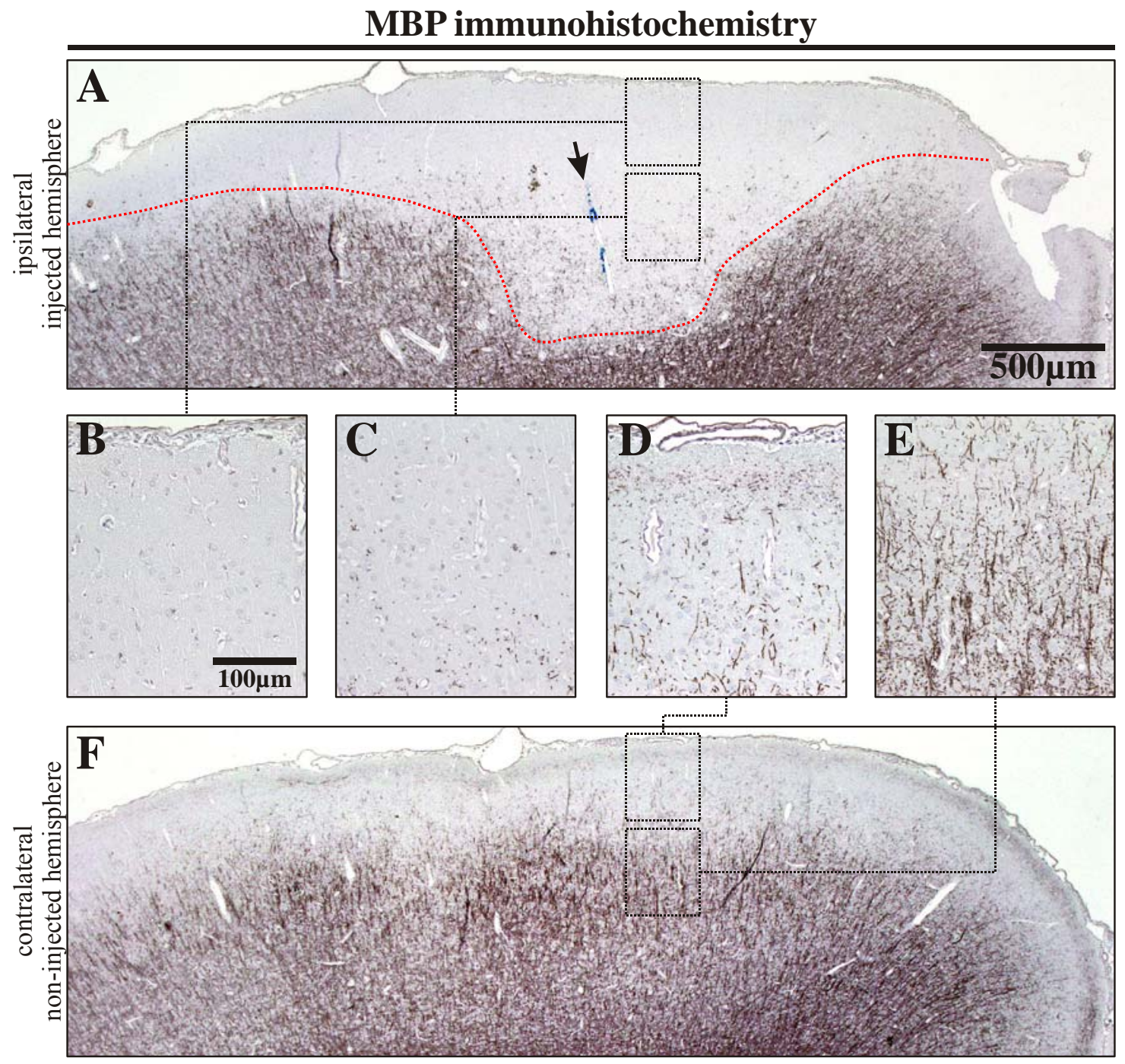

\section{Figure 7: Focal cortical EAE lesion}

Representative photographs of MBP immunostained cerebral cortex of s.c. MOG primed Lewis rats at day 3 post lesion induction (AF). Proinflammatory cytokines such as TNF- $\alpha$ and IFN- $\gamma$ were targeted to the cerebral cortex (indicated by arrow with a blue traced needle track underneath), leading to extensive focal demyelination (lesion border indicated by dotted line) within the ipsilateral hemisphere (A-C). The contralateral non-injected hemisphere was not affected (D-F).

Scale bars: $A$ and $F=500 \mu \mathrm{m}, \mathrm{B}-\mathrm{E}=100 \mu \mathrm{m}$ 


\section{MBP immunohistochemistry}

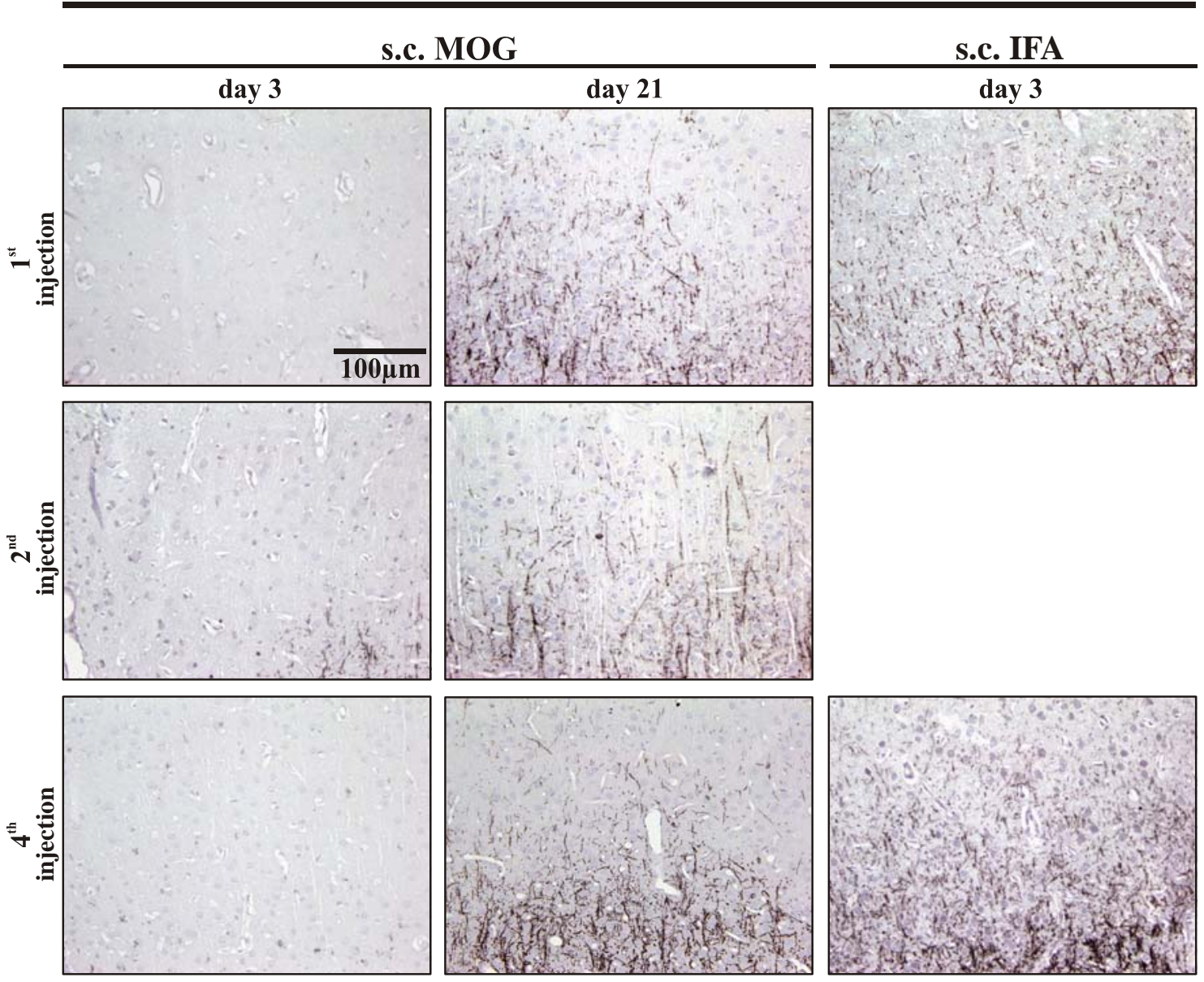

Figure 8: Cortical demyelination and remyelination after repetitive lesion induction

Representative photographs of MBP stained sections of cortical layer 3 (center of lesion). The different time points (days 3 and 21) and immunization protocols (s.c. MOG versus s.c. IFA) are arranged in columns. The numbers of lesion inductions $\left(1^{\text {st }}, 2^{\text {nd }}\right.$ and $\left.4^{\text {th }}\right)$ are arranged in rows. Repeated cortical demyelination (MBP-negative) was observed in s.c. MOG immunized animals 3 days after cytokine injection (left column). At 21 days after lesion induction, extensive remyelination (MBP-positive: dark stained fibres) took place, even after repetitive demyelinating events (middle column). S.c. MOG immunized control animals showed no signs of demyelination (right column).

Scale bars: $100 \mu \mathrm{m}$

\subsubsection{Extent of demyelinated area}

The extent of demyelination was quantified using computerbased analysis performed on photographs of MBP-stained sections. Intracerebral cytokine injection led to focal cortical demyelination in all s.c. MOG primed animals (Figure 9, A). Demyelinated area did not differ significantly between animals with singular induced lesions $\left(1.53 \times 10^{6} \pm\right.$ $\left.2.67 \times 10^{5} \mu \mathrm{m}^{2}\right)$ compared to those animals with two $\left(1.73 \times 10^{6} \pm 2.34 \times 10 \mu \mathrm{m}^{2}\right)$ and four 
$\left(1.76 \times 10^{6} \pm 3.12 \times 10^{5} \mu \mathrm{m}^{2}\right)$ demyelinating episodes. Demyelinated area decreased significantly (one-way ANOVA $\mathrm{F}_{5,52}=11,013, \mathrm{p}<0,001$ ) twenty-one days after each previous demyelinating episode (post-hoc LSD-test: $1^{\text {st }}$ inj. $p<0,001,2^{\text {nd }}$ inj. $p=0,002$, $4^{\text {th }}$ inj. $\left.\mathrm{p}<0,001\right)$. No significant difference was observed comparing groups at day 21 post lesion induction after single or repetitive lesioning. S.c. IFA immunized and cytokine injected control animals did not show any sign of demyelination.

A

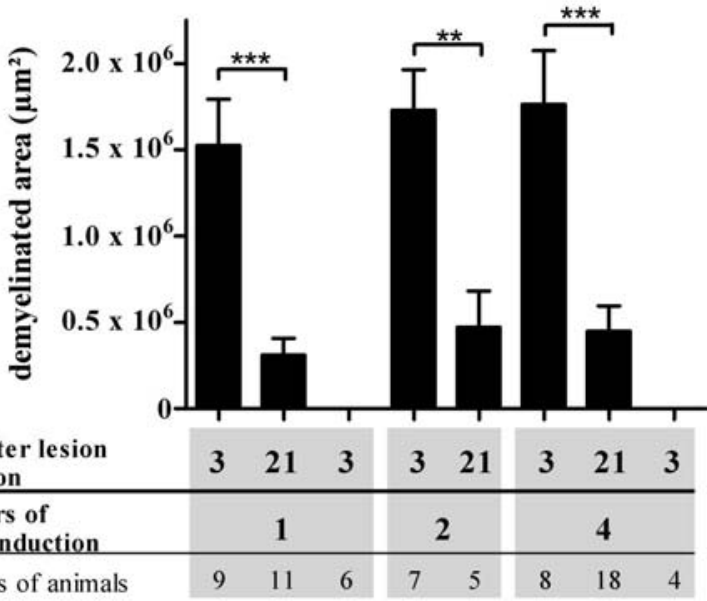

s.c. MOG

$\square$ s.c. IFA controls

B

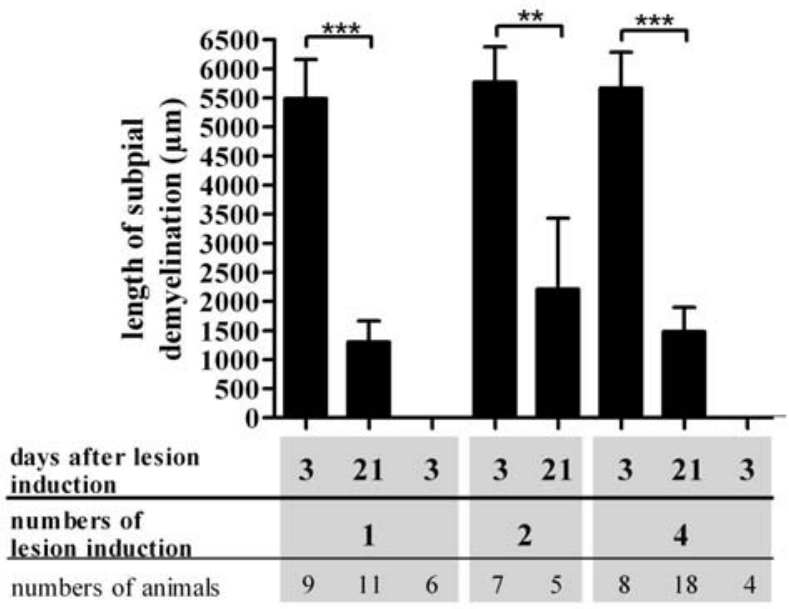

s.c. MOG $\square$ s.c. IFA controls

Figure 9: Extent of demyelination

(A) Extent of demyelination was determined on MBP-stained sections. Intracerebral cytokine injection following immunization with MOG led to extensive demyelination following each cytokine injection. Demyelinated area decreased significantly even after repetitive lesioning. S.c. IFA immunized control animals showed no signs of demyelination. (B) Analysis of subpial lesion length 
revealed similar outcome. Data are expressed as mean + SEM. For statistical evaluation, one-way ANOVA followed by post-hoc LSD-test was performed $(* *=\mathrm{p}<0.01, * * *=\mathrm{p}<0.001)$.

\subsubsection{Length of subpial lesions}

As an additional parameter, length of subpial lesion was measured. At day three post lesion induction, average subpial lesion length did not differ between singly induced lesions $(5490 \pm 670.3 \mu \mathrm{m})$ compared to those animals with two $(5769 \pm 606.9 \mu \mathrm{m})$ and four $(5666 \pm 621 \mu \mathrm{m})$ demyelinating episodes (Figure 9, B). Twenty-one days after each previous lesion induction, length of subpial lesion decreased significantly (ANOVA $\mathrm{F}_{5,52}$ $=14,936, \mathrm{p}<0,001)$ compared to those lesions measured at day 3 (post-hoc LSD-test: $1^{\text {st }}$ inj. $\mathrm{p}<0,001,2^{\text {nd }}$ inj. $\mathrm{p}=0,001,4^{\text {th }}$ inj. $\left.\mathrm{p}<0,001\right)$. No significant difference was observed comparing groups at day 21 post lesion induction. As expected, s.c. IFA immunized control groups showed no signs of demyelination.

\subsubsection{Fraction of myelinated axons}

To determine the ratio of myelin density to axons, the fraction of myelinated axons was measured in de- and remyelinated areas of cortical layer III. Fraction of myelinated axons is defined as the ratio of MBP-positive fibres to axons (determined on Bielschowsky silver-stained sections). In untreated age matched control animals, a considerably high fraction of myelinated axons (mean $40.58 \pm 2.67 \%$ ) was determined. At day 3 post lesion induction, almost no myelin was detected in s.c. MOG immunized animals (Figure 10, $1^{\text {st }}$ inj.: $1.27 \pm 0.58 \%, 2^{\text {nd }}$ inj.: $2.67 \pm 1.12 \%, 4^{\text {th }}$ inj.: $\left.0.52 \pm 0.34 \%\right)$. Twenty-one days after lesion induction, the fraction of myelinated axons $\left(1^{\text {st }}\right.$ inj.: $16.22 \pm 3.02 \%, 2^{\text {nd }}$ inj.: 21.95 $\pm 3.84,4^{\text {th }}$ inj.: $16.64 \pm 2.99 \%$ ) increased significantly (one-way ANOVA $F_{8,61}=10,727 \mathrm{p}$ $<0,001$ ) in all s.c. MOG immunized groups (post-hoc LSD-test: $1^{\text {st }}$ inj.: $p=0.012,2^{\text {nd }}$ inj.: $p=0.02,4^{\text {th }}$ inj.: $\left.p=0.011\right)$. Comparisons between s.c. MOG immunized groups at day 21 revealed no significant statistical differences. Albeit a substantial fraction of axon remyelinated at day 21 , the obtained values were still significantly lower as compared to the control groups (post-hoc LSD-test: $1^{\text {st }}$ inj.: $\mathrm{p}<0.001,2^{\text {nd }}$ inj.: $\mathrm{p}=0.013,4^{\text {th }}$ inj.: $\mathrm{p}<$ 0.001). At day 3 post lesion induction, fraction of myelinated axons was significantly reduced compared to control groups (post-hoc LSD-test: $1^{\text {st }}, 2^{\text {nd }}$ and $4^{\text {th }}$ inj.: $p<0.001$ ). 


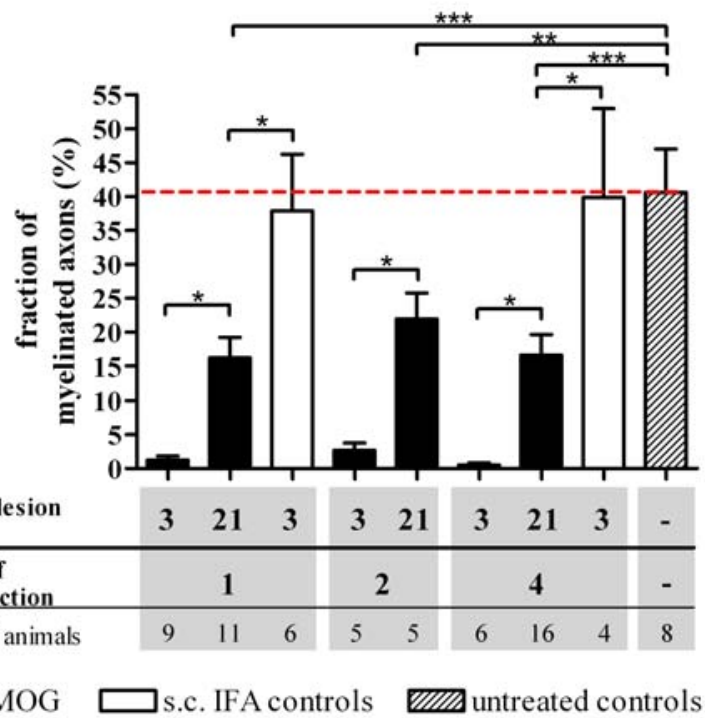

\section{Figure 10: Fraction of myelinated axons}

Fraction of myelinated axons was expressed as the percentage of myelin density normalized to axonal density. After each lesion induction, almost complete loss of myelin content was determined within the center of lesion of s.c. MOG immunized animals. Twenty-one days after lesion induction, the fraction of myelinated axons recovered significantly. However, remyelinated lesions showed significantly reduced fraction of myelinated axons compared to normally myelinated cerebral cortex (untreated controls). In contrast, IFA immunized controls showed similar fraction of myelin as untreated controls. Data are expressed as mean + SEM. For statistical evaluation, one-way ANOVA followed by post-hoc LSD-test was performed $(*=\mathrm{p}<0.05, * *=\mathrm{p}<0.01, * * *=\mathrm{p}<0.001)$.

\subsection{Evaluation of activated macrophages/microglia}

To assess inflammatory activity during de- and remyelination, immunohistochemistry was performed using ED1 as a marker for activated macrophages/microglia.

Demyelination was accompanied by inflammation (Figure 11). At day 3 after lesion induction, ED1-positive cells were detected within and near demyelinated areas (Figure 11, H). With regard to morphology, two different ED1-positive cell types were observed:

1) Ramified macrophages/microglia were the predominant population in s.c. IFA immunized control animals (Figure 11, G) but were also abundant within lesions of s.c. MOG primed animals.

2) Foamy macrophages were mainly found at day 3 post lesion induction in s.c. MOG immunized animals, indicating demyelination (Figure 11, F). 
Extensive and dense parenchymal infiltrates were predominantly located in the center of subpial lesions (Figure 11, E and H). In contrast, perivascular infiltrates (Figure 11, D) were also observed in nearby non-demyelinated cortical areas (Figure 11, H). Inflammation was more pronounced after single lesioning in both density and extent of activated macrophages/microglia. ED1-positive cells were also detected in repetitively injected animals, but macrophage/microglia activation seemed to be less pronounced compared to singly injected ones (Figure 12). Inflammation resolved 21 days after lesion induction. Just few ED1-positive cells were observed in close vicinity to the needle track, similar to s.c. IFA immunized control animals. The contralateral non injected side appeared normal and rarely few ED1-positive cells were detected in the subpial region of the sulcus centralis. 

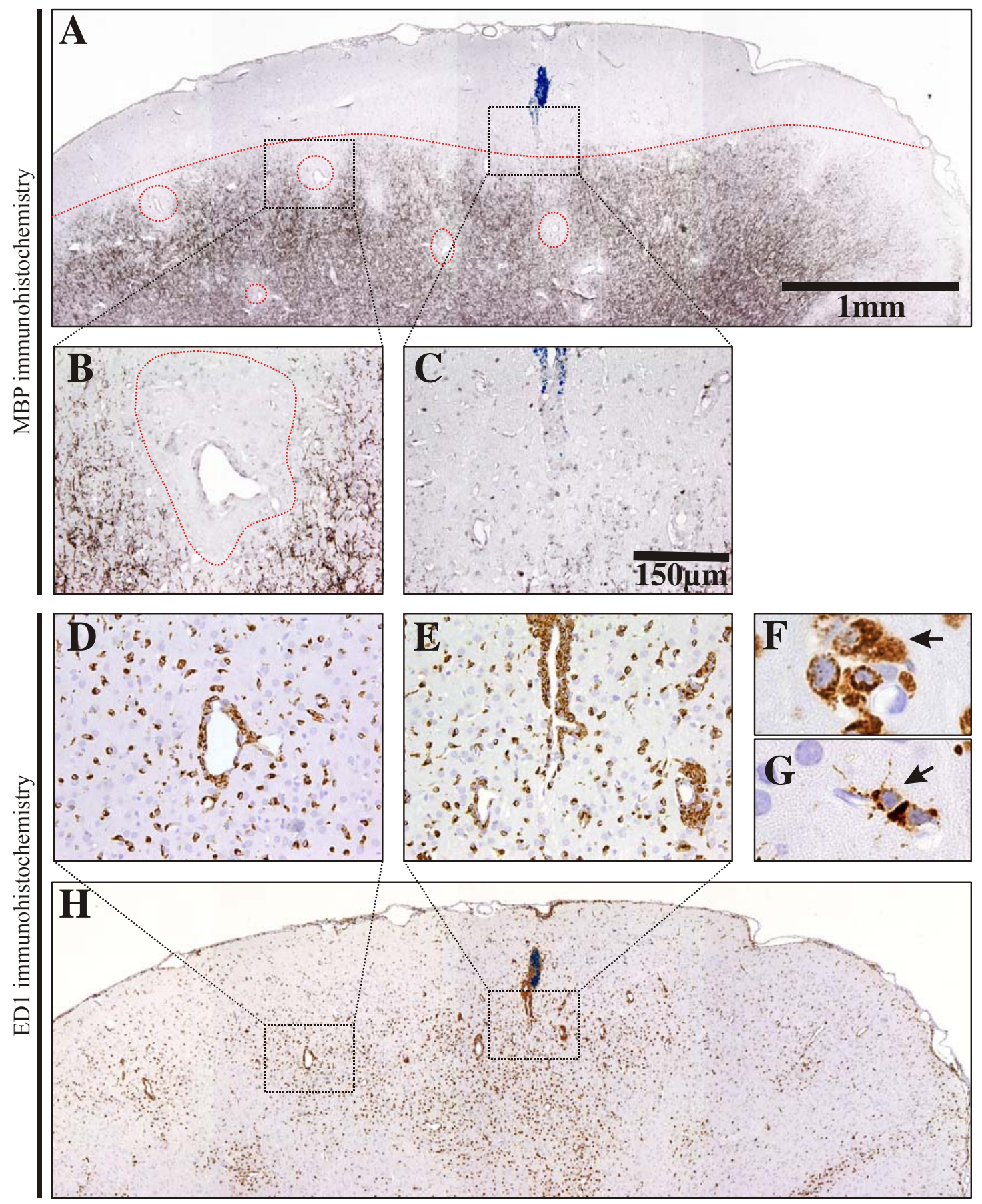

Figure 11: Inflammatory demyelination in the focal cortical EAE model

Representative photographs of the cerebral cortex of s.c. MOG primed Lewis rats at day 3 post lesion induction. Subpially demyelinated lesions (A and $\mathrm{C}$, lesion border is indicated by dotted line) and perivascular lesions (A and B, lesions are surrounded by dotted circles) were identified by MBP immunohistochemistry (lesions are MBP-negative). Demyelination was accompanied by activation of microglia/macrophages visualized by ED1 immunohistochemistry (D-H). Perivascular (D) and parenchymal (E) spots of ED1-positive cells were distributed within and near demyelinated areas ( $\mathrm{H}$, see also A-C). Foamy macrophages indicating demyelination, were predominantly found at day 3 after lesion induction (F, indicated by arrow). Ramified ED1-positive cells (G, indicated by arrow) were observed in s.c. MOG primed demyelinated/remyelinated animals and s.c. IFA controls, respectively.

Scale bars: $A$ and $H=1 \mathrm{~mm}, B-E=150 \mu \mathrm{m}$ 


\section{ED1 immunohistochemistry}

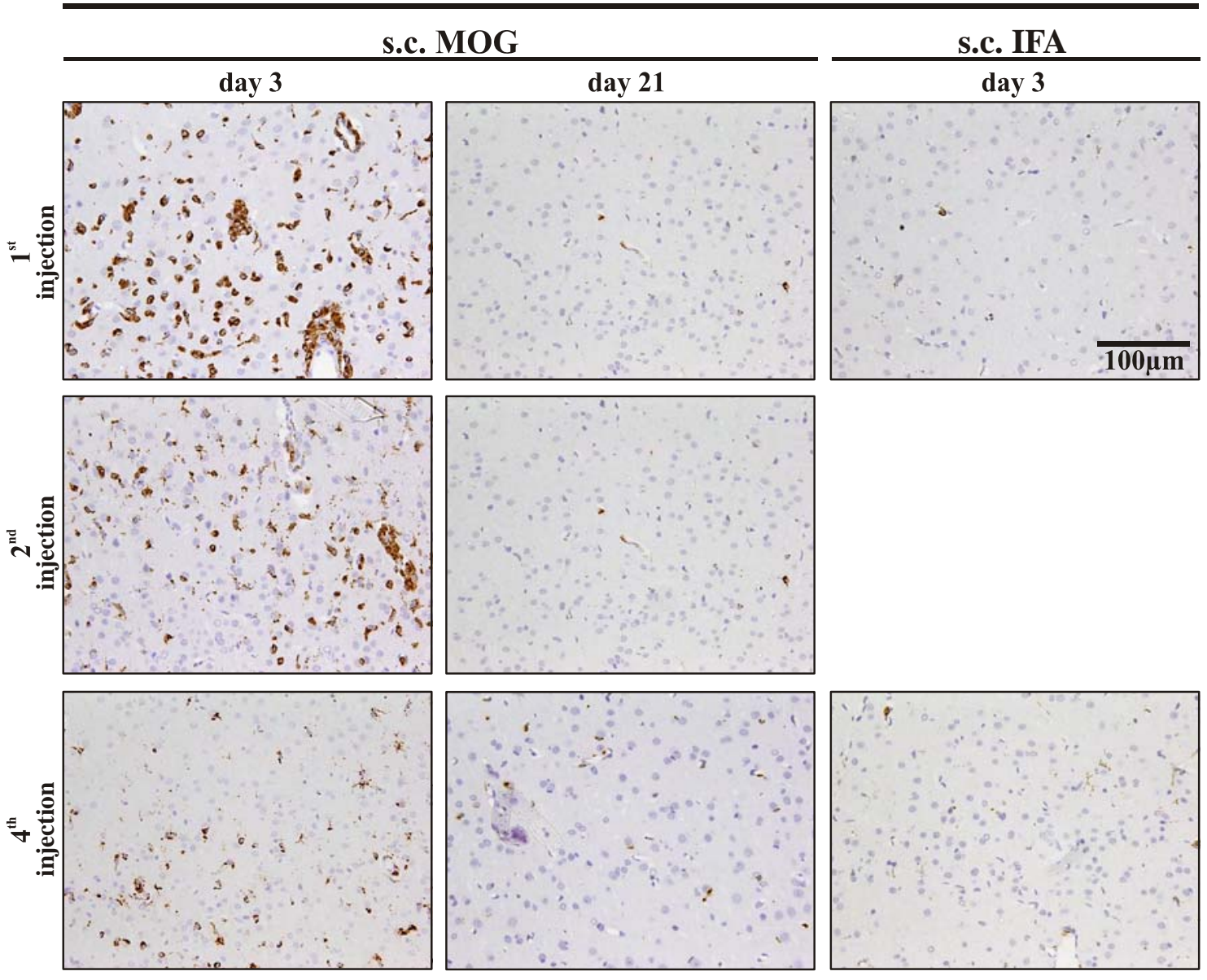

Figure 12: Transient activation of macrophages/microglia

Representative photographs of ED1 stained sections of the lesioned cerebral cortex. The time points of histological evaluation (days 3 and 21) and immunization protocols (s.c. MOG versus s.c. IFA) are arranged in columns. The numbers of lesion inductions $\left(1^{\text {st }}, 2^{\text {nd }}\right.$ and $4^{\text {th }}$ ) are arranged in rows. Strong activation of microglia/macrophages was observed in s.c. MOG immunized animals at day 3 post lesion induction (left column). Inflammation resolved within 21 days post lesion induction (middle column). In s.c. IFA immunized control animals, no substantial activation of microglia/macrophages was observed (right column).

Scale bar: $100 \mu \mathrm{m}$

\subsubsection{Density of activated macrophages within center of lesion}

Density of activated macrophages/microglia was analysed on ED1 stained sections in cortical layer 3 within the center of lesion:

At day 3 post lesion induction, high densities of ED1-positive cells were detected after each demyelinating episode in s.c. MOG immunized animals (Figure $13 \mathrm{~A}, 1^{\text {st }}$ inj.: 537.1 
\pm 56.64 cells $/ \mathrm{mm}^{2}, 2^{\text {nd }}$ inj.: $485.3 \pm 52.81$ cells $/ \mathrm{mm}^{2}, 4^{\text {th }}$ inj.: $360.0 \pm 66.32$ cells $\left./ \mathrm{mm}^{2}\right)$. After four demyelinating episodes, values decreased significantly (one-way ANOVA $\mathrm{F}_{7,59}$ $=41,874, \mathrm{p}<0,001)$ compared to animals with a single (post-hoc LSD-test: $\mathrm{p}=0.01$ ) or two demyelinating episodes (post-hoc LSD-test: $\mathrm{p}=0.022$ ). Twenty-one days after each demyelinating episode, density of ED1-positive cells $\left(1^{\text {st }}\right.$ inj.: $67.64 \pm 13.05$ cells $/ \mathrm{mm}^{2}, 2^{\text {nd }}$ inj.: $70.4 \pm 17.23$ cells $/ \mathrm{mm}^{2}, 4^{\text {th }}$ inj.: $57.33 \pm 5.83 \mathrm{cells} / \mathrm{mm}^{2}$ ) decreased significantly compared to day 3 animals (post-hoc LSD-test: $1^{\text {st }}, 2^{\text {nd }}$ and $4^{\text {th }}$ inj.: $p<0.001$ ) and were similar to s.c. IFA immunized control groups $\left(1^{\text {st }}\right.$ inj.: $56.00 \pm 10.73$ cells $/ \mathrm{mm}^{2}, 4^{\text {th }}$ inj.: $72.00 \pm 4.62 \mathrm{cells} / \mathrm{mm}^{2}$ ). S.c. MOG immunized animals analysed at day 3 post lesion induction showed significantly increased values when compared to their corresponding s.c. IFA immunized control group (post-hoc LSD-test: $1^{\text {st }}$ and $4^{\text {th }}$ inj.: $\mathrm{p}<0.001$ ).

\subsubsection{Density of activated macrophages/microglia throughout all cortical layers}

As mentioned above, activated macrophages/microglia were also distributed beyond the border of demyelinated lesions. Therefore, quantification of activated macrophages/microglia was performed in a broad area including all cortical layers (Figure 3, B). Density of ED1-positive cells reached highest values at day 3 of singly injected s.c. MOG immunized animals $\left(58.48 \pm 10.75 \mathrm{cells} / \mathrm{mm}^{2}\right.$, Figure 13, B). Although a substantial accumulation of ED1-positive cells were observed after two and four demyelinating episodes $\left(2^{\text {nd }}\right.$ inj.: $28.80 \pm 4.84$ cells $/ \mathrm{mm}^{2}, 4^{\text {th }}$ inj.: $25.11 \pm 3.99$ cells $\left./ \mathrm{mm}^{2}\right)$, their numbers were decreased (one-way ANOVA $F_{7,59}=19,031, p<0,001$ ) when compared to single injected animals (post-hoc LSD-test: $2^{\text {nd }}$ and $4^{\text {th }}$ inj.: $p<0.001$ ). Twenty-one days after each demyelinating episode, density of ED1-positive cell counts $\left(1^{\text {st }}\right.$ inj.: $4.77 \pm 1.88$ cells $/ \mathrm{mm}^{2}, 2^{\text {nd }}$ inj.: $6.04 \pm 1.29$ cells $/ \mathrm{mm}^{2}, 4^{\text {th }}$ inj.: $4.33 \pm$ 0.67 cells $/ \mathrm{mm}^{2}$ ) dropped sharply and significantly compared to day 3 animals (post-hoc LSD-test: $1^{\text {st }}$ inj.: $\mathrm{p}<0.001,2^{\text {nd }}$ inj.: $\mathrm{p}=0.007,4^{\text {th }}$ inj.: $\mathrm{p}=0.001$ ), reaching similar values as s.c. IFA immunized control groups $\left(1^{\text {st }}\right.$ inj.: $3.113 \pm 0.19$ cells $/ \mathrm{mm}^{2}, 4^{\text {th }}$ inj.:4.88 $\pm 0.58 \mathrm{cells} / \mathrm{mm}^{2}$ ). S.c. MOG immunized animals analyzed at day 3 post lesion induction showed significantly increased values when compared to their corresponding s.c. IFA immunized control group (post-hoc LSD-test: $1^{\text {st }}$ inj.: $p<0.001,4^{\text {th }}$ inj.: $p<0.016$ ). 
A

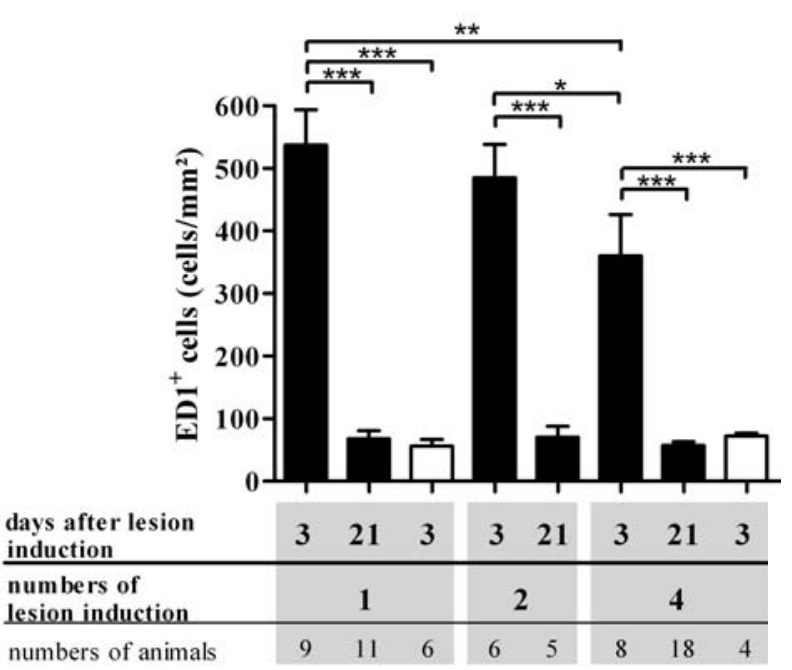

s.c. MOG $\square$ s.c. IFA controls

B

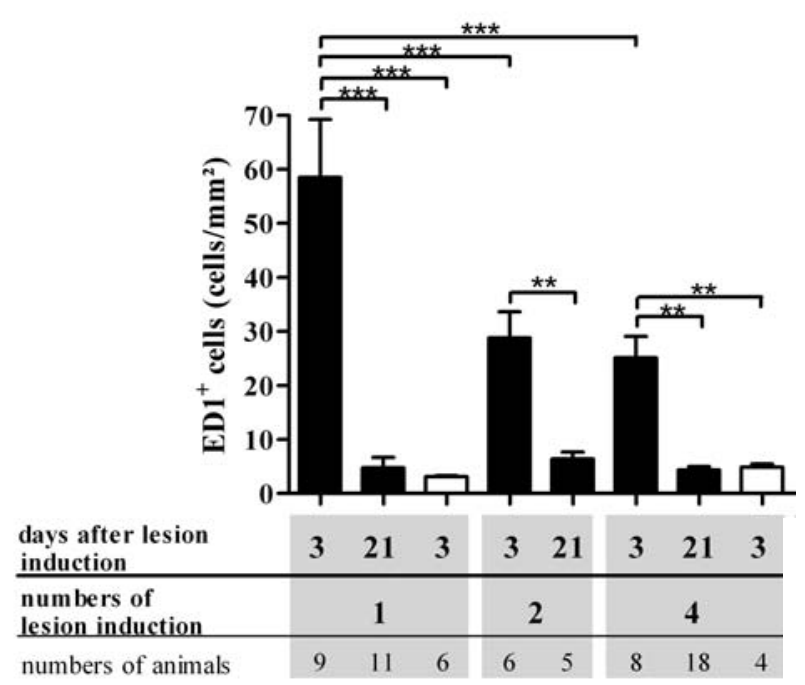

\section{s.c. MOG $\square$ s.c. IFA controls}

Figure 13: Density of activated macrophages/microglia

Density of activated macrophages was determined on ED1-stained sections. Strong and extensive activation of macrophages/microglia was observed in s.c. MOG immunized animals 3 days post lesion induction. (A) Within the center of lesion in cortical layer III, density of ED1-positive cells decreased significantly after four lesion inductions compared to previous ones. (B) Quantification of ED1-positive cells performed in a wider cortical lesional area (ranging from layer I-V) revealed significantly decreased cell counts already after two lesion inductions. Twenty-one days after each lesion induction, inflammation resolved as only few ED1-positive cells were detected (A and B). S.c. IFA immunized controls showed negligible numbers of ED1-positive cells (A and B). Data are expressed as mean + SEM. For statistical evaluation, one-way ANOVA followed by post-hoc LSD-test was performed $(*=\mathrm{p}<0.05$, $* *=\mathrm{p}<0.01, * * *=\mathrm{p}<0.001)$. 


\subsection{Axonal integrity}

To analyse putative degenerative effects on axons, Bielschowsky silver stained sections were analysed in cortical layer III at the center of lesion. Bielschowsky silver staining showed no substantial alterations of axonal morphology, except in areas immediately adjacent to the injection site due to surgical minitrauma (Figure 14). Quantitative analysis revealed constant levels in axonal density in s.c. MOG immunized animals (Figure 15, $1^{\text {st }}$ inj.: $92.16 \pm 9.48 \%, 2^{\text {nd }}$ inj.: $112.0 \pm 14.27 \%, 4^{\text {th }}$ inj.: $\left.90.33 \pm 12.91 \%\right)$ and s.c. IFA immunized control animals ( $1^{\text {st }}$ inj.: $96.68 \pm 7.95 \%, 4^{\text {th }}$ inj.: $\left.116.0 \pm 19.27 \%\right)$ at day 3 after lesion induction. No significant differences were detected. These results show that neither cortical demyelination nor surgical intervention causes substantial loss of axonal structures.
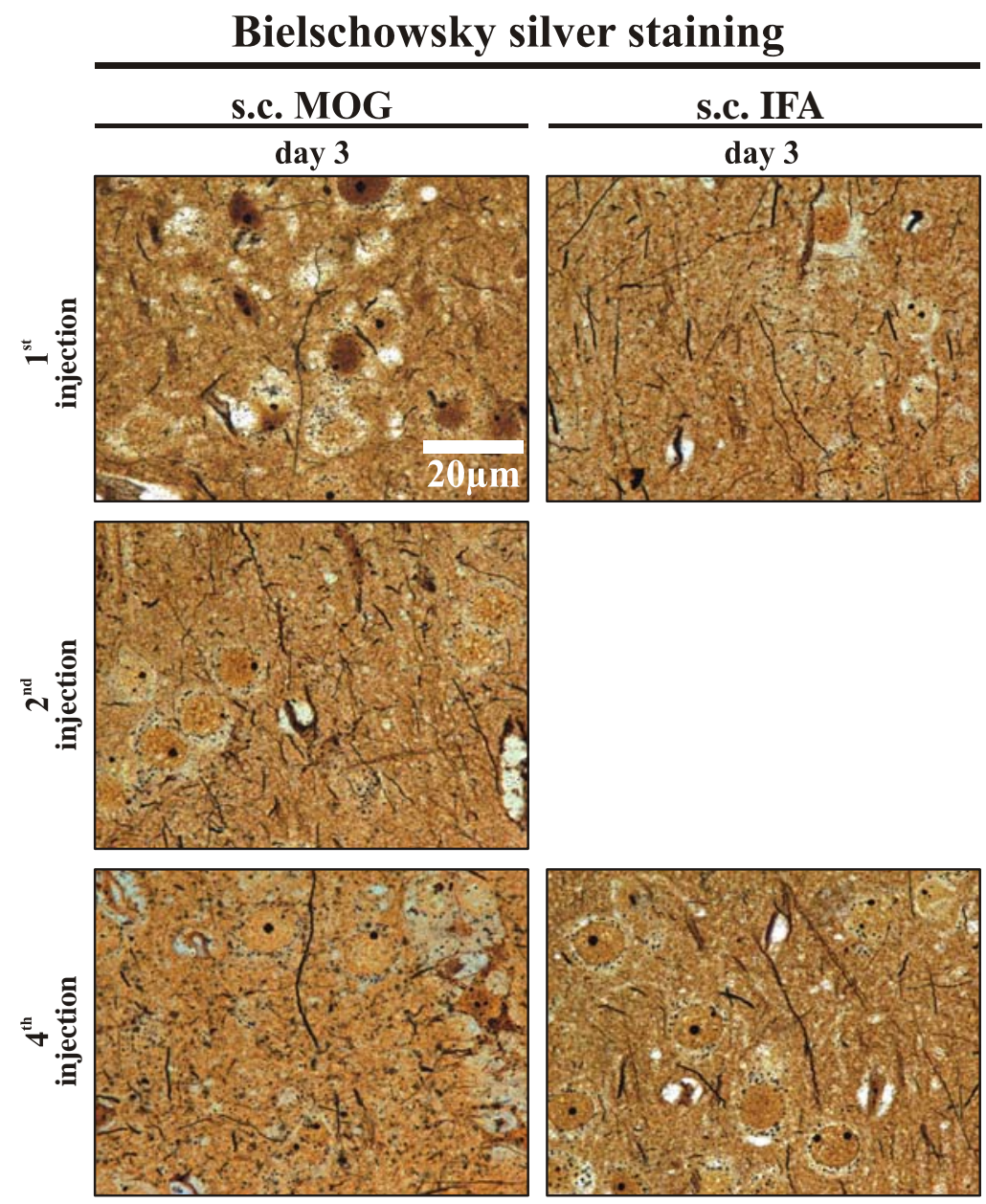

Figure 14: Axonal integrity 
Representative photographs of Bielschowsky silver-stained sections of cortical layer 3 (center of lesion). The different immunization protocols (s.c. MOG and s.c. IFA) are arranged in columns. The different numbers of lesion inductions $\left(1^{\text {st }}, 2^{\text {nd }}\right.$ and $\left.4^{\text {th }}\right)$ are arranged in rows. Axonal distribution appeared normal in s.c. MOG and s.c. IFA immunized control animals.

Scale bars: $20 \mu \mathrm{m}$

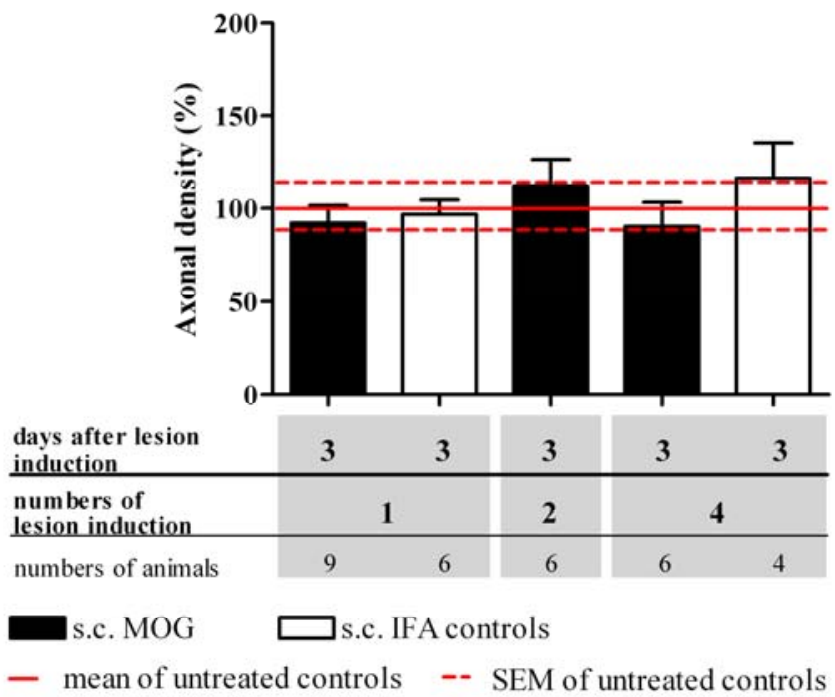

Figure 15: Axonal density

Axonal density was determined on Bielschowsky silver-stained sections. No alterations in axonal density were detected within center of lesion in cortical layer III. Data are expressed as mean + SEM.

\subsection{Oligodendrocyte loss and recovery}

To determine an effect of demyelination and subsequent remyelination on oligodendrocyte population, immunohistochemistry was performed using NogoA as a marker for mature oligodendrocytes.

Three days after intracerebral cytokine injection, substantial loss of oligodendrocytes was observed within demyelinated cortical lesions of s.c. MOG immunized animals. Oligodendroglial loss was most obvious within the center of intracortical lesions of several animals (Figure 16). Furthermore, a reduction of oligodendrocyte densities was also evident in demyelinated subpial areas after single and repeated lesioning (Figure 17). Following remyelination at 21 after lesion induction, the oligodendrocyte population was again recovered. No loss of oligodendrocytes was observed in s.c. IFA immunized animals. 


\section{NogoA/MBP double immunohistochemistry}
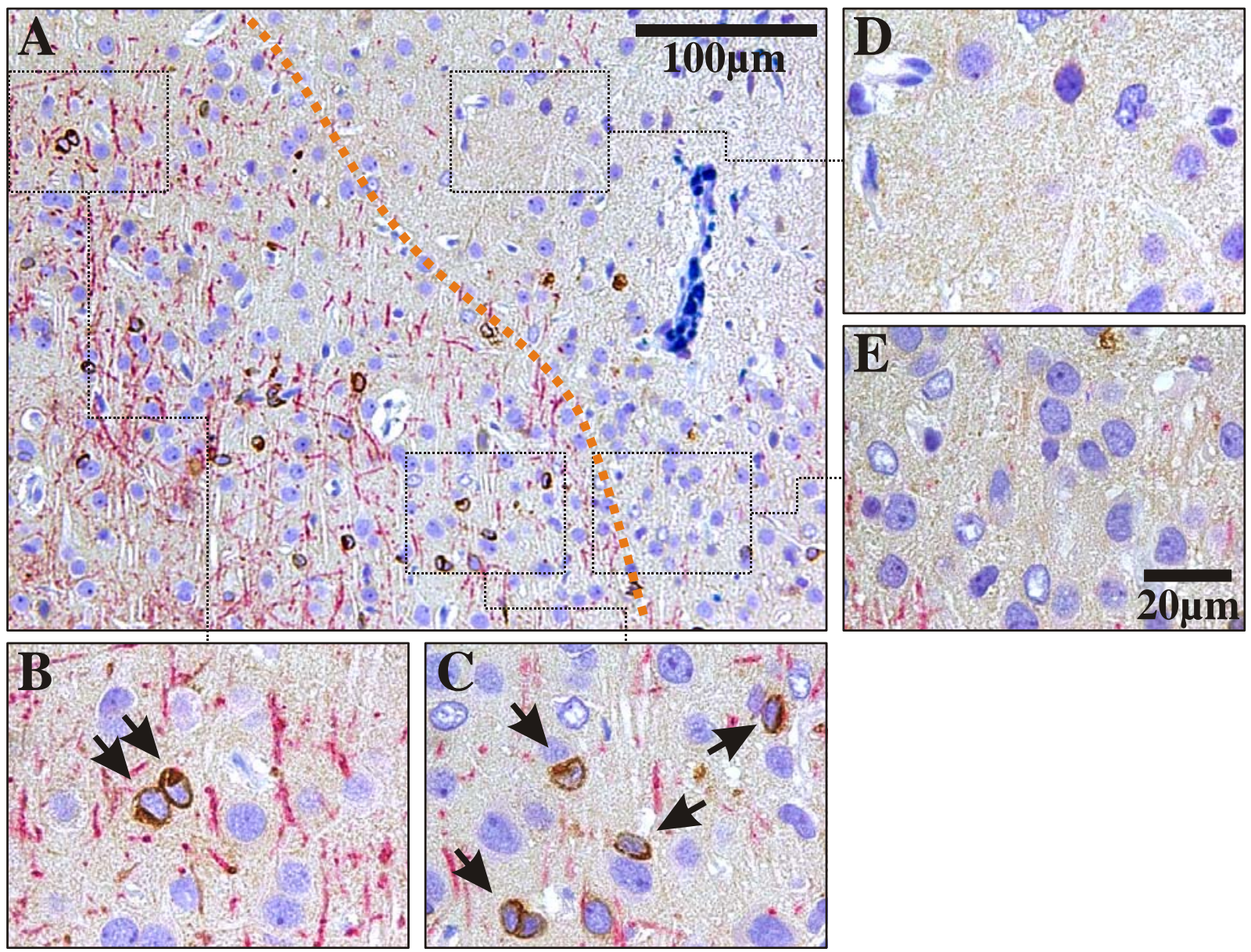

Figure 16: Loss of oligodendrocytes during focal cortical inflammatory demyelination

Representative photographs of a NogoA/MBP double-immunostained section of a cortical lesion. In normal appearing gray matter $(\mathrm{MBP}-$ positive myelin sheaths $=$ red) numerous oligodendrocytes (indicated by arrows) were observed $(\mathrm{A}, \mathrm{B}$ and $\mathrm{C})$. Demyelination (lesion border is indicated by dotted line) was accompanied by loss of oligodendrocytes (A, D and E).

Scale bars: $A=100 \mu \mathrm{m}, \mathrm{B}-\mathrm{E}=20 \mu \mathrm{m}$

\subsubsection{Oligodendrocyte density}

Quantitative analysis of oligodendrocyte density in subpial lesions revealed significant differences between analysed groups (Figure 18, one-way ANOVA $\mathrm{F}_{8,51}=4,041, \mathrm{p}=$ 0.001). At day 3 after singly induced lesion in s.c. MOG immunized animals, post-hoc LSD-test revealed decreased oligodendrocyte density $\left(4.91 \pm 1.54\right.$ cells $\left./ \mathrm{mm}^{2}\right)$ compared to remyelinated animals $\left(16.27 \pm 3.59\right.$ cells $\left./ \mathrm{mm}^{2}, \mathrm{p}=0.004\right)$, s.c. IFA controls $\left(1^{\text {st }} \mathrm{inj} .: 20.77\right.$ \pm 2.63 cells $\left./ \mathrm{mm}^{2}, \mathrm{p}=0.001\right)$ and untreated controls $\left(17.89 \pm 2.64 \mathrm{cells} / \mathrm{mm}^{2}, \mathrm{p}=0.002\right)$. After a second demyelinating episode, s.c. MOG immunized animals showed a decrease 
in oligodendrocyte density at day $3\left(11.14 \pm 3.04 \mathrm{cell} / \mathrm{s} / \mathrm{mm}^{2}\right)$ compared to remyelinated animals at day $21\left(23.52 \pm 3.88\right.$ cells $/ \mathrm{mm}^{2}$, post-hoc LSD-test: $\left.\mathrm{p}=0.011\right)$. After a fourth demyelinating episode, oligodendrocyte density was not significantly decreased in day 3 animals $\left(6.75 \pm 2.84 \mathrm{cells} / \mathrm{mm}^{2}\right)$ compared to the corresponding remyelinated s.c. MOG immunized group at day $21\left(11.57 \pm 3.0\right.$ cells $\left./ \mathrm{mm}^{2}\right)$ and the corresponding s.c. IFA control group ( $4^{\text {th }}$ inj.: $16.07 \pm 0.8$ cells $/ \mathrm{mm}^{2}$ ), but was significantly decreased when compared to untreated controls (post-hoc LSD-test: $\mathrm{p}=0.014$ ).

\section{NogoA/MBP double immunohistochemistry}
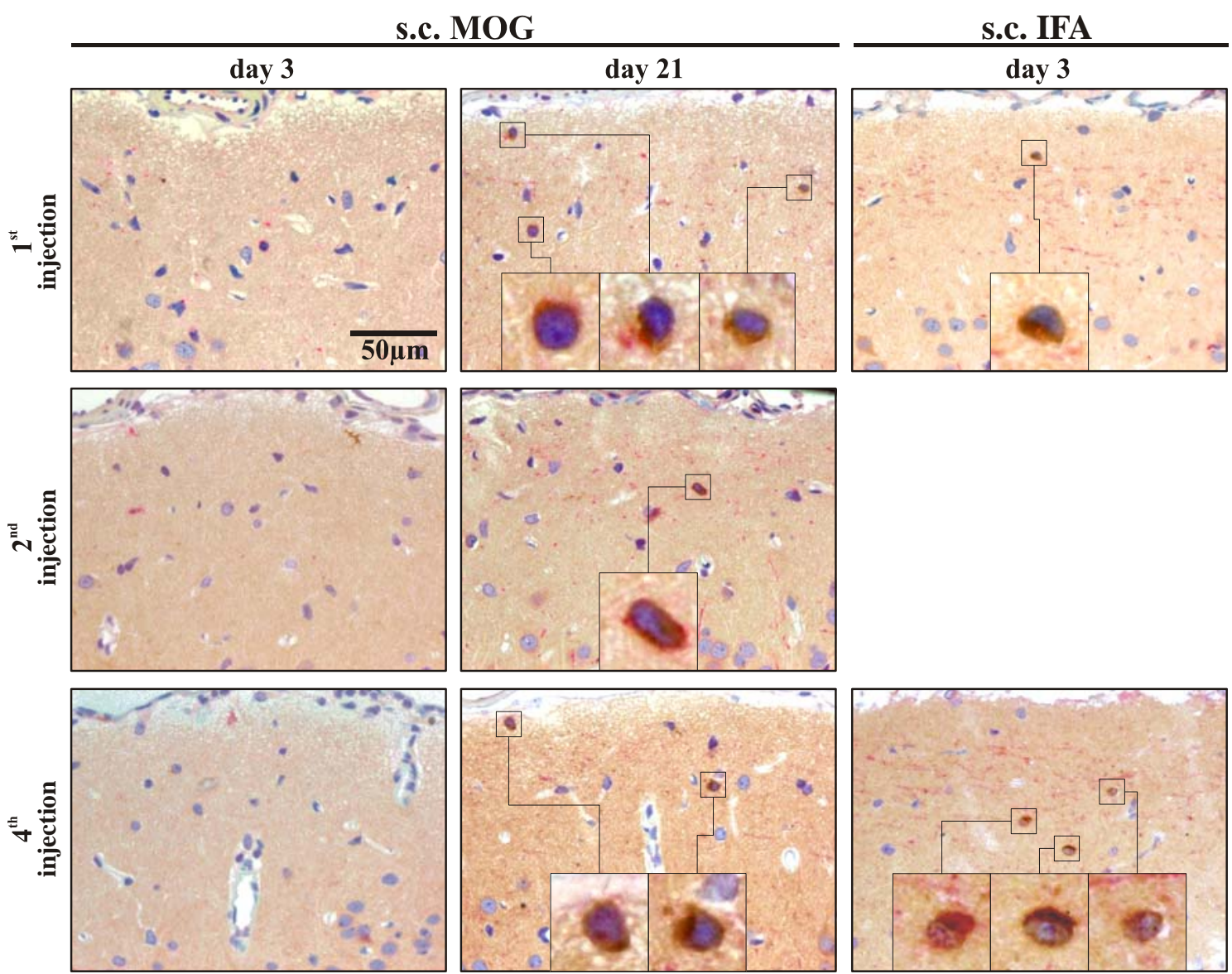

Figure 17: Spontaneous recovery of oligodendrocytes in subpial lesions

Representative photographs of NogoA/MBP double immunostained sections of lesioned subpial cortical area. The different time points (days 3 and 21) and immunization protocols (s.c. MOG and s.c. IFA) are arranged in columns. The different numbers of lesion inductions $\left(1^{\text {st }}, 2^{\text {nd }}\right.$ and $\left.4^{\text {th }}\right)$ are arranged in rows. Loss of oligodendrocytes (brown shaped cells) was observed within subpial lesions at day 3 post lesion induction (left column). Twenty-one days after lesion induction, NogoA-positive cell population recovered (middle column). NogoA-positive cell population was not affected in s.c. IFA primed controls (right column).

Scale bars: $50 \mu \mathrm{m}$, length of enlarged image $=14 \mu \mathrm{m}$ 


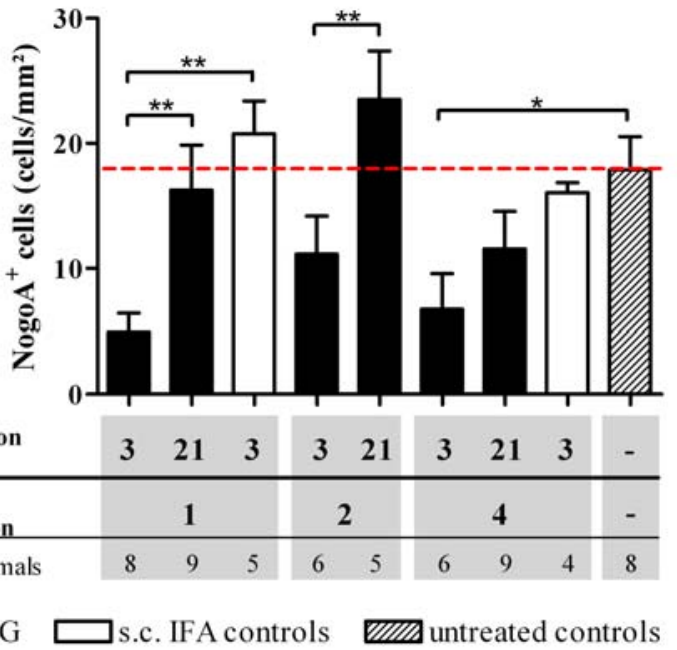

\section{Figure 18: Density of oligodendrocytes}

Oligodendrocyte density was determined within lesioned subpial cerebral cortex of NogoA/MBP double stained sections. At 3 days post lesion induction, NogoA-positive cell density decreased significantly followed by recovery (at day 21) after single and two demyelinating events. At day 3 post fourth lesion induction, loss of oligodendrocytes was only significant when compared to untreated controls. Data are expressed as mean + SEM. The mean of the untreated controls is indicated by dotted line. For statistical evaluation, one-way ANOVA followed by post-hoc LSD-test was performed $(*=\mathrm{p}<0.05, * *=\mathrm{p}<0.01)$.

\subsubsection{Proliferation of NogoA-positive oligodendrocytes}

To assess the effect of repeated lesion induction on the proliferation of oligodendrocytes, NogoA-positive cells were labelled with the proliferation marker BrdU. Oligodendrocytes which underwent cell division during BrdU administration were detected by NogoA/BrdU double immunohistochemistry (Figure 19).

At day 21 after single lesioning, few cells double-positive for NogoA and BrdU were detected within remyelinated subpial areas of s.c. MOG immunized animals (Figure 20, $3.87 \pm 1.14$ cells $\left./ \mathrm{mm}^{2}\right)$. NogoA/BrdU-double positive cell density did not differ significantly in repetitively injected animals $\left(2^{\text {nd }}\right.$ inj.: $0.57 \pm 0.51$ cells $/ \mathrm{mm}^{2}, 4^{\text {th }}$ inj.: 2.34 \pm 0.73 cells $\left./ \mathrm{mm}^{2}\right)$.

The proliferation of oligodendrocytes was analysed in more detail in a further experiment. Three days post lesion induction (Figure 21), few NogoA/BrdU doublepositive cells were detected in s.c. MOG immunized $\left(4.66 \pm 2.15 \mathrm{cell} / \mathrm{s} / \mathrm{mm}^{2}\right)$ and IFA 
immunized controls animals $\left(2.87 \pm 1.98 \mathrm{cells} / \mathrm{mm}^{2}\right)$. At 21 days post lesion induction (Figure 22), comparably low densities of NogoA/BrdU double-positive cells were detected in s.c. MOG immunized animals $\left(2.30 \pm 2.30 \mathrm{cells} / \mathrm{mm}^{2}\right)$ and s.c. IFA immunized control animals (cytokine injection: $1.16 \pm 0.804$; PBS injection: $0.78 \pm 0.49$ cells $/ \mathrm{mm}^{2}$; no injection: $0.35 \pm 0.35$ cells $/ \mathrm{mm}^{2}$ ). No significant differences were detected between the groups at day three or day 21 post lesion induction.

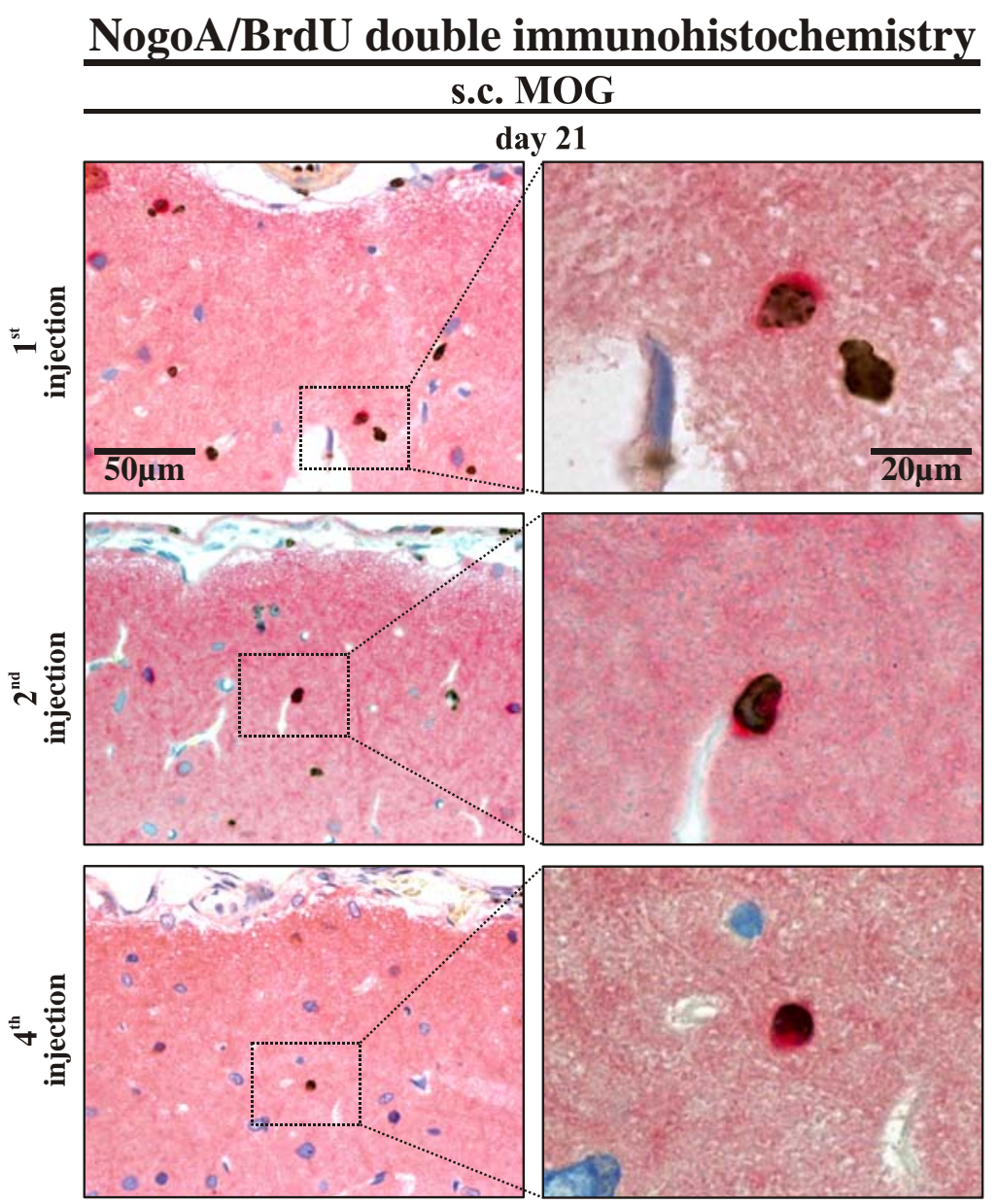

Figure 19: Oligodendrocyte proliferation during remyelination

Representative photographs of NogoA/BrdU double immunostained sections of subpial lesions. The different numbers of lesion inductions $\left(1^{\text {st }}, 2^{\text {nd }}\right.$ and $\left.4^{\text {th }}\right)$ are arranged in rows. Few mature NogoA-labelled oligodendrocytes cells (red) incorporated the proliferation marker BrdU (brown), which was administrated at days 2 to 7 post lesion induction.

Scale bars: left column $=50 \mu \mathrm{m}$, right column $=20 \mu \mathrm{m}$ 


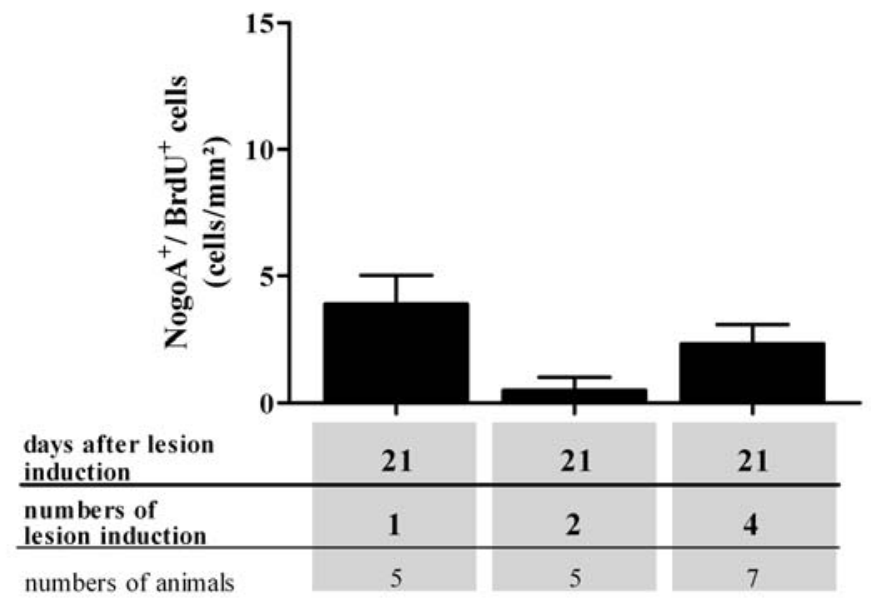

s.c. MOG

Figure 20: Proliferation of NogoA-positive cells after repeated demyelinating events

Density of proliferated oligodendrocytes within lesioned subpial cerebral cortex was determined on NogoA/BrdU double positive stained sections. Twenty-one days post lesion induction, few NogoA/BrdU double positive cells were detected. No statistical differences were observed between singly and repetitively lesioned animals. Data are expressed as mean + SEM.

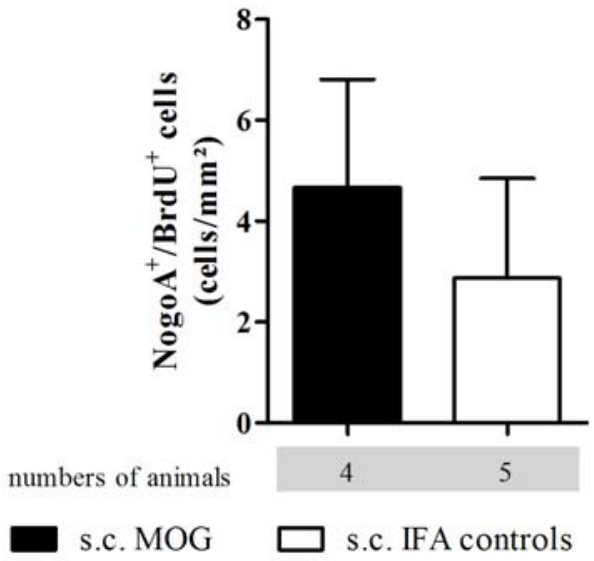

Figure 21: Early effects of lesion induction on proliferation of NogoA-positive cells

Proliferation of mature oligodendrocytes was determined within lesioned subpial cerebral cortex on NogoA/BrdU double immunostained sections. Three days post lesion induction, proliferating NogoA-positive cells were observed in both s.c. MOG and s.c. IFA immunized animals. Values did not differ significantly between groups. Data are expressed as mean + SEM. 


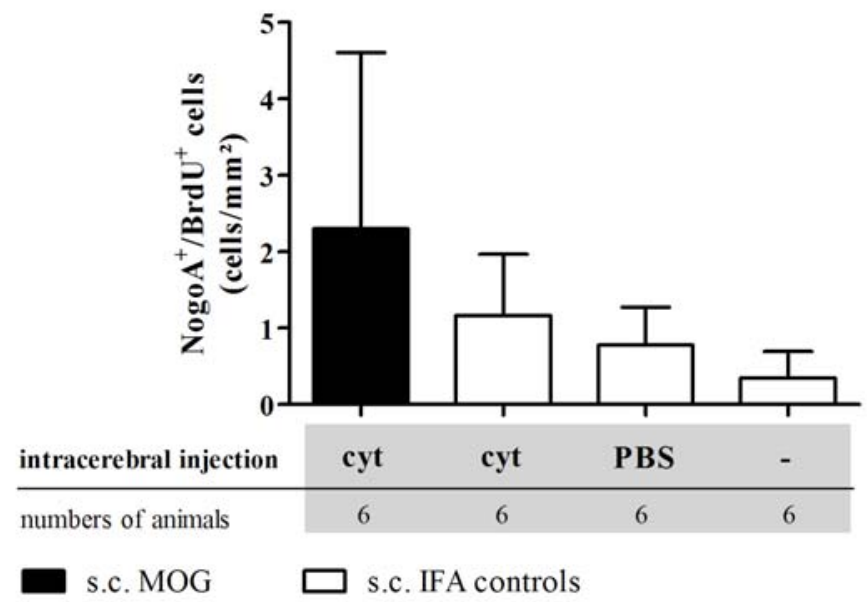

Figure 22: Effect of lesion induction on proliferation of mature oligodendrocytes after remyelination Proliferation of mature oligodendrocytes was determined within lesioned subpial cerebral cortex on NogoA/BrdU double immunohistochemical sections. Twenty-one days post lesion induction, few proliferated oligodendrocytes were detected. S.c. MOG immunized animals did not differ significantly from PBS-injected and non-injected controls. Abbreviations: cyt $=$ cytokines. Data are expressed as mean $+\mathrm{SEM}$.

\subsection{Oligodendroglial progenitors}

To investigate the effect of inflammatory demyelination on oligodendroglial progenitor population, we performed immunohistochemical staining for olig2 (Figure 23).

At the peak of demyelination at day three after lesion induction, density of olig2-positive cells did not alter in s.c. MOG immunized animals $\left(45.75 \pm 2.9\right.$ cells $\left./ \mathrm{mm}^{2}\right)$. However, at day 21 after lesion induction, olig2-positive cell density $\left(60.05 \pm 6.21 \mathrm{cells} / \mathrm{mm}^{2}\right)$ increased significantly (one-way ANOVA $\mathrm{F}_{8,48}=3,045 \mathrm{p}=0.007$ ) compared to day 3 animals (post-hoc LSD-test: $\mathrm{p}=0.005)$, s.c. IFA controls $\left(1^{\text {st }} \mathrm{inj} .: 40.8 \pm 0.97\right.$ cells $/ \mathrm{mm}^{2}$, post-hoc LSD-test: $\mathrm{p}=0.001)$ and untreated controls $\left(45.69 \pm 2.53 \mathrm{cells} / \mathrm{mm}^{2}\right.$, post-hoc LSD-test: $p=0.005)$. After two demyelinating episodes, cell density was increased in both day 3 group $\left(54.14 \pm 3.08\right.$ cells $/ \mathrm{mm}^{2}$, post-hoc LSD-test: $\left.\mathrm{p}=0.041\right)$ and day 21 group $\left(57.69 \pm 4.27\right.$ cells $/ \mathrm{mm}^{2}$, post-hoc LSD-test: $\left.\mathrm{p}=0.014\right)$ compared to repetitively injected s.c. IFA immunized controls $\left(46.1 \pm 5.54 \mathrm{cells} / \mathrm{mm}^{2}\right)$. Three days after four repetitively induced lesions, olig2-positive cell density $\left(59.9 \pm 5.2 \mathrm{cell} / \mathrm{s} / \mathrm{mm}^{2}\right)$ was increased compared to repetitively injected s.c. IFA immunized controls $(46.1 \pm$ 5.34cells $/ \mathrm{mm}^{2}$, post-hoc LSD-test: $\left.\mathrm{p}=0.02\right)$ and untreated controls (45.69 \pm 2.53 cells $/ \mathrm{mm}^{2}$, post-hoc LSD-test: $\mathrm{p}=0.013$ ). Twenty-one days after the last 
intracerebral cytokine injection, cell density $\left(49.44 \pm 6.24 \mathrm{cell} / \mathrm{s} / \mathrm{mm}^{2}\right)$ did not differ compared to control groups. 
Olig2/PLP double immunofluorescence

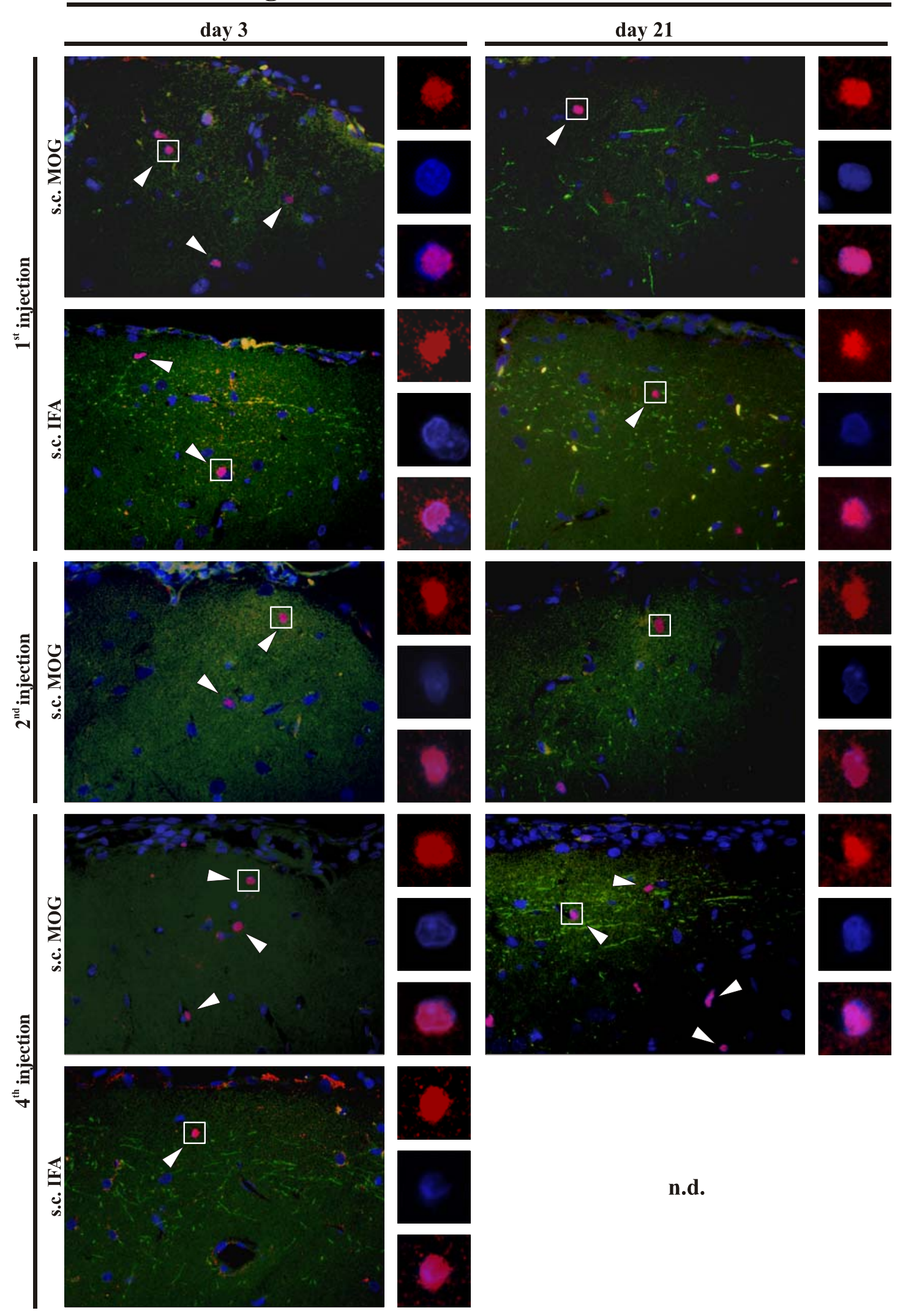




\section{Figure 23: Unaltered oligodendroglial progenitor population}

Representative photographs of olig2/PLP double fluorescent sections of the lesioned subpial cerebral cortex. The different time points (days 3 and 21) are arranged in columns. Lesion inductions $\left(1^{\text {st }}, 2^{\text {nd }}\right.$ and $\left.4^{\text {th }}\right)$ and immunization protocols (s.c. MOG and s.c. IFA) are arranged in rows. Merged overview photographs consist of olig2 (red), PLP (green) and DAPI (blue). Magnifications of single cells show olig2 (red, upper inset), DAPI (blue, middle inset) and merged signals (lower inset). Numbers of olig2-positive cell population remained unaltered even after repetitive lesion inductions. Abbreviation: .n.d. $=$ not determined.

Scale bar $=50 \mu \mathrm{m}$, length of enlarged image $=16 \mu \mathrm{m}$

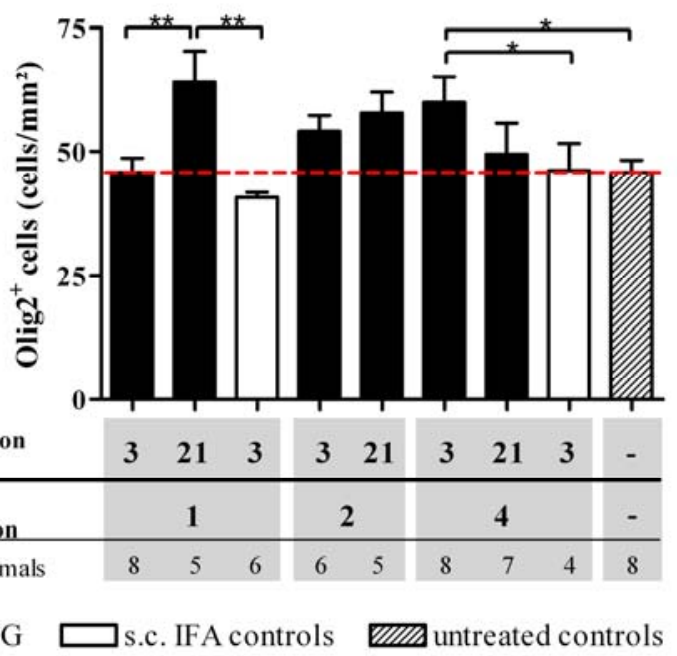

\section{Figure 24: Density of oligodendroglial progenitors}

Oligodendroglial progenitor density was determined within lesioned subpial cerebral cortex of olig2-stained sections. Olig2-positive cell density did not decrease at any examined time point, even after repetitive lesioning. Twenty-one days after single lesioning and 3 days after four demyelinating events, olig2-positive cell density increased significantly. Data are expressed as mean + SEM. Mean of untreated controls is indicated by dotted line. For statistical evaluation, one-way ANOVA followed by post-hoc LSD-test was performed $(*=\mathrm{p}<0.05, * *=\mathrm{p}<0.01)$.

\subsubsection{Proliferation of oligodendroglial progenitors}

To assess the effect of repeated lesion induction on the proliferation of oligodendrocytes, NogoA-positive cells were labelled with the proliferation marker BrdU. Oligodendrocytes which underwent cell division during BrdU administration were detected by NogoA/BrdU double immunohistochemistry (Figure 19). Cells double positive for olig2/BrdU were quantified in subpial lesions of s.c. MOG immunized animals at day 21 after lesion induction. 
Olig2/BrdU double-positive cells were detected within the subpial cortical lesions (Figure $25)$. Constant values were measured after one $\left(12.32 \pm 2.65 \mathrm{cells} / \mathrm{mm}^{2}\right)$, two $(8.78 \pm$ $\left.2.08 \mathrm{cells} / \mathrm{mm}^{2}\right)$ and four $\left(8.57 \pm 1.84 \mathrm{cells} / \mathrm{mm}^{2}\right)$ demyelinating events (Figure 26).

In a further experiment, the proliferation of oligodendroglial cells was analysed in more detail. Three days post lesion induction (Figure 27), relatively high numbers of olig2/BrdU double-positive cells were detected in s.c. MOG immunized (23.34 \pm $\left.6.69 \mathrm{cells} / \mathrm{mm}^{2}\right)$ and IFA immunized controls animals (12.29 \pm 2.88$)$. No significant differences were detected between both groups. Twenty-one days post lesion induction (Figure 28), high numbers of olig2/BrdU double-positive cells were detected in s.c. MOG immunized animals $(15.83 \pm 2.06)$, which were significantly increased (one-way ANOVA $\mathrm{F}_{3,2}=6,594, \mathrm{p}=0.003$ ) compared to all s.c. IFA immunized control groups (cytokine injection: $9.94 \pm 1.23$ cells $/ \mathrm{mm}^{2}, \quad \mathrm{p}=0.048$; PBS injection: $7.70 \pm$ 2.63cells $/ \mathrm{mm}^{2}, \mathrm{p}=0.007$; no injection: $4.34 \pm 1.12$ cells $/ \mathrm{mm}^{2}, \mathrm{p}<0.001$ ). Within the control groups, no statistical differences were observed, but there was a trend for increase between non-injected animals and those which received an intracebral cytokine injection $(\mathrm{p}=0.06)$. These experiments showed an increased proliferation of OPCs upon demyelinating insult within the cerebral cortex. 


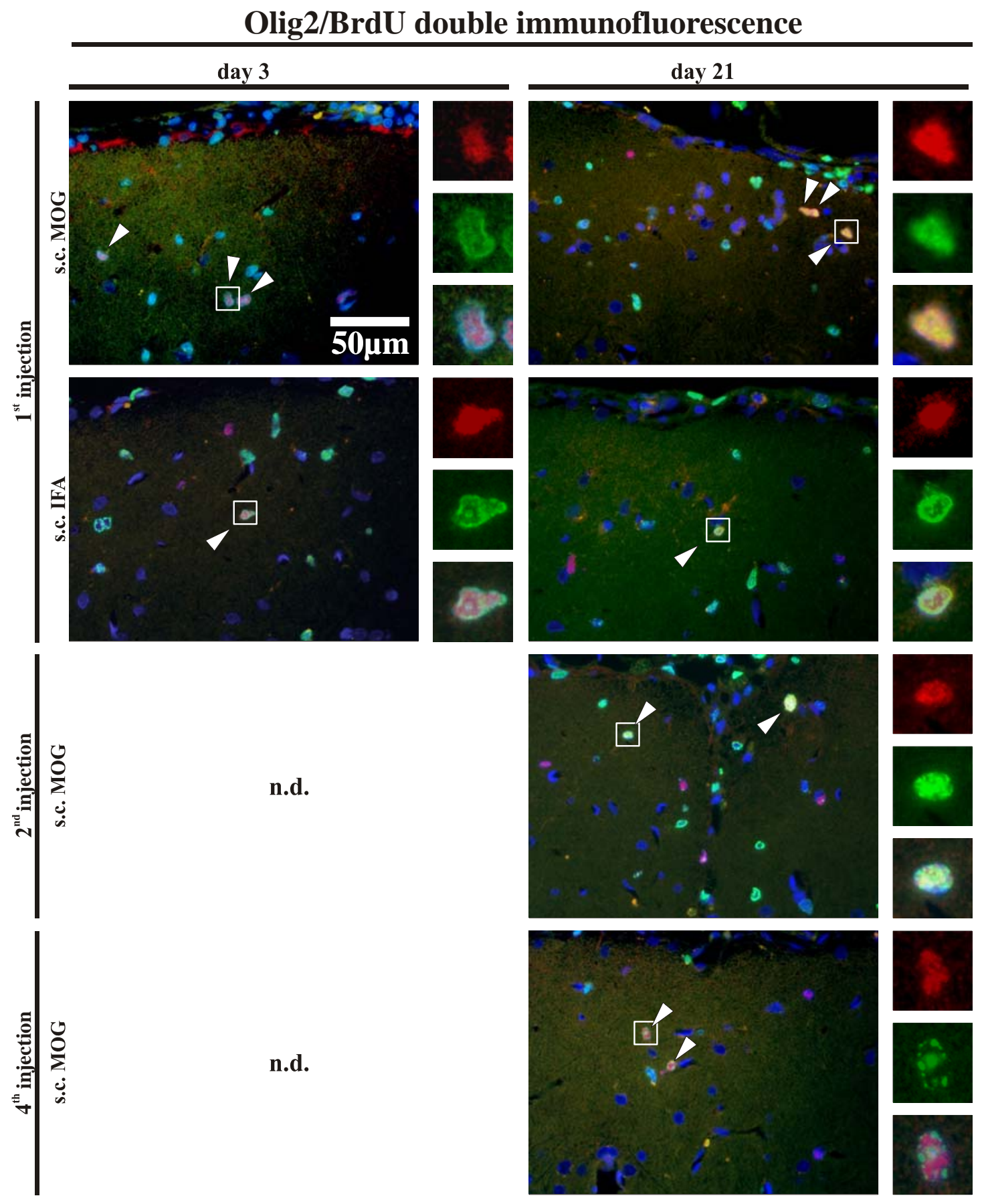

Figure 25: Proliferation of olig2-positive OPCs within subpial lesions

Representative photographs of olig2/BrdU double fluorescent sections of the lesioned subpial cerebral cortex. The different time points (days 3 and 21$)$ are arranged in columns. Lesion inductions $\left(1^{\text {st }}, 2^{\text {nd }}\right.$ and $\left.4^{\text {th }}\right)$ and immunization protocols (s.c. MOG and s.c. IFA) are arranged in rows. Merged overview photographs consist of olig2 (red), BrdU (green) and DAPI (blue). Magnifications of 
single cells show olig2 (red, upper inset), BrdU (green, middle inset) and merged signals (incl. DAPI, lower inset). Substantial proliferation of olig2-positive cells was observed at days 3 and 21 after lesion induction. Abbreviation: .n.d. $=$ not determined.

Scale bar $=50 \mu \mathrm{m}$, length of enlarged image $=16 \mu \mathrm{m}$

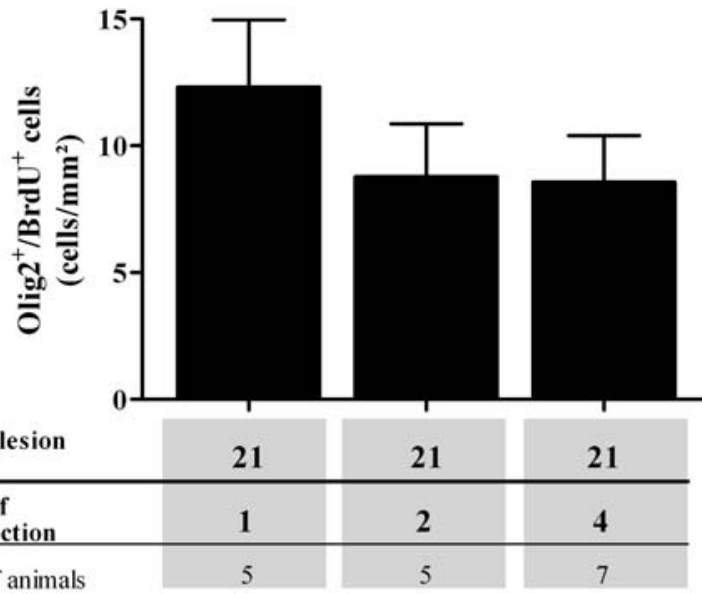

s.c. MOG

\section{Figure 26: OPC proliferation after repeated demyelinating events}

Proliferated oligodendroglial progenitor population was determined within lesioned subpial cerebral cortex by olig2/BrdU double immunofluorescence. Twenty-one days post lesion induction, moderate density of Olig2/BrdU double-positive cells was detected. Values did not differ significantly after repetitive lesion induction. Data are expressed as mean + SEM.

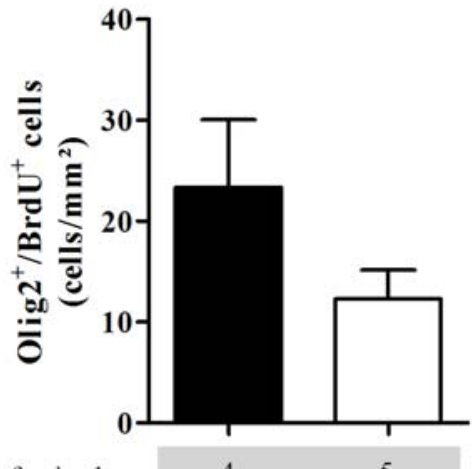

numbers of animals

s.c. MOG

s.c. IFA controls

Figure 27: Early effects of lesion induction on OPC proliferation

Proliferation of the oligodendroglial progenitor population was determined within lesioned subpial cerebral cortex by olig2/BrdU double immunofluorescence. At 3 days post lesion induction, substantial proliferation of olig2-positive cells was observed in both s.c. MOG and s.c. IFA immunized animals. Values did not differ significantly between groups. Data are expressed as mean + SEM. 


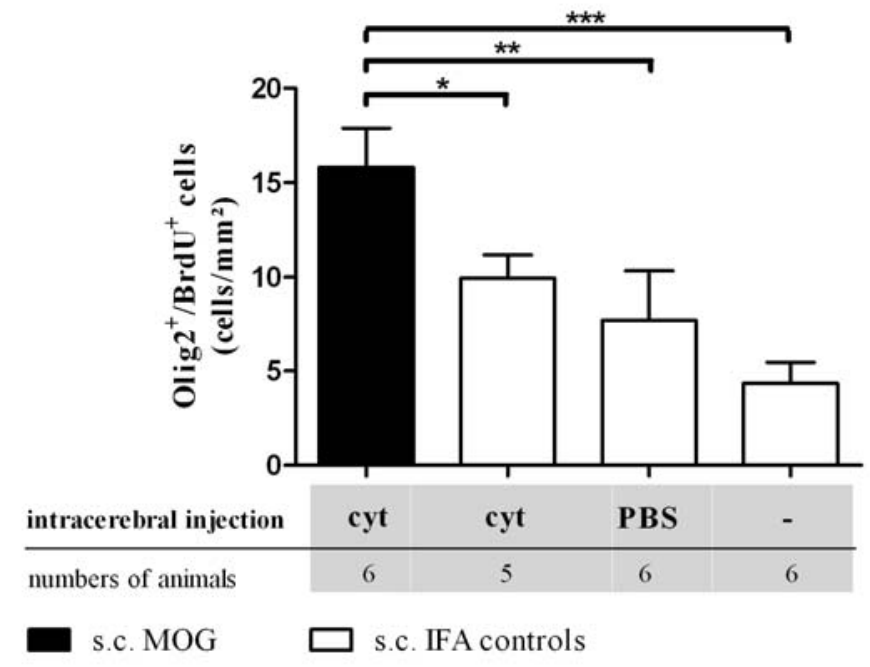

Figure 28: Effects of lesion induction on OPC proliferation after remyelination

Proliferation of the oligodendroglial progenitor population was determined within lesioned subpial cerebral cortex by olig2/BrdU double immunofluorescence. Twenty-one days post lesion induction, Olig2/brdU double-positive cell density was significantly increased compared to the s.c. IFA control groups. Abbreviations: cyt $=$ cytokines. Data are expressed as mean + SEM. For statistical evaluation, one-way ANOVA followed by post-hoc LSD-test was performed $(*=\mathrm{p}<0.05, * *=\mathrm{p}<0.01, * * *=\mathrm{p}<0.001$ ) 


\section{DISCUSSION}

In the presented study I investigated the impact of repeated cortical demyelination on the intrinsic remyelination capacity.

Histological analysis revealed widespread subpial and intracortical demyelinated lesions within the injected cortical hemisphere. Demyelination was accompanied by loss of oligodendrocytes and activation of macrophages/microglia but without apparent axonal loss. Although the fraction of myelinated axons did not fully recover, an extensive remyelination, restored oligodendrocyte population and resolution of inflammation was observed even after repeated lesioning. This was accompanied by a proliferative response of olig2 and NogoA-positive cell populations that was already observed during demyelination.

\subsection{Targeted cortical demyelination shares similarities with cortical MS lesions}

The study of cortical pathology in MS and its clinical manifestations, as well as underlying mechanisms has been hampered by the lack of suitable animal models. The cerebral cortex shows frequent involvement in MS patients. In contrast, in the classical rodent EAE model, lesions are mostly confined to the spinal cord but only rarely affected the cerebral cortex. Alternatively, injection of gliotoxins e.g. lysolecithin or ethidium bromide were used to induce lesions within the brain of rodents (Yajima and Suzuki, 1979; Hall, 1972). However, these models do not reflect the immunopathological nature of MS lesions in the cerebral cortex. Interestingly, the evolvement of cortical EAE lesions was observed in the marmoset EAE model. These lesions occurred spontaneously during the disease course and highly resemble cortical MS lesion pathology (von Budingen et al., 2004; Pomeroy et al., 2005; Merkler et al., 2006; Merkler et al., 2006b). However, experiments with outbread primates show high requirements for infrastructure and animal husbandry, that can only be accomplished in highly specialized centers. A further limitation in using outbread primates is the unpredictable disease course, making it difficult to reproduce cortical lesions in a standardized manner. 
To gain insight into the important aspects of cortical MS, a novel animal model was recently developed in our laboratoty that allows for the targeted induction of cortical demyelinating lesions (Merkler et al., 2006). Sensitization of rats against MOG resulted in a subclinical immune response. In a second step, stereotactic injection of proinflammatory cytokines into a defined area of the animal's cortex led to cortical demyelination that shows considerable similarities to human cortical MS pathology (Merkler et al., 2006). Importantly, neither subclinical MOG sensitization nor cytokine injection alone can cause demyelination or important cellular inflammation in the CNS.

As described in the previous study, we could detect predominantly subpial but also intracortical lesions in the targeted EAE model that were reminiscent of cortical lesion type II and III described in MS patients (Peterson et al. 2001). This lesion topology remained consistent over repeated cycles of de- and re-myelination. Furthermore, cellular composition of inflammatory infiltrates matched the observation of cortical MS lesions. It is possible that the observed topology may be caused by the distribution of injected cytokines in our model. After having been targeted to the deeper cortical layers, the injected cytokines are likely to partially drain back to the subpial surface. Thereby, the BBB may predominantly be affected in these areas resulting in transient BBB breakdown and/or upregulation of adhesion molecules on endothelial cells (Yusuf-Makagiansar et al., 2002). In a setting of previous priming against MOG, it is conceivable that demyelinating anti-MOG autoantibodies cross the altered BBB as a consequence of cytokine injection and subsequently trigger a localized inflammatory response within the affected areas. An alternative hypothesis for the observed lesion distribution would be that macrophages accumulate preferentially at the meningeal area of cytokine injection and thereby secrete demyelinating inflammatory cytokines into the subpial cortical area (Serafini et al., 2007). However, this latter scenario is rather unlikely in our model, since IFA immunized animals did not reveal signs of demyelination despite the fact that these animals showed a certain accumulation of macrophages in the meningeal areas following cytokine injection (data not shown). Furthermore, recent findings in MS showed that meningeal inflammation seems not to be associated with cortical demyelination (Geurts et al., 2009). 


\subsection{Effect of repeated demyelinating lesions on remyelination}

Cortical remyelination is a frequent and important repair mechanism in MS (Patani et al., 2007; Patrikios et al., 2006). The cerebral cortex showed a more extensive remyelinating capacity as compared to white matter MS lesions (Albert et al., 2007). Nevertheless, the number of chronic demyelinated plaques in the cerebral cortex increases with ongoing disease progression (Peterson et al., 2001; Bo et al., 2003; Patani et al., 2007; Goldschmidt et al., 2009; Gilmore et al., 2009; Bo, 2009). Therefore, the objective of this study was to investigate the effect of repetitive inflammatory demyelination on the endogenous cortical remyelination capacity.

Although cortical lesions were repeatedly induced in our study, animals revealed extensive and in some cases nearly complete remyelination, even after four demyelinating episodes. Our results are in line with a previous study which proved successful myelin restoration after repeated cycles of ethidium bromide-induced demyelination (Penderis et al., 2003). Together, these results suggest at first glance that remyelination failure - as can be observed in chronic MS cases - might not solely be the result of repetitive demyelinating episodes and further suggest that there are still other unknown mediators that may contribute to this phenomenon. Clearly, our study can nevertheless not exclude that four cycles of of de- and re-myelination may just not be enough to exhaust the intrinsic remyelinating capacity of the cerebral cortex, and that remyelination failure in MS may reflect the final consequence of a multitude of such events that was not sufficiently recreated by our repeated lesioning approach. One may therefore speculate that the targeted cortical EAE lesions reflect the early relapsingremitting disease course of MS, in which chronic cortical demyelination is less pronounced (Stadelmann et al., 2008). Furthermore, possible differences in the intrinsic properties of remyelinating oligodendrocytes in humans and rodents may account for these observations.

As a further parameter of remyelination, we determined the fraction of myelinated fibres in the remyelinated cortex. This analysis revealed a reduced fraction of remyelinated fibres three weeks after lesioning. To exclude that this change might be explained by still incomplete remyelination at this time point, we performed in a subset of animals similar 
analysis five weeks after demyelination (data not shown). However, the fraction of remyelinating fibres remained reduced even at this later time point as compared to agematched controls. Thus, this data indicates that the process of remyelination was almost already complete three weeks after lesion induction. These results indicate that although remyelination is extensive, the restoration of myelin content in the cortex is incomplete, therefore as expected not equating to normal developmental myelination (Lazzarini, 2004). The limitations of remyelination are obvious in the ultrastructure of myelin, showing reduced myelin sheath thickness and internode length (Perier and Grégoire, 1965; Blakemore, 1974; Merkler et al., 2006).

\subsection{Inflammation in repeated targeted cortical EAE lesions}

In accordance to a previous report demyelination was accompanied by inflammation which resolved within three weeks after each lesion induction (Merkler et al., 2006). The initial inflammatory response measured by the density of activated macrophages/microglia was markedly stronger compared to the subsequent episodes. Macrophage/microglia activation might be related to myelin content, as the fraction of myelinated axons was also higher before demyelination when compared to remyelination time points. However, this seemed not related to lesion size as the extent of demyelination did not alter after repetated lesions. The relationship between myelin content and inflammation becomes clear when comparing myelin rich white matter lesions, which present with strong inflammation, to grey matter lesions, which present with relatively little myelin and reduced inflammation (Kerschensteiner et al., 2004: Merkler et al., 2006; Peterson et al., 2001; Bo et al., 2003). However, the different local environment of white and grey matter could influence the inflammatory response within a given lesion. Anti-MOG autoantibody titres were consistently high over time and therefore are not the cause for the observed alterations in inflammatory response. Speculatively, excessive blood born monocytes were recruited into the area of inflammation during the initial demyelinating lesion. Why the repeated inflammatory responses were markedly reduced is not clear. One discussed theory is that neurons, 
which are abundant in the cerebral cortex could have damped the activation of microglia as proposed by Biber and colleagues (Biber et al., 2007).

The inflammatory process causes tissue damage in EAE and MS. For instance, proinflammatory cytokines such as TNF- $\alpha$, IFN- $\gamma$, interleukin-1 $\beta$ (IL-1 $\beta$ ) and IL-2 have been shown to promote oligondendrocyte death in vitro (Selmaj and Raine, 1988; Vartanian et al., 1995; Curatolo et al., 1997; Hisahara et al., 1997; Jurewicz et al., 2005). Apoptosis-inducing factor-positive oligodendrocyte nuclei were detected around MS plaques, suggesting this pathway may contribute to oligodendrocyte loss and disease progression (Jurewicz et al., 2005). Furthermore, macrophages and microglia are activated by pro-inflammatory cytokines which promote apoptosis of oligodendrocytes through oxidative stress or via activation of transcription factor p53 (Merill and Scolding, 1999; Eizenberg et al., 1995; Ladiwala et al., 1999; Wosik et al., 2003). However, the cytokine concentrations used in our model are not cytotoxic, as no effects were observed in IFA-immunized control animals.

\subsection{Preserved axonal intregrity after repetitive demyelination}

Repetitive lesion induction did not lead to substantial axonal loss. This goes in line with a previous study by Merkler and colleagues (Merkler et al., 2006) which reported preserved axonal integrity and minimal neuronal death in the targeted cortical EAE model. Furthermore, they showed transient accumulation of amyloid precursor protein (APP)positive spheroids, correlating with inflammation. Acute axonal damage and minimal neuronal loss is also to be assumed in our repetitive lesioning approach, but apparently without any cumulating harming effects, as no axonal loss was detected. The fast resolution of inflammation in targeted cortical EAE lesions possibly prevented further axonal damage. This is supported by several studies suggesting a relationship between the extent of axonal damage and the severity of the inflammatory process in EAE and MS (Mancardi et al., 2001, Shrivel and Dittel, 2006; Rasmussen et al., 2007; Lassmann et al., 2001). However, transected neurites and apoptotic neurons were observed in cortical MS lesions (Peterson et al., 2001). Extensive remyelination observed in the presented study 
might have supported axonal preservation as reported by previous studies (Kornek et al., 2000; Irvine and Blakemore, 2008; Trapp and Nave, 2008).

\subsection{Oligodendrocyte recruitment in the targeted cortical EAE model}

Histological assessment revealed normal olig2-positive cells density within the subpial cerebral cortex which did not decrease even after repeated cycles of demyelination. The cell density even increased at particular time points after lesion induction. This can be explained by the fast proliferative response of oligodendroglial cells observed within demyelinated areas. From this proliferative population the majority were olig2-positive OPCs and only few NogoA-positive cells. This leads to the assumption that the restored oligodendrocyte population in the remyelinated cortex, did not derive from proliferated OPCs. More likely, oligodendrocytes were preferentially recruited from the local pool of abundant OPCs which already persisted before the demylinating lesion was induced (Dawson et al., 2003, Levine et al., 2001). One can further speculate that the proliferated olig2-positive OPCs might restore the pool of quiescent adult oligodendroglial population to replace those which have differentiated into remyelinating oligodendrocytes. This seems plausible as, differentiation of OPCs offers a repair mechanism which is fast when compared to the longer process required during proliferation and subsequent maturation. Moreover, it allows for oligodendrocyte restoration and extensive remyelination within 21 days. However, both proliferation and differentiation are important mechanisms of oligodendrocyte recruitment and which of both mechanisms finally fail in MS is a controversial issue. Numerous studies reported OPC recruitment in MS lesions (Prineas et al., 1989; Schonrock et al., 1998; Scolding et al., 1998; Chang et al, 2000; Maeda et al., 2001). This is supported by experimental demyelination studies underlining the potential of OPC recruitment (Carrol and Jennings, 1994; Penderis et al., 2003; Fancy et al., 2004; Levine and Reynolds, 1999; Sim et al., 2002). Despite OPC numbers decreasing with disease progression, they remain within the lesion, however are unresponsive, which therefore indicates a differentiation failure of oligodendroglial progenitor cells as the major determinant of remyelination failure in chronic MS (Kuhlmann et al., 2008). The importance of efficient differentiation is obvious in GFP- 
PDGF- $\alpha$ transgenic animals, where elevated OPC numbers did not improve remyelination after chemical demyelination (Woodruff et al., 2004). Nevertheless, the likelihood of OPC recruitment failure can not be excluded since OPC depletion may occur after a single demyelinating event (Keirstead et al., 1998). This effect is more obvious after protracted and sustained exposure to a demyelinating stimulus (Linington et al., 1992; Ludwin, 1980). However, in our experimental setting we could not detect a reduction of OPC in the demyelinated cortex. This can be explained by the fact that MOG EAE is not directed against OPCs since these cells do not express the MOG antigen.

The density of proliferated OPCs appeared higher at day three after lesion induction than after 21 days. A reason for this may be the excessive recruitment of OPCs undergoing apoptosis as reported in a previous study (Calver et al., 1998). In addition, this observed process can be partly explained by the normal turn over of OPCs, as Olig2 and NG2positive cells are the major cycle related cell population in the CNS (Dawson et al., 2000; Levine et al., 2001; Geha et al., 2009; Dimou et al., 2008; Zhu et al., 2008).

Not all OPCs within the cerebral cortex do differentiate to myelinating/remyelinating oligodendrocytes (Franklin and ffrench-Constant 2008). Several studies present evidence that different OPC subpopulations with different functions such as synaptic transmission may exist (Karadottir et al., 2008; Jacobs et al., 2005). This may be achieved by glutamate and N-methyl D-aspartate (NMDA) receptors which have been shown to be expressed on oligodendroglial membranes (Bergles et al., 2000; Karadottir et al., 2005; Kukley et al., 2007). The putative existence of further OPC subpopulations could explain why a substantial number of quiescent OPC remain in high numbers in the normal cerebral cortex (Dawson et al., 2003, Levine et al., 2001). Another supporting reason is that OPC subpopulations derived from OPCs responded differentially to trophic factors such as PDGF-AA, FGF-2 and IGF-1 (Mason et al., 2002). Furthermore, competing waves of embryonic oligodendrocyte lineages during development support the existence of two different oligodendroglial populations (Kessaris et al., 2006). Whether aforementioned cells are also present in the brain of the Lewis rat and whether these cells respond to inflammatory demyelination is unknown. 
NogoA is considered a reliable marker for adult mature oligodendrocytes (Kuhlmann et al., 2007). However, during the transition from OPCs to remyelinating oligodendrocytes, some cells may express both olig2 and NogoA. Nevertheless, the proportion of wrong positive cells might be small. In all probability, the restored population of NogoApositive oligodendrocytes contributed to remyelination. However, the presence of remyelinating oligodendrocytes in the targeted EAE model should be confirmed by PLP in-situ hybridization and electron microscopy in future experiments.

\subsection{The origin of proliferated OPCs}

The origin of proliferated OPCs reported in this study is unknown. However, our data indicate that OPCs were locally recruited as substantial numbers of proliferated OPCs were already observed within demyelinated areas at day three after lesion induction. Thus, recruitment from remote brain areas unlikely occurred in such a short time frame. Additionally, few OPCs might have migrated from adjacent cortical areas as increased numbers of proliferated OPCs were also detected in unaffected cortical areas located close to the lesion (data not shown). Furthermore, the subventricular zone (SVZ) is discussed in the literature as a potent source for OPCs. The SVZ harbours mitogenic type B cells from which OPCs but also astrocytes and neurons derive from this region (Levison and Goldman, 1997; Carrol et al., 1998; Menn et al., 2006). These cells migrate through the rostral migratory pathway (RMS) to their destination and have been shown to be a potential source of oligodendrocyte recruitment in experimental demyelination studies (Aguirre et al., 2007; Nait-Oumesmar et al., 1999; Picard-Riera et al., 2002). SVZ activation was also described in MS patients (Nait-Oumesmar et al., 2007), although the role of SVZ proliferation and migration might play only a minor role in human disease. Firstly, the contribution of SVZ-derived cells may be relatively small compared to local OPCs, and especially as it occurs in remote places of the brain. Secondly, oligodendroglial precursors may be recruited from areas adjacent to demyelinated lesions. This is supported by increased oligodendroglial cell counts observed at the rim of MS lesions (Raine et al., 1981; Prineas et al., 1989; Robinson et al., 1998). 


\subsection{Indications of overstrained remyelination capacity}

Histological evaluation revealed extensive remyelination after repetitive demyelination. In addition, oligodendrocyte population recovered at least after the first two demyelinating events. However, twenty-one days after the fourth lesion induction NogoA-positive cells counts ranged between the values of the demyelinated and control groups. Therefore, it is hard to state whether the oligodendrocyte population is fully restored or not. Assuming the previous statement, reduced oligodendrocyte number could indicate the start of impaired oligodendrocyte recruitment, which is unclear after the fourth injection. This may have become more apparent if further lesioning was performed. Similarly, exhaustion of the remyelination capacity can be induced after protracted and sustained exposure to a demyelinating stimulus, this does not reflect those conditions of cortical MS lesions (Linington et al., 1992; Ludwin, 1980).

Furthermore, one should keep in mind that MS patients may experience many demyelinating episodes during the usually long disease course, whereby cortical demyelinating lesions can be observed in early disease stages (Okuda et al., 2009; Lebrun et al., 2008). Moreover, signs of previous demyelination were detected in normal appearing grey matter of MS patients (Albert et al., 2007). When considering the number of undetected and obvious lesions that MS patients suffer throughout disease, loss of remyelination capacity due to frequent demyelinating episodes still provides a possible explanation for chronic demyelinated plaques.

\subsection{Role of reactive astrocytes on remyelination}

Moderate astrogliosis was observed in close proximity to the needle track. In concordance to our results, cortical MS lesions present with moderate astrogliosis compared to white matter lesions (Stadelmann et al., 2008). The role of astrocytes on deand re-myelination is not fully understood. On the one hand astrocyte-derived hyaluronan seem to inhibit OPC maturation and thereby may contribute to the chronicity of plaques (Back et al., 2005). On the other hand astrocytes may also be beneficial as they secrete the neuroprotective ciliary neurotrophic factor (Albrecht et al., 2007). Furthermore, lack of astrocytes is associated with reduced numbers of OPCs in experimental demyelination, 
which indicates an important role of these cells on remyelination (Talbott et al., 2005). However, aforementioned effects may play a minor role in our model, since astrogliosis observed in our study is negligible.

\subsection{Hormonal effects on targeted cortical EAE}

For induction of targeted EAE lesions female Lewis rats were used. To analyse whether disturbances in estrous cycle may interfere with the outcome of our experiments, the estrous cycle was determined in a subgroup of animals. Preliminary results indicate a transient disturbance of the estrous cycle in the targeted cortical EAE model (Appendix, Figure A). Whether a disturbed estrous cycle might interfere with remyelination and oligodendrocyte recruitment needs to be analysed in more detail. However, sex hormonal alterations play a role in MS, as some patients experience an alleviation of symptoms during the third trimester of pregnancy which may be related to high levels of estrogen (Confavreux et al., 1998). Furthermore, 17- $\beta$-estradiol and estriol promoted immunosuppression was confirmed in EAE experiments (Confavreaux et al., 1998; Voskuhl, 2002; Kim et al., 1999; Bebo et al., 2001; Ito et al. 2001). In contrast, hormonal fluctuations in menstrual cycle or menopause seems to be associated with exacerbations of MS symptoms, however definite conclusions are missing due to technical limitations and conflicting results (Smith and Studd, 1992; Nicot, 2009).

Stress is linked to hormonal changes and may thereby influence the disease course in autoimmune human diseases and animal models (Heesen et al., 2007; Morale et al., 2001; Foster et al., 2003; Kalantaridou et al., 2004; Herzog et al., 2009). Ovariectomies can be performed to reduce sex hormone related interferences in animal experiments, as for instance estrogen promoted neuroprotection (Hoffman et al., 2001; Offner et al., 2006; Morales et al., 2006). However, changes in estrous cycle related hormonal function may possibly occur in our model, although it is likely not do not to have a strong impact on the disease course, as no obvoius intraindividual differences were observed in the analysed parameters. 


\subsection{Conclusions}

This work demonstrates the extensive intrinsic regenerative capacity of the rat cerebral cortex after repeated demyelinating insult. Four cycles of cortical demyelinating episodes did not lead to reduction of the cortical remyelinating capacity in our experimental setting. Our results suggest furthermore that oligodendroglial recruitment occurs by differentiation of existing rather than newly generated OPCs within the cerebral cortex. Findings from these studies will contribute to understanding the underlying processes of remyelination with implications for MS. 


\section{REFERENCES}

Adelmann M, Wood J, Benzel I et al. The N-terminal domain of the myelin oligodendrocyte glycoprotein (MOG) induces acute demyelinating experimental autoimmune encephalomyelitis in the Lewis rat. J Neuroimmunol 1995; 63: 17-27.

Aguirre A, Gallo V. Reduced EGFR signaling in progenitor cells of the adult subventricular zone attenuates oligodendrogenesis after demyelination. Neuron Glia Biol 2007; 3: 209-220.

Albert M, Antel J, Bruck W, Stadelmann C. Extensive cortical remyelination in patients with chronic multiple sclerosis. Brain Pathol 2007; 17: 129-138.

Albrecht PJ, Enterline JC, Cromer J, Levison SW. CNTF-activated astrocytes release a soluble trophic activity for oligodendrocyte progenitors. Neurochem Res 2007; 32: 263271.

Back SA, Tuohy TM, Chen $\mathrm{H}$ et al. Hyaluronan accumulates in demyelinated lesions and inhibits oligodendrocyte progenitor maturation. Nat Med 2005; 11: 966-972.

Bagert BA. Epstein-Barr virus in multiple sclerosis. Curr Neurol Neurosci Rep 2009; 9: 405-410.

Bansal R, Pfeiffer SE. Inhibition of protein and lipid sulfation in oligodendrocytes blocks biological responses to FGF-2 and retards cytoarchitectural maturation, but not developmental lineage progression. Dev Biol 1994; 162: 511-524.

Barkhof F, Bruck W, De Groot CJ et al. Remyelinated lesions in multiple sclerosis: magnetic resonance image appearance. Arch Neurol 2003; 60: 1073-1081.

Barres BA, Hart IK, Coles HS et al. Cell death and control of cell survival in the oligodendrocyte lineage. Cell 1992; 70: 31-46.

Barres BA, Raff MC, Gaese F, Bartke I, Dechant G, Barde YA. A crucial role for neurotrophin-3 in oligodendrocyte development. Nature 1994; 367: 371-375. 
Bebo BF, Jr., Fyfe-Johnson A, Adlard K, Beam AG, Vandenbark AA, Offner H. Lowdose estrogen therapy ameliorates experimental autoimmune encephalomyelitis in two different inbred mouse strains. J Immunol 2001; 166: 2080-2089.

Beebe GW, Kurtzke JF, Kurland LT, Auth TL, Nagler B. Studies on the natural history of multiple sclerosis. 3. Epidemiologic analysis of the army experience in World War II. Neurology 1967; 17: 1-17.

Ben-Nun A, Wekerle H, Cohen IR. Vaccination against autoimmune encephalomyelitis with T-lymphocyte line cells reactive against myelin basic protein. Nature 1981; 292: 6061.

Bergles DE, Roberts JD, Somogyi P, Jahr CE. Glutamatergic synapses on oligodendrocyte precursor cells in the hippocampus. Nature 2000; 405: 187-191.

Besnard F, Perraud F, Sensenbrenner M, Labourdette G. Effects of acidic and basic fibroblast growth factors on proliferation and maturation of cultured rat oligodendrocytes. Int J Dev Neurosci 1989; 7: 401-409.

Biber K, Neumann H, Inoue K, Boddeke HW. Neuronal 'On' and 'Off' signals control microglia. Trends Neurosci 2007; 30: 596-602.

Blakemore WF. Ethidium bromide induced demyelination in the spinal cord of the cat. Neuropathol Appl Neurobiol 1982; 8: 365-375.

Blakemore WF. Pattern of remyelination in the CNS. Nature 1974; 249: 577-578.

Blakemore WF. Remyelination of the superior cerebellar peduncle in the mouse following demyelination induced by feeding cuprizone. J Neurol Sci 1973; 20: 73-83.

Bo L, Vedeler CA, Nyland HI, Trapp BD, Mork SJ. Subpial demyelination in the cerebral cortex of multiple sclerosis patients. J Neuropathol Exp Neurol 2003; 62: 723-732.

Bo L. The histopathology of grey matter demyelination in multiple sclerosis. Acta Neurol Scand Suppl 2009; 51-57.

Brownell B, Hughes JT. The distribution of plaques in the cerebrum in multiple sclerosis. J Neurol Neurosurg Psychiatry 1962; 25: 315-320. 
Calver AR, Hall AC, Yu WP et al. Oligodendrocyte population dynamics and the role of PDGF in vivo. Neuron 1998; 20: 869-882.

Carroll WM, Jennings AR, Ironside LJ. Identification of the adult resting progenitor cell by autoradiographic tracking of oligodendrocyte precursors in experimental CNS demyelination. Brain 1998; 121 ( Pt 2): 293-302.

Carroll WM, Jennings AR. Early recruitment of oligodendrocyte precursors in CNS demyelination. Brain 1994; 117 ( Pt 3): 563-578.

Chang A, Nishiyama A, Peterson J, Prineas J, Trapp BD. NG2-positive oligodendrocyte progenitor cells in adult human brain and multiple sclerosis lesions. J Neurosci 2000; 20: 6404-6412.

Confavreux C, Hutchinson M, Hours MM, Cortinovis-Tourniaire P, Moreau T. Rate of pregnancy-related relapse in multiple sclerosis. Pregnancy in Multiple Sclerosis Group. N Engl J Med 1998; 339: 285-291.

Curatolo L, Valsasina B, Caccia C, Raimondi GL, Orsini G, Bianchetti A. Recombinant human IL-2 is cytotoxic to oligodendrocytes after in vitro self aggregation. Cytokine 1997; 9: 734-739.

Dawson MR, Levine JM, Reynolds R. NG2-expressing cells in the central nervous system: are they oligodendroglial progenitors? J Neurosci Res 2000; 61: 471-479.

Dawson MR, Polito A, Levine JM, Reynolds R. NG2-expressing glial progenitor cells: an abundant and widespread population of cycling cells in the adult rat CNS. Mol Cell Neurosci 2003; 24: 476-488.

Dimou L, Simon C, Kirchhoff F, Takebayashi H, Gotz M. Progeny of Olig2-expressing progenitors in the gray and white matter of the adult mouse cerebral cortex. J Neurosci 2008; 28: 10434-10442.

Dustin ML, Cooper JA. The immunological synapse and the actin cytoskeleton: molecular hardware for T cell signaling. Nat Immunol 2000; 1: 23-29.

Dutta R, McDonough J, Yin X et al. Mitochondrial dysfunction as a cause of axonal degeneration in multiple sclerosis patients. Ann Neurol 2006; 59: 478-489. 
Edgar JM, Garbern J. The myelinated axon is dependent on the myelinating cell for support and maintenance: molecules involved. J Neurosci Res 2004; 76: 593-598.

Eizenberg O, Faber-Elman A, Gottlieb E, Oren M, Rotter V, Schwartz M. Direct involvement of p53 in programmed cell death of oligodendrocytes. EMBO J 1995; 14: 1136-1144.

Fancy SP, Zhao C, Franklin RJ. Increased expression of Nkx2.2 and Olig2 identifies reactive oligodendrocyte progenitor cells responding to demyelination in the adult CNS. Mol Cell Neurosci 2004; 27: 247-254.

Filippi M, Yousry T, Horsfield MA et al. A high-resolution three-dimensional T1weighted gradient echo sequence improves the detection of disease activity in multiple sclerosis. Ann Neurol 1996; 40: 901-907.

Foster SC, Daniels C, Bourdette DN, Bebo BF, Jr. Dysregulation of the hypothalamicpituitary-gonadal axis in experimental autoimmune encephalomyelitis and multiple sclerosis. J Neuroimmunol 2003; 140: 78-87.

Franklin RJ, Ffrench-Constant C. Remyelination in the CNS: from biology to therapy. Nat Rev Neurosci 2008; 9: 839-855.

Franklin RJ, Kotter MR. The biology of CNS remyelination: the key to therapeutic advances. J Neurol 2008; 255 Suppl 1: 19-25.

Franklin RJ. Why does remyelination fail in multiple sclerosis? Nat Rev Neurosci 2002; 3: $705-714$.

Fritz RB, Chou CH, McFarlin DE. Relapsing murine experimental allergic encephalomyelitis induced by myelin basic protein. J Immunol 1983; 130: 1024-1026.

Fruttiger M, Karlsson L, Hall AC et al. Defective oligodendrocyte development and severe hypomyelination in PDGF-A knockout mice. Development 1999; 126: 457-467.

Geha S, Pallud J, Junier MP et al. NG2+/Olig2+ Cells Are the Major Cycle-Related Cell Population of the Adult Human Normal Brain. Brain Pathol 2009.

Genain CP, Nguyen MH, Letvin NL et al. Antibody facilitation of multiple sclerosis-like lesions in a nonhuman primate. J Clin Invest 1995; 96: 2966-2974. 
Geurts JJ, Bo L, Pouwels PJ, Castelijns JA, Polman CH, Barkhof F. Cortical lesions in multiple sclerosis: combined postmortem MR imaging and histopathology. AJNR Am J Neuroradiol 2005; 26: 572-577.

Geurts JJ, Stys PK, Minagar A, Amor S, Zivadinov R. Gray matter pathology in (chronic) MS: modern views on an early observation. J Neurol Sci 2009; 282: 12-20.

Gilmore CP, Donaldson I, Bo L, Owens T, Lowe J, Evangelou N. Regional variations in the extent and pattern of grey matter demyelination in multiple sclerosis: a comparison between the cerebral cortex, cerebellar cortex, deep grey matter nuclei and the spinal cord. J Neurol Neurosurg Psychiatry 2009; 80: 182-187.

Gold R, Linington C, Lassmann H. Understanding pathogenesis and therapy of multiple sclerosis via animal models: 70 years of merits and culprits in experimental autoimmune encephalomyelitis research. Brain 2006; 129: 1953-1971.

Goldschmidt T, Antel J, Konig FB, Bruck W, Kuhlmann T. Remyelination capacity of the MS brain decreases with disease chronicity. Neurology 2009; 72: 1914-1921.

Griffiths I, Klugmann M, Anderson T et al. Axonal swellings and degeneration in mice lacking the major proteolipid of myelin. Science 1998; 280: 1610-1613.

Griot C, Vandevelde M, Richard A, Peterhans E, Stocker R. Selective degeneration of oligodendrocytes mediated by reactive oxygen species. Free Radic Res Commun 1990; 11: 181-193.

Haase CG, Tinnefeld M, Lienemann M, Ganz RE, Faustmann PM. Depression and cognitive impairment in disability-free early multiple sclerosis. Behav Neurol 2003; 14: $39-45$.

Haines JL, Terwedow HA, Burgess K et al. Linkage of the MHC to familial multiple sclerosis suggests genetic heterogeneity. The Multiple Sclerosis Genetics Group. Hum Mol Genet 1998; 7: 1229-1234.

Hall SM. The effect of injections of lysophosphatidyl choline into white matter of the adult mouse spinal cord. J Cell Sci 1972; 10: 535-546. 
Hampton DW, Anderson J, Pryce G et al. An experimental model of secondary progressive multiple sclerosis that shows regional variation in gliosis, remyelination, axonal and neuronal loss. J Neuroimmunol 2008; 201-202: 200-211.

Heesen C, Gold SM, Huitinga I, Reul JM. Stress and hypothalamic-pituitary-adrenal axis function in experimental autoimmune encephalomyelitis and multiple sclerosis - a review. Psychoneuroendocrinology 2007; 32: 604-618.

Herzog CJ, Czeh B, Corbach S et al. Chronic social instability stress in female rats: a potential animal model for female depression. Neuroscience 2009; 159: 982-992.

Hillert J, Olerup O. Multiple sclerosis is associated with genes within or close to the HLA-DR-DQ subregion on a normal DR15,DQ6,Dw2 haplotype. Neurology 1993; 43: 163-168.

Hinks GL, Chari DM, O'Leary MT et al. Depletion of endogenous oligodendrocyte progenitors rather than increased availability of survival factors is a likely explanation for enhanced survival of transplanted oligodendrocyte progenitors in X-irradiated compared to normal CNS. Neuropathol Appl Neurobiol 2001; 27: 59-67.

Hisahara S, Shoji S, Okano H, Miura M. ICE/CED-3 family executes oligodendrocyte apoptosis by tumor necrosis factor. J Neurochem 1997; 69: 10-20.

Hoffman GE, Le WW, Murphy AZ, Koski CL. Divergent effects of ovarian steroids on neuronal survival during experimental allergic encephalitis in Lewis rats. Exp Neurol 2001; 171: 272-284.

Hohlfeld R, Wekerle H. Immunological update on multiple sclerosis. Curr Opin Neurol 2001; 14: 299-304.

Ibarrola N, Mayer-Proschel M, Rodriguez-Pena A, Noble M. Evidence for the existence of at least two timing mechanisms that contribute to oligodendrocyte generation in vitro. Dev Biol 1996; 180: 1-21.

Irvine KA, Blakemore WF. Remyelination protects axons from demyelination-associated axon degeneration. Brain 2008; 131: 1464-1477. 
Issazadeh S, Mustafa M, Ljungdahl A et al. Interferon gamma, interleukin 4 and transforming growth factor beta in experimental autoimmune encephalomyelitis in Lewis rats: dynamics of cellular mRNA expression in the central nervous system and lymphoid cells. J Neurosci Res 1995; 40: 579-590.

Ito A, Bebo BF, Jr., Matejuk A et al. Estrogen treatment down-regulates TNF-alpha production and reduces the severity of experimental autoimmune encephalomyelitis in cytokine knockout mice. J Immunol 2001; 167: 542-552.

Itoyama Y, Sternberger NH, Webster HD, Quarles RH, Cohen SR, Richardson EP, Jr. Immunocytochemical observations on the distribution of myelin-associated glycoprotein and myelin basic protein in multiple sclerosis lesions. Ann Neurol 1980; 7: 167-177.

Jabs R, Pivneva T, Huttmann K et al. Synaptic transmission onto hippocampal glial cells with hGFAP promoter activity. J Cell Sci 2005; 118: 3791-3803.

Jacobs EC, Pribyl TM, Feng JM et al. Region-specific myelin pathology in mice lacking the golli products of the myelin basic protein gene. J Neurosci 2005; 25: 7004-7013.

Jeffery ND, Blakemore WF. Locomotor deficits induced by experimental spinal cord demyelination are abolished by spontaneous remyelination. Brain 1997; 120 ( Pt 1): 2737.

Johnson RT. The virology of demyelinating diseases. Ann Neurol 1994; 36 Suppl: S54S60.

Jurewicz A, Matysiak M, Tybor K, Kilianek L, Raine CS, Selmaj K. Tumour necrosis factor-induced death of adult human oligodendrocytes is mediated by apoptosis inducing factor. Brain 2005; 128: 2675-2688.

Kabat EA, Wolf A, Bezer AE, Murray JP. Studies on acute disseminated encephalomyelitis produced experimentally in rhesus monkeys. J Exp Med 1951; 93: 615-633.

Kalantaridou SN, Makrigiannakis A, Zoumakis E, Chrousos GP. Stress and the female reproductive system. J Reprod Immunol 2004; 62: 61-68. 
Kangarlu A, Bourekas EC, Ray-Chaudhury A, Rammohan KW. Cerebral cortical lesions in multiple sclerosis detected by MR imaging at 8 Tesla. AJNR Am J Neuroradiol 2007; 28: 262-266.

Karadottir R, Cavelier P, Bergersen LH, Attwell D. NMDA receptors are expressed in oligodendrocytes and activated in ischaemia. Nature 2005; 438: 1162-1166.

Karadottir R, Hamilton NB, Bakiri Y, Attwell D. Spiking and nonspiking classes of oligodendrocyte precursor glia in CNS white matter. Nat Neurosci 2008; 11: 450-456.

Keirstead HS, Blakemore WF. Identification of post-mitotic oligodendrocytes incapable of remyelination within the demyelinated adult spinal cord. J Neuropathol Exp Neurol 1997; 56: 1191-1201.

Keirstead HS, Levine JM, Blakemore WF. Response of the oligodendrocyte progenitor cell population (defined by NG2 labelling) to demyelination of the adult spinal cord. Glia 1998; 22: 161-170.

Kerschensteiner M, Stadelmann C, Buddeberg BS et al. Targeting experimental autoimmune encephalomyelitis lesions to a predetermined axonal tract system allows for refined behavioral testing in an animal model of multiple sclerosis. Am J Pathol 2004; 164: 1455-1469.

Kessaris N, Fogarty M, Iannarelli P, Grist M, Wegner M, Richardson WD. Competing waves of oligodendrocytes in the forebrain and postnatal elimination of an embryonic lineage. Nat Neurosci 2006; 9: 173-179.

Kidd D, Barkhof F, McConnell R, Algra PR, Allen IV, Revesz T. Cortical lesions in multiple sclerosis. Brain 1999; 122 ( Pt 1): 17-26.

Kim S, Liva SM, Dalal MA, Verity MA, Voskuhl RR. Estriol ameliorates autoimmune demyelinating disease: implications for multiple sclerosis. Neurology 1999; 52: 12301238.

Kornek B, Storch MK, Weissert R et al. Multiple sclerosis and chronic autoimmune encephalomyelitis: a comparative quantitative study of axonal injury in active, inactive, and remyelinated lesions. Am J Pathol 2000; 157: 267-276. 
Kuhlmann T, Miron V, Cuo Q, Wegner C, Antel J, Bruck W. Differentiation block of oligodendroglial progenitor cells as a cause for remyelination failure in chronic multiple sclerosis. Brain 2008; 131: 1749-1758.

Kuhlmann T, Remington L, Maruschak B, Owens T, Bruck W. Nogo-A is a reliable oligodendroglial marker in adult human and mouse CNS and in demyelinated lesions. J Neuropathol Exp Neurol 2007; 66: 238-246.

Kukley M, Capetillo-Zarate E, Dietrich D. Vesicular glutamate release from axons in white matter. Nat Neurosci 2007; 10: 311-320.

Kurtzke JF. Rating neurologic impairment in multiple sclerosis: an expanded disability status scale (EDSS). Neurology 1983; 33: 1444-1452.

Kutzelnigg A, Faber-Rod JC, Bauer J et al. Widespread demyelination in the cerebellar cortex in multiple sclerosis. Brain Pathol 2007; 17: 38-44.

Kutzelnigg A, Lucchinetti CF, Stadelmann $\mathrm{C}$ et al. Cortical demyelination and diffuse white matter injury in multiple sclerosis. Brain 2005; 128: 2705-2712.

Ladiwala U, Li H, Antel JP, Nalbantoglu J. p53 induction by tumor necrosis factor-alpha and involvement of p53 in cell death of human oligodendrocytes. J Neurochem 1999; 73: 605-611.

Lappe-Siefke C, Goebbels S, Gravel M et al. Disruption of Cnp1 uncouples oligodendroglial functions in axonal support and myelination. Nat Genet 2003; 33: 366374.

Lassmann H, Bruck W, Lucchinetti C. Heterogeneity of multiple sclerosis pathogenesis: implications for diagnosis and therapy. Trends Mol Med 2001; 7: 115-121.

Lazzarini, RA. Myelin biology and disorders. San Diego, CA: Elsevier Academic press, 2004.

Lebrun C, Bensa C, Debouverie M et al. Unexpected multiple sclerosis: follow-up of 30 patients with magnetic resonance imaging and clinical conversion profile. J Neurol Neurosurg Psychiatry 2008; 79: 195-198. 
Levine JM, Reynolds R, Fawcett JW. The oligodendrocyte precursor cell in health and disease. Trends Neurosci 2001; 24: 39-47.

Levine JM, Reynolds R. Activation and proliferation of endogenous oligodendrocyte precursor cells during ethidium bromide-induced demyelination. Exp Neurol 1999; 160: 333-347.

Levison SW, Goldman JE. Multipotential and lineage restricted precursors coexist in the mammalian perinatal subventricular zone. J Neurosci Res 1997; 48: 83-94.

Liebetanz D, Merkler D. Effects of commissural de- and remyelination on motor skill behaviour in the cuprizone mouse model of multiple sclerosis. Exp Neurol 2006; 202: 217-224.

Linington C, Bradl M, Lassmann H, Brunner C, Vass K. Augmentation of demyelination in rat acute allergic encephalomyelitis by circulating mouse monoclonal antibodies directed against a myelin/oligodendrocyte glycoprotein. Am J Pathol 1988; 130: 443-454. Linington C, Engelhardt B, Kapocs G, Lassman H. Induction of persistently demyelinated lesions in the rat following the repeated adoptive transfer of encephalitogenic T cells and demyelinating antibody. J Neuroimmunol 1992; 40: 219224.

Lu QR, Sun T, Zhu Z et al. Common developmental requirement for Olig function indicates a motor neuron/oligodendrocyte connection. Cell 2002; 109: 75-86.

Lublin FD, Reingold SC. Defining the clinical course of multiple sclerosis: results of an international survey. National Multiple Sclerosis Society (USA) Advisory Committee on Clinical Trials of New Agents in Multiple Sclerosis. Neurology 1996; 46: 907-911.

Lucchinetti C, Bruck W, Parisi J, Scheithauer B, Rodriguez M, Lassmann H. Heterogeneity of multiple sclerosis lesions: implications for the pathogenesis of demyelination. Ann Neurol 2000; 47: 707-717.

Lucchinetti C, Bruck W, Parisi J, Scheithauer B, Rodriguez M, Lassmann H. A quantitative analysis of oligodendrocytes in multiple sclerosis lesions. A study of 113 cases. Brain 1999; 122 ( Pt 12): 2279-2295. 
Ludwin SK, Maitland M. Long-term remyelination fails to reconstitute normal thickness of central myelin sheaths. J Neurol Sci 1984; 64: 193-198.

Ludwin SK. Chronic demyelination inhibits remyelination in the central nervous system. An analysis of contributing factors. Lab Invest 1980; 43: 382-387.

Maeda Y, Solanky M, Menonna J, Chapin J, Li W, Dowling P. Platelet-derived growth factor-alpha receptor-positive oligodendroglia are frequent in multiple sclerosis lesions. Ann Neurol 2001; 49: 776-785.

Magliozzi R, Howell O, Vora A et al. Meningeal B-cell follicles in secondary progressive multiple sclerosis associate with early onset of disease and severe cortical pathology. Brain 2007; 130: 1089-1104.

Mancardi G, Hart B, Roccatagliata L et al. Demyelination and axonal damage in a nonhuman primate model of multiple sclerosis. J Neurol Sci 2001; 184: 41-49.

Martinez-Caceres EM, Espejo C, Brieva L et al. Expression of chemokine receptors in the different clinical forms of multiple sclerosis. Mult Scler 2002; 8: 390-395.

Mason JL, Goldman JE. A2B5+ and O4+ Cycling progenitors in the adult forebrain white matter respond differentially to PDGF-AA, FGF-2, and IGF-1. Mol Cell Neurosci 2002; 20: $30-42$.

Matsushima GK, Morell P. The neurotoxicant, cuprizone, as a model to study demyelination and remyelination in the central nervous system. Brain Pathol 2001; 11: 107-116.

McKinnon RD, Matsui T, Aranda M, Dubois-Dalcq M. A role for fibroblast growth factor in oligodendrocyte development. Ann N Y Acad Sci 1991; 638: 378-386.

McKinnon RD, Matsui T, Dubois-Dalcq M, Aaronson SA. FGF modulates the PDGFdriven pathway of oligodendrocyte development. Neuron 1990; 5: 603-614.

McMorris FA, Dubois-Dalcq M. Insulin-like growth factor I promotes cell proliferation and oligodendroglial commitment in rat glial progenitor cells developing in vitro. J Neurosci Res 1988; 21: 199-209. 
McRae BL, Kennedy MK, Tan LJ, Dal Canto MC, Picha KS, Miller SD. Induction of active and adoptive relapsing experimental autoimmune encephalomyelitis (EAE) using an encephalitogenic epitope of proteolipid protein. J Neuroimmunol 1992; 38: 229-240.

McTigue DM, Horner PJ, Stokes BT, Gage FH. Neurotrophin-3 and brain-derived neurotrophic factor induce oligodendrocyte proliferation and myelination of regenerating axons in the contused adult rat spinal cord. J Neurosci 1998; 18: 5354-5365.

Menn B, Garcia-Verdugo JM, Yaschine C, Gonzalez-Perez O, Rowitch D, varez-Buylla A. Origin of oligodendrocytes in the subventricular zone of the adult brain. J Neurosci 2006; 26: 7907-7918.

Merkler D, Boretius S, Stadelmann C et al. Multicontrast MRI of remyelination in the central nervous system. NMR Biomed 2005; 18: 395-403.

Merkler D, Ernsting T, Kerschensteiner M, Bruck W, Stadelmann C. A new focal EAE model of cortical demyelination: multiple sclerosis-like lesions with rapid resolution of inflammation and extensive remyelination. Brain 2006; 129: 1972-1983.

Merkler D, Schmelting B, Czeh B, Fuchs E, Stadelmann C, Bruck W. Myelin oligodendrocyte glycoprotein-induced experimental autoimmune encephalomyelitis in the common marmoset reflects the immunopathology of pattern II multiple sclerosis lesions. Mult Scler 2006; 12: 369-374.

Merrill JE, Scolding NJ. Mechanisms of damage to myelin and oligodendrocytes and their relevance to disease. Neuropathol Appl Neurobiol 1999; 25: 435-458.

Miller RH. Regulation of oligodendrocyte development in the vertebrate CNS. Prog Neurobiol 2002; 67: 451-467.

Morale C, Brouwer J, Testa N et al. Stress, glucocorticoids and the susceptibility to develop autoimmune disorders of the central nervous system. Neurol Sci 2001; 22: 159162.

Morales LB, Loo KK, Liu HB, Peterson C, Tiwari-Woodruff S, Voskuhl RR. Treatment with an estrogen receptor alpha ligand is neuroprotective in experimental autoimmune encephalomyelitis. J Neurosci 2006; 26: 6823-6833. 
Munz C, Steinman RM, Fujii S. Dendritic cell maturation by innate lymphocytes: coordinated stimulation of innate and adaptive immunity. J Exp Med 2005; 202: 203-207. Nait-Oumesmar B, Decker L, Lachapelle F, vellana-Adalid V, Bachelin C, Van Evercooren AB. Progenitor cells of the adult mouse subventricular zone proliferate, migrate and differentiate into oligodendrocytes after demyelination. Eur J Neurosci 1999; 11: 4357-4366.

Nait-Oumesmar B, Picard-Riera N, Kerninon C et al. Activation of the subventricular zone in multiple sclerosis: evidence for early glial progenitors. Proc Natl Acad Sci U S A 2007; 104: 4694-4699.

Nicot A. Gender and sex hormones in multiple sclerosis pathology and therapy. Front Biosci 2009; 14: 4477-4515.

Nishiyama A, Lin XH, Giese N, Heldin CH, Stallcup WB. Co-localization of NG2 proteoglycan and PDGF alpha-receptor on O2A progenitor cells in the developing rat brain. J Neurosci Res 1996; 43: 299-314.

Noble M, Murray K, Stroobant P, Waterfield MD, Riddle P. Platelet-derived growth factor promotes division and motility and inhibits premature differentiation of the oligodendrocyte/type-2 astrocyte progenitor cell. Nature 1988; 333: 560-562.

Offner H, Polanczyk M. A potential role for estrogen in experimental autoimmune encephalomyelitis and multiple sclerosis. Ann N Y Acad Sci 2006; 1089: 343-372.

Oksenberg JR, Baranzini SE, Sawcer S, Hauser SL. The genetics of multiple sclerosis: SNPs to pathways to pathogenesis. Nat Rev Genet 2008; 9: 516-526.

Okuda DT, Mowry EM, Beheshtian A et al. Incidental MRI anomalies suggestive of multiple sclerosis: the radiologically isolated syndrome. Neurology 2009; 72: 800-805.

Ono K, Bansal R, Payne J, Rutishauser U, Miller RH. Early development and dispersal of oligodendrocyte precursors in the embryonic chick spinal cord. Development 1995; 121: 1743-1754. 
Ono K, Fujisawa H, Hirano S, Norita M, Tsumori T, Yasui Y. Early development of the oligodendrocyte in the embryonic chick metencephalon. J Neurosci Res 1997; 48: 212225.

Park SK, Miller R, Krane I, Vartanian T. The erbB2 gene is required for the development of terminally differentiated spinal cord oligodendrocytes. J Cell Biol 2001; 154: 12451258.

Patani R, Balaratnam M, Vora A, Reynolds R. Remyelination can be extensive in multiple sclerosis despite a long disease course. Neuropathol Appl Neurobiol 2007; 33: 277-287.

Patrikios P, Stadelmann C, Kutzelnigg A et al. Remyelination is extensive in a subset of multiple sclerosis patients. Brain 2006; 129: 3165-3172.

Paxinos, G., Watson, C. The rat brain in stereotaxic coordinates. Fourth edition. New York: Academic Press, Spiral Bound, 1998.

Pender MP. Demyelination and neurological signs in experimental allergic encephalomyelitis. J Neuroimmunol 1987; 15: 11-24.

Penderis J, Shields SA, Franklin RJ. Impaired remyelination and depletion of oligodendrocyte progenitors does not occur following repeated episodes of focal demyelination in the rat central nervous system. Brain 2003; 126: 1382-1391.

Perier O, Gregoire A. Electron microscopic features of multiple sclerosis lesions. Brain 1965; 88: 937-952.

Peterson JW, Bo L, Mork S, Chang A, Trapp BD. Transected neurites, apoptotic neurons, and reduced inflammation in cortical multiple sclerosis lesions. Ann Neurol 2001; 50: $389-400$.

Pfeiffer SE, Warrington AE, Bansal R. The oligodendrocyte and its many cellular processes. Trends Cell Biol 1993; 3: 191-197.

Picard-Riera N, Decker L, Delarasse $\mathrm{C}$ et al. Experimental autoimmune encephalomyelitis mobilizes neural progenitors from the subventricular zone to undergo oligodendrogenesis in adult mice. Proc Natl Acad Sci U S A 2002; 99: 13211-13216. 
Pomeroy IM, Matthews PM, Frank JA, Jordan EK, Esiri MM. Demyelinated neocortical lesions in marmoset autoimmune encephalomyelitis mimic those in multiple sclerosis. Brain 2005; 128: 2713-2721.

Prineas JW, Kwon EE, Goldenberg PZ et al. Multiple sclerosis. Oligodendrocyte proliferation and differentiation in fresh lesions. Lab Invest 1989; 61: 489-503.

Pringle NP, Mudhar HS, Collarini EJ, Richardson WD. PDGF receptors in the rat CNS: during late neurogenesis, PDGF alpha-receptor expression appears to be restricted to glial cells of the oligodendrocyte lineage. Development 1992; 115: 535-551.

Probert L, Eugster HP, Akassoglou K et al. TNFR1 signalling is critical for the development of demyelination and the limitation of T-cell responses during immunemediated CNS disease. Brain 2000; 123 ( Pt 10): 2005-2019.

Qian X, Davis AA, Goderie SK, Temple S. FGF2 concentration regulates the generation of neurons and glia from multipotent cortical stem cells. Neuron 1997; 18: 81-93.

Quarles RH. Myelin-associated glycoprotein (MAG): past, present and beyond. J Neurochem 2007; 100: 1431-1448.

Raff MC, Abney ER, Miller RH. Two glial cell lineages diverge prenatally in rat optic nerve. Dev Biol 1984; 106: 53-60.

Raine CS, Scheinberg L, Waltz JM. Multiple sclerosis. Oligodendrocyte survival and proliferation in an active established lesion. Lab Invest 1981; 45: 534-546.

Rasmussen S, Wang Y, Kivisakk P et al. Persistent activation of microglia is associated with neuronal dysfunction of callosal projecting pathways and multiple sclerosis-like lesions in relapsing — remitting experimental autoimmune encephalomyelitis. Brain 2007; 130: $2816-2829$.

Reynolds R, Hardy R. Oligodendroglial progenitors labeled with the O4 antibody persist in the adult rat cerebral cortex in vivo. J Neurosci Res 1997; 47: 455-470.

Rivers TM, Sprunt DH, Berry GP. Observations on attempts to produce acute disseminated encephalomyelitis in monkeys. J Exp Med 1933; 58: 39-53. 
Robinson S, Tani M, Strieter RM, Ransohoff RM, Miller RH. The chemokine growthregulated oncogene-alpha promotes spinal cord oligodendrocyte precursor proliferation. $\mathrm{J}$ Neurosci 1998; 18: 10457-10463.

Sander M. Hirnrindenbefunde bei multipler Sklerose. Monatsschr. Psych. Neurol. 1898; IV: 429-436.

Saneto RP, Low KG, Melner MH, de VJ. Insulin/insulin-like growth factor I and other epigenetic modulators of myelin basic protein expression in isolated oligodendrocyte progenitor cells. J Neurosci Res 1988; 21: 210-219.

Schluesener HJ, Sobel RA, Linington C, Weiner HL. A monoclonal antibody against a myelin oligodendrocyte glycoprotein induces relapses and demyelination in central nervous system autoimmune disease. J Immunol 1987; 139: 4016-4021.

Schonrock LM, Kuhlmann T, Adler S, Bitsch A, Bruck W. Identification of glial cell proliferation in early multiple sclerosis lesions. Neuropathol Appl Neurobiol 1998; 24: 320-330.

Schwab C, McGeer PL. Complement activated C4d immunoreactive oligodendrocytes delineate small cortical plaques in multiple sclerosis. Exp Neurol 2002; 174: 81-88.

Scolding N, Franklin R, Stevens S, Heldin CH, Compston A, Newcombe J. Oligodendrocyte progenitors are present in the normal adult human CNS and in the lesions of multiple sclerosis. Brain 1998; 121 ( Pt 12): 2221-2228.

Selmaj KW, Raine CS. Tumor necrosis factor mediates myelin and oligodendrocyte damage in vitro. Ann Neurol 1988; 23: 339-346.

Serafini B, Rosicarelli B, Franciotta D et al. Dysregulated Epstein-Barr virus infection in the multiple sclerosis brain. J Exp Med 2007; 204: 2899-2912.

Serafini B, Rosicarelli B, Magliozzi R, Stigliano E, Aloisi F. Detection of ectopic B-cell follicles with germinal centers in the meninges of patients with secondary progressive multiple sclerosis. Brain Pathol 2004; 14: 164-174.

Shen S, Sandoval J, Swiss VA et al. Age-dependent epigenetic control of differentiation inhibitors is critical for remyelination efficiency. Nat Neurosci 2008; 11: 1024-1034. 
Shriver LP, Dittel BN. T-cell-mediated disruption of the neuronal microtubule network: correlation with early reversible axonal dysfunction in acute experimental autoimmune encephalomyelitis. Am J Pathol 2006; 169: 999-1011.

Sibley WA, Bamford CR, Clark K. Clinical viral infections and multiple sclerosis. Lancet 1985; 1: 1313-1315.

Sim FJ, Zhao C, Penderis J, Franklin RJ. The age-related decrease in CNS remyelination efficiency is attributable to an impairment of both oligodendrocyte progenitor recruitment and differentiation. J Neurosci 2002; 22: 2451-2459.

Simpson JE, Newcombe J, Cuzner ML, Woodroofe MN. Expression of monocyte chemoattractant protein-1 and other beta-chemokines by resident glia and inflammatory cells in multiple sclerosis lesions. J Neuroimmunol 1998; 84: 238-249.

Skegg K. Multiple sclerosis presenting as a pure psychiatric disorder. Psychol Med 1993; 23: 909-914.

Smith EJ, Blakemore WF, McDonald WI. Central remyelination restores secure conduction. Nature 1979; 280: 395-396.

Smith R, Studd JW. A pilot study of the effect upon multiple sclerosis of the menopause, hormone replacement therapy and the menstrual cycle. J R Soc Med 1992; 85: 612-613.

Sospedra M, Martin R. Immunology of multiple sclerosis. Annu Rev Immunol 2005; 23: 683-747.

Stadelmann C, Albert M, Wegner C, Bruck W. Cortical pathology in multiple sclerosis. Curr Opin Neurol 2008; 21: 229-234.

Stadelmann C, Bruck W. Interplay between mechanisms of damage and repair in multiple sclerosis. J Neurol 2008; 255 Suppl 1: 12-18.

Stangel M, Trebst C. Remyelination strategies: new advancements toward a regenerative treatment in multiple sclerosis. Curr Neurol Neurosci Rep 2006; 6: 229-235.

Takeda K, Kaisho T, Akira S. Toll-like receptors. Annu Rev Immunol 2003; 21: 335-376. 
Talbott JF, Loy DN, Liu Y et al. Endogenous Nkx2.2+/Olig2+ oligodendrocyte precursor cells fail to remyelinate the demyelinated adult rat spinal cord in the absence of astrocytes. Exp Neurol 2005; 192: 11-24.

Taylor EW. Zur pathologischen Anatomie der multiplen Sklerose. Deutsche Zeitschrift für Nervenheilkunde 1892; 1-26.

Trapp BD, Nave KA. Multiple sclerosis: an immune or neurodegenerative disorder? Annu Rev Neurosci 2008; 31: 247-269.

Tsai HH, Frost E, To V et al. The chemokine receptor CXCR2 controls positioning of oligodendrocyte precursors in developing spinal cord by arresting their migration. Cell 2002; 110: 373-383.

Vana AC, Lucchinetti CF, Le TQ, Armstrong RC. Myelin transcription factor 1 (Myt1) expression in demyelinated lesions of rodent and human CNS. Glia 2007; 55: 687-697. Vartanian T, Fischbach G, Miller R. Failure of spinal cord oligodendrocyte development in mice lacking neuregulin. Proc Natl Acad Sci U S A 1999; 96: 731-735.

Vartanian T, Li Y, Zhao M, Stefansson K. Interferon-gamma-induced oligodendrocyte cell death: implications for the pathogenesis of multiple sclerosis. Mol Med 1995; 1: 732743.

Vercellino M, Merola A, Piacentino C et al. Altered glutamate reuptake in relapsingremitting and secondary progressive multiple sclerosis cortex: correlation with microglia infiltration, demyelination, and neuronal and synaptic damage. J Neuropathol Exp Neurol 2007; 66: 732-739.

Vercellino M, Plano F, Votta B, Mutani R, Giordana MT, Cavalla P. Grey matter pathology in multiple sclerosis. J Neuropathol Exp Neurol 2005; 64: 1101-1107.

von Budingen HC, Hauser SL, Ouallet JC, Tanuma N, Menge T, Genain CP. Frontline: Epitope recognition on the myelin/oligodendrocyte glycoprotein differentially influences disease phenotype and antibody effector functions in autoimmune demyelination. Eur $\mathbf{J}$ Immunol 2004; 34: 2072-2083. 
Voskuhl RR. Gender issues and multiple sclerosis. Curr Neurol Neurosci Rep 2002; 2: 277-286.

Warrington AE, Pfeiffer SE. Proliferation and differentiation of O4+ oligodendrocytes in postnatal rat cerebellum: analysis in unfixed tissue slices using anti-glycolipid antibodies. J Neurosci Res 1992; 33: 338-353.

Watanabe M, Hadzic T, Nishiyama A. Transient upregulation of Nkx2.2 expression in oligodendrocyte lineage cells during remyelination. Glia 2004; 46: 311-322.

Wegner C, Esiri MM, Chance SA, Palace J, Matthews PM. Neocortical neuronal, synaptic, and glial loss in multiple sclerosis. Neurology 2006; 67: 960-967.

Wolswijk G, Riddle PN, Noble M. Platelet-derived growth factor is mitogenic for O2Aadult progenitor cells. Glia 1991; 4: 495-503.

Woodruff RH, Franklin RJ. Demyelination and remyelination of the caudal cerebellar peduncle of adult rats following stereotaxic injections of lysolecithin, ethidium bromide, and complement/anti-galactocerebroside: a comparative study. Glia 1999; 25: 216-228.

Woodruff RH, Fruttiger M, Richardson WD, Franklin RJ. Platelet-derived growth factor regulates oligodendrocyte progenitor numbers in adult CNS and their response following CNS demyelination. Mol Cell Neurosci 2004; 25: 252-262.

Wosik K, Antel J, Kuhlmann T, Bruck W, Massie B, Nalbantoglu J. Oligodendrocyte injury in multiple sclerosis: a role for p53. J Neurochem 2003; 85: 635-644.

Wren D, Wolswijk G, Noble M. In vitro analysis of the origin and maintenance of O2Aadult progenitor cells. J Cell Biol 1992; 116: 167-176.

Yajima K, Suzuki K. Demyelination and remyelination in the rat central nervous system following ethidium bromide injection. Lab Invest 1979; 41: 385-392.

Yeh HJ, Ruit KG, Wang YX, Parks WC, Snider WD, Deuel TF. PDGF A-chain gene is expressed by mammalian neurons during development and in maturity. Cell 1991; 64: 209-216. 
Yusuf-Makagiansar H, Anderson ME, Yakovleva TV, Murray JS, Siahaan TJ. Inhibition of LFA-1/ICAM-1 and VLA-4/VCAM-1 as a therapeutic approach to inflammation and autoimmune diseases. Med Res Rev 2002; 22: 146-167.

Zarei M. Clinical characteristics of cortical multiple sclerosis. J Neurol Sci 2006; 245: 53-58.

Zhou Q, Choi G, Anderson DJ. The bHLH transcription factor Olig2 promotes oligodendrocyte differentiation in collaboration with Nkx2.2. Neuron 2001; 31: 791-807. Zhu X, Hill RA, Nishiyama A. NG2 cells generate oligodendrocytes and gray matter astrocytes in the spinal cord. Neuron Glia Biol 2008; 4: 19-26. 


\section{APPENDIX}

\subsection{Effect of targeted cortical EAE lesion on estrous cycle}

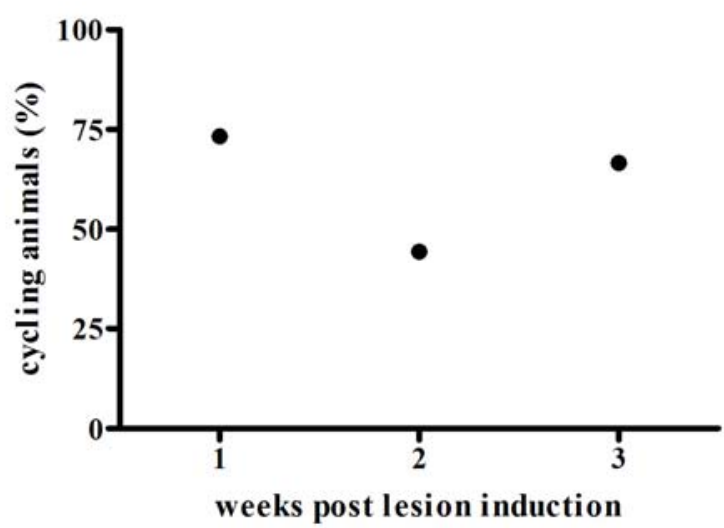

Figure A: Effect of targeted cortical EAE on estrous cycle

The effect of targeted cortical EAE on the estrous cycle was analyzed. Daily vaginal smears were collected and values are given as percentage of rats having regular estrous cycle each week. Two weeks post lesion induction a transient disruption of the estrous cycle was observed in some s.c. MOG immunized animals. The phases of estrous cycle were determined using standard criteria as described by Herzog and colleagues (Herzog et al., 2009). Animals per group: $\mathrm{n}=15$ (week 1) and $\mathrm{n}=9$ (weeks 2 and 3). 


\subsection{Acknowledgements}

The present study was completed in the Department of Neuropathology at the University Medical Center Göttingen. I would like to thank Prof. Wolfgang Brück for facilitating and providing the research environment for my work.

I am especially thankful to my supervisors and mentors Prof. Christine Stadelmann and Dr. Doron Merkler for their great support, guidance and helpful discussions over the past three years. Furthermore, I would like to thank Dr. Doron Merkler for teaching me so many valuable techniques.

I wish to thank Mariann Schedensack, Uta Scheidt, Brigitte Maruschak, Angela Detmar and Katja Schulz for their technical assistance.

Thanks to my friends and colleagues at the Department of Neuropathology for the great working atmosphere. Special thanks go to Dr. Pascal Dowling for proofreading my manuscript. I am grateful to Prof. Fuchs for giving me the opportunity and time to complete my project.

I am grateful to my family for the support throughout my life.

Finally, I would like to thank Tina for her endless patience and love. 


\subsection{Curriculum Vitae}

\section{CURRICULUM VITAE}

\section{PERSONAL DATA}

Name: $\quad$ Enrique Garea Rodriguez

Date of birth: $\quad$ 23/10/1980

Place of birth: $\quad$ Minden, Germany

Nationality: Spanish

Contact information: German Primate Center

Clinical Neuroscience Laboratory

Kellner Weg 4, 37077 Göttingen

egarea-rodriguez@cnl-dpz.de

\section{EDUCATION AND QUALIFICATIONS}

Since 2006

2000-2006

2000

\section{Department of Neuropathology, University Medical Center} Göttingen

PhD student

Research project: "Damage and repair in experimental cortical demyelination"

Supervisors: Prof. Christine Stadelmann and Dr. Doron Merkler

University of Bielefeld, Germany

Biological studies

Degree: Diplom "MIT AUSZEICHNUNG"

Besselgymnasium, Minden

Abitur 
PROFESSIONAL EXPERIENCE

Since 2009

2006-2009
German Primate Center, Göttingen

Scientist

University Medical Center, Göttingen

Scientist Merkler D. Sustained oligodendroglial recruitment after repetitive cortical inflammatory demyelination. Poster presentation $8^{\text {th }}$ Meeting of the Göttingen Neuroscience Society

Garea-Rodriguez E, Kreutzfeldt M, Stadelmann C, Merkler D. Effect of repeated inflammatory demyelination on intrinsic remyelination in the targeted cortical EAE model. Poster presentation DGNN 2008, Würzburg

Lehmann K, Rodriguez EG, Kratz O, Moll GH, Dawirs RR, Teuchert-Noodt G. Early preweaning metamphetamine and postweaning rearing conditions interfere with the development of peripheral stress parameters and neural growth factors in gerbils. Int J Neurosci. 2007 Nov; 117 (11): 1621-38.

Garea-Rodriguez E, Stadelmann C, Merkler D, Brück W. Copaxone in the cuprizone mouse model. Poster presentation ECTRIMS 2007, Prague

Garea-Rodriguez E, Merkler D, Brück W, Stadelmann C. Repetitive demyelination in the rat cerebral cortex. Poster presentation $7^{\text {th }}$ Meeting of the Göttingen Neuroscience Society 